Southern Methodist University

SMU Scholar

Anthropology Theses and Dissertations

Anthropology

Spring 5-18-2019

\title{
Rethinking Repatriation: Karen Refugees on the Thai-Myanmar Border
}

Carrie Perkins

Southern Methodist University, caperkins@smu.edu

Follow this and additional works at: https://scholar.smu.edu/hum_sci_anthropology_etds

\section{Recommended Citation}

Perkins, Carrie, "Rethinking Repatriation: Karen Refugees on the Thai-Myanmar Border" (2019).

Anthropology Theses and Dissertations. DOI: https://doi.org/10.25172/td/14463626

https://scholar.smu.edu/hum_sci_anthropology_etds/7

This Dissertation is brought to you for free and open access by the Anthropology at SMU Scholar. It has been accepted for inclusion in Anthropology Theses and Dissertations by an authorized administrator of SMU Scholar. For more information, please visit http://digitalrepository.smu.edu. 
RETHINKING REPATRIATION:

KAREN REFUGEES ON THE THAI-MYANMAR BORDER

Approved by:

Professor Caroline Brettell

Professor Nia Parson

Professor Nicolas Sternsdorff-Cisterna

Professor Ward Keeler 
RETHINKING REPATRIATION:

KAREN REFUGEES ON THE THAI-MYANMAR BORDER

\author{
A Dissertation Presented to the Graduate Faculty of \\ Dedman College \\ Southern Methodist University \\ in \\ Partial Fulfillment of the Requirements \\ for the Degree of \\ Doctor of Philosophy \\ with a \\ Major in Cultural Anthropology \\ by \\ Carrie Anne Perkins \\ B.A. University of North Texas \\ M.Sc. University of North Texas \\ M.A. Southern Methodist University
}

May 18, 2019 
Perkins, Carrie

Rethinking Repatriation:

Karen Refugees on the Thai-Myanmar Border

Advisor: Professor Caroline Brettell

Doctor of Philosophy conferred May 18, 2019

Dissertation completed March 22, 2019
B.A., University of North Texas

M.Sc., University of North Texas

M.A., Southern Methodist University

In this dissertation, I explore the experience of Karen refugees living inside a refugee camp along the Thai-Myanmar border in one of the world's most protracted refugee situations. This research situates displacement within theories of time, (im)mobility and resistance while also drawing on literature in forced migration concerning repatriation, exile, protracted refugee situations and policy development. A key component of this work focuses on analyzing the relationship between resistance and waiting by applying these concepts to the experience of Karen refugees who have spent decades waiting in camps while currently being faced with a voluntary repatriation program. I frame voluntary repatriation as a globally accepted durable solution to protracted refugee situations and as such, the preferred outcome of protracted displacement by the international refugee regime. Building on conceptualizations of waiting as an active strategy, I add both strategy and resistance to this concept in the context of protracted refugee situations, showing how I will further develop this theoretical 
framework through my own ethnographic work. Since my contribution to this theoretical trajectory is to make 'waiting as resistance' and 'waiting as strategy' central to an analysis of the repatriation framework, I will explain how holistic frameworks of return can guide effective policy implementation.

This dissertation also traces the specific histories and geo-political situations that gave rise to the current state of a protracted refugee crisis along the Thailand-Myanmar border. With special consideration paid to the emergence of a voluntary repatriation program being implemented by the UNHCR in the region, I explore how Karen refugees respond to the notion of return to Myanmar. In the concluding chapters I offer an applied contribution in the form of a policy recommendation for Thailand that I have termed Protracted Sanctuary Status. Within this framework I offer a suggestion that is modeled after the U.S. immigration category of Temporary Protected Status with a few key changes that address both the need for legal employment in Thailand as well as the precariousness refugees from Myanmar currently face.

To explore these issues, this dissertation is based on three months of archival research at The University of Oxford's Refugee Studies Centre in addition to a total of 10 months of fieldwork in Yangon, Myanmar, Mae Sot, Thailand and Mae La Refugee Camp on the Thai-Myanmar border. During this time, 28 interviews were conducted during the pilot phase of research in 2015, and an additional 40 interviews were conducted with both refugees and other stakeholders during the primary fieldwork period in 2017. Other data was collected through the use of participant observation while living inside Mae La Refugee camp as well as two focus groups and an ongoing analysis of local publications, media, art and music related to repatriation and the refugee experience along the border. 


\section{TABLE OF CONTENTS}

LIST OF MAPS, FIGURES, TABLES and PHOTOS viii

A NOTE ON TERMINOLOGY AND PSEUDONYMS Xii

LIST OF TERMS AND ACRONYMS X xiv

MAP: THAILAND $\quad$ XV

MAP: MYANMAR $\quad$ Xvi

Chapter

1. INTRODUCTION 1

1.1 The Thai-Myanmar Friendship Bridge 1

1.2 Mae La 4

1.3 A Brief History of the Karen 8

1.4 Overview of Theoretical Orientations and Contributions 16

$\begin{array}{ll}1.5 \text { Overview of Chapters } & 20\end{array}$

2. RESEARCH CONTEXT AND METHODOLOGY 23

2.1 Introduction 23

2.2 Preliminary Research and Feasibility 25

$\begin{array}{ll}2.3 \text { Returning to the Field } & 31\end{array}$

2.4 Methodological Approaches 38

2.5 Concluding Remarks about Ethical Challenges in the Field 47

3. POLITICS AND THE PRECARIAT 50

$\begin{array}{ll}3.1 \text { Introduction } & 50\end{array}$

3.2 From Siam to Thailand 53 
3.3 Negotiating Refugee Status in Thailand and the Case of the Missing Bangkok Principles $\quad 59$

3.4 A New Myanmar, a New Outlook on Refugees? 64

$\begin{array}{ll}3.5 \text { Conclusion } & 75\end{array}$

4. WAITING: Experiences of Exile and Protractedness 77

$\begin{array}{ll}4.1 \text { Introduction } & 77\end{array}$

4.2 Time, Waiting and (Im)mobility $\quad 79$

4.3 Waiting for Change: resistance in its many forms 89

4.4 Refugee Experiences of Exile 97

4.5 Christianity and the Karen 102

$\begin{array}{ll}4.6 \text { Conclusion } & 105\end{array}$

5. NEGOTIATING RETURN: Strategies, Compromise and Barriers 107

5.1 Introduction 107

5.2 Durable Solutions 110

5.3 The Current State of Voluntary Repatriation on the Thai-Myanmar Border 122

5.4 Barriers to Return 130

5.5 Conclusion - An Impossible Choice 140

6. BEYOND DURABLE SOLUTIONS: Rethinking Repatriation 141

6.1 Introduction 141

6.2 Moving Beyond Three Durable Solutions 142

6.3 Labor Migration as the Fourth Durable Solution 144

6.4 Self-Reliance Pending Return 148

6.5 The Case of Lay Kay Kaw 152

6.6 Conclusion 156

7. CONCLUSIONS 158

$\begin{array}{ll}7.1 \text { Introduction } & 158\end{array}$ 
7.2 Scholarly Contributions

161

7.3 Applied Contributions: Towards Protracted Sanctuary

7.4 Final Remarks and Recommendations for Future Research

APPENDIX

170

1.1 UNHCR Documents

170

1.2 Interview Guide

183

REFERENCES

184 


\section{LIST OF MAPS}

1. Thailand xiii

2. Myanmar xiv

3. The nine camps on the Thai-Myanmar border 15

4. Mae La Refugee Camp 36

5. Southeast Asia during the high colonial age, 1870 - 1914 


\section{LIST OF FIGURES}

1. An illustration highlighting the cultural mandates of Phibun's Ratthaniyom 56

2. Myanmar GDP Growth 2012-2022 66

3. Major refugee-Hosting Countries 2015-2016 113

4. Resettlement of Myanmar Refugees in Thailand 2005-2018 117

5. INGO Repatriation Strategy Political Cartoon 124 


\section{LIST OF TABLES}

1. Timeline of Repatriation Activity 25

2. Summary of Interview Data Collected (2017) 44

3. Summary of Current UNHCR Mandate for Voluntary Repatriation 122

4. KSNG Position Paper on Refugee Return to Burma 127

5. Protected Status (TPS) vs. Protracted Sanctuary Status (PSS) 166 


\section{LIST OF PHOTOS}

1. Repatriation at the Mae Sot-Myawaddy Border Crossing 3

2. Lay Kay Kaw Village, Kawkareik Township, Southeastern Myanmar 154

3. An overview of Lay Kay Kaw as seen from footage shot by drone 154

4. Care Villa for Landmine Survivors, Mae La Refugee Camp, Thailand 160 


\section{A NOTE ON TERMINOLOGY AND PSEUDONYMS}

Myanmar or Burma?

The military government of Burma officially changed its name to the "Union of Myanmar" in 1989, while also renaming many of the cities and regions that bore English translations that dated back to Burma's colonial period. Many political and ethnic opposition groups contested the renaming as they did not recognize the legitimacy of the ruling military government or its authority to rename the country. Political reforms in Myanmar between 2011-2012 resulted in the dissolution of the military junta and the country was once again renamed to the "Republic of the Union of Myanmar". Subsequently, general elections were held in November 2015, marking the first openly contested elections since 1990. While the results gave the National League for Democracy and its leader, Aung San Suu Kyi, an absolute majority of seats in both chambers of the national parliament, the military retained 25 percent of seats, effectively making any constitutional changes impossible without their consent. In light of this, many of those who have fled the country as the result of civil war and persecution, still refer to the country as Burma and reject the legitimacy of the name Myanmar. However, as a result of on-going democratic reforms, many people and organizations now recognize the country as "Myanmar" including the United Nations and the Association of Southeast Asian Nations (ASEAN). 
Throughout this dissertation I have chosen to use "Myanmar" when speaking generally about the country, and "Burma" when relating conversations or quotations from individuals who have used this name, out of respect for their preferences.

\section{Use of Pseudonyms}

In accordance with the American Anthropological Association's 2012 Statement on Ethics, pseudonyms may be utilized in order to avoid identification of a source and to protect confidentiality and limit exposure of people to risks. As such, all names of research participants and informants in this dissertation have been changed to maintain anonymity, unless I have received express written consent otherwise. 


\section{LIST OF TERMS AND ACRONYMS}

ASEAN: Association of South East Asian Nations

ASSK: Aung San Suu Kyi

CBO: Community Based Organization

COERR: Catholic Office for Emergency Relief and Refugees

EAO: Ethnic Armed Organization

EBO: Ethnic Based Organization

IDP: Internally Displaced Person

INGO: International Non-governmental Organization

IOM: International Organization for Migration

KNU: Karen National Union

KNLA: Karen National Liberation Army

KRC: Karen Refugee Committee

KRCEE: Karen Refugee Committee Educational Entity

KWO: Karen Women's Organization

MNHRC: Myanmar National Human Rights Commission

MOI: Ministry of Interior (Thailand)

NCA: Nationwide Ceasefire Agreement

NGO: Non-governmental Organization

NLD: National League for Democracy, a social-democratic and liberal democratic political party in Myanmar

NMSP: New Mon State Party

PRS: Protracted Refugee Situation

RTG: Royal Thai Government

Tatmadaw: The official name of the armed forces of Myanmar

TBC: The Border Consortium

UDHR: Universal Declaration of Human Rights

UN: United Nations

UNHCR: United Nations High Commissioner for Refugees 


\section{MAP: THAILAND}

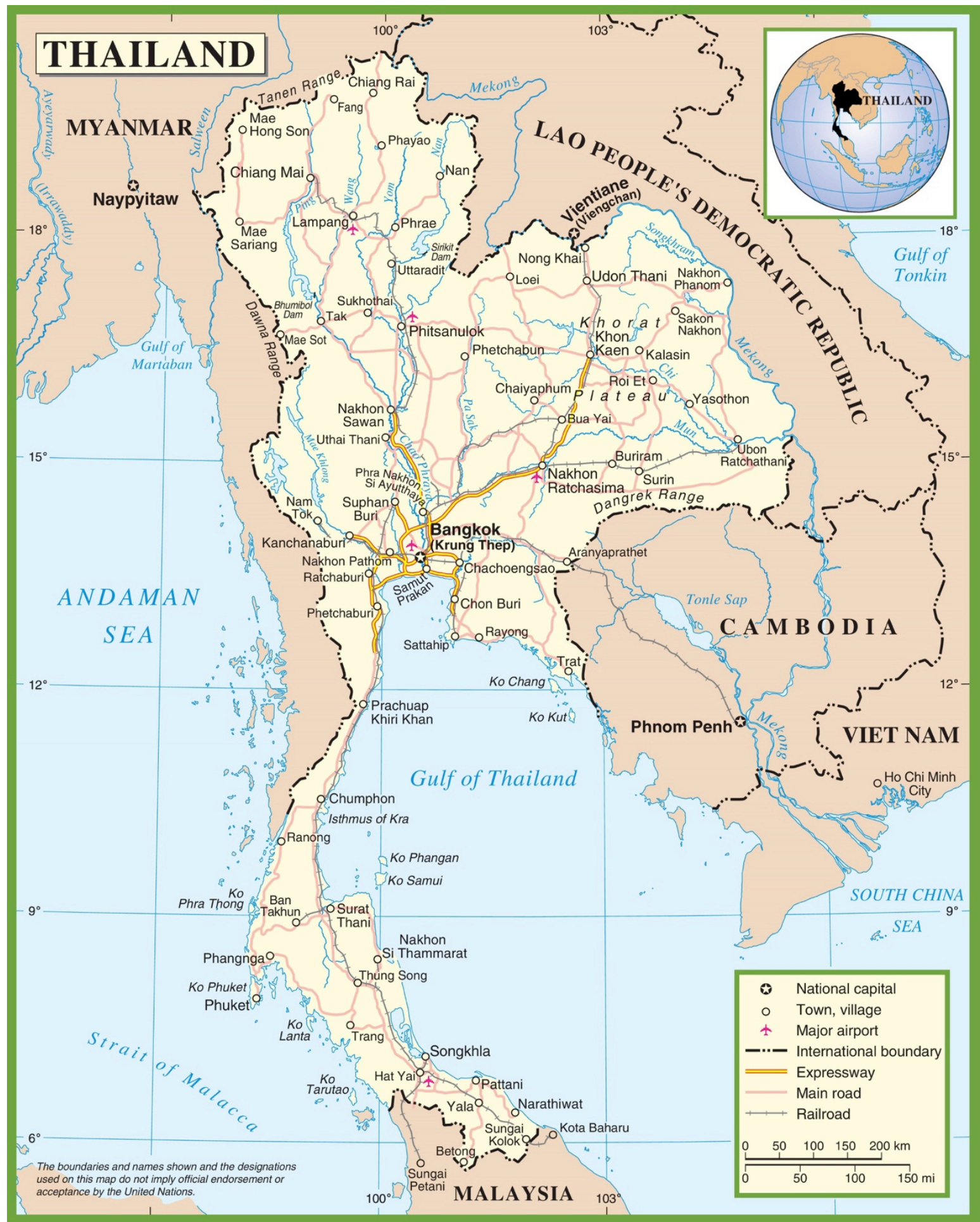

Map 1 - Thailand (Source: 2012-2019 Ontheworldmap.com) 


\section{MAP: MYANMAR}

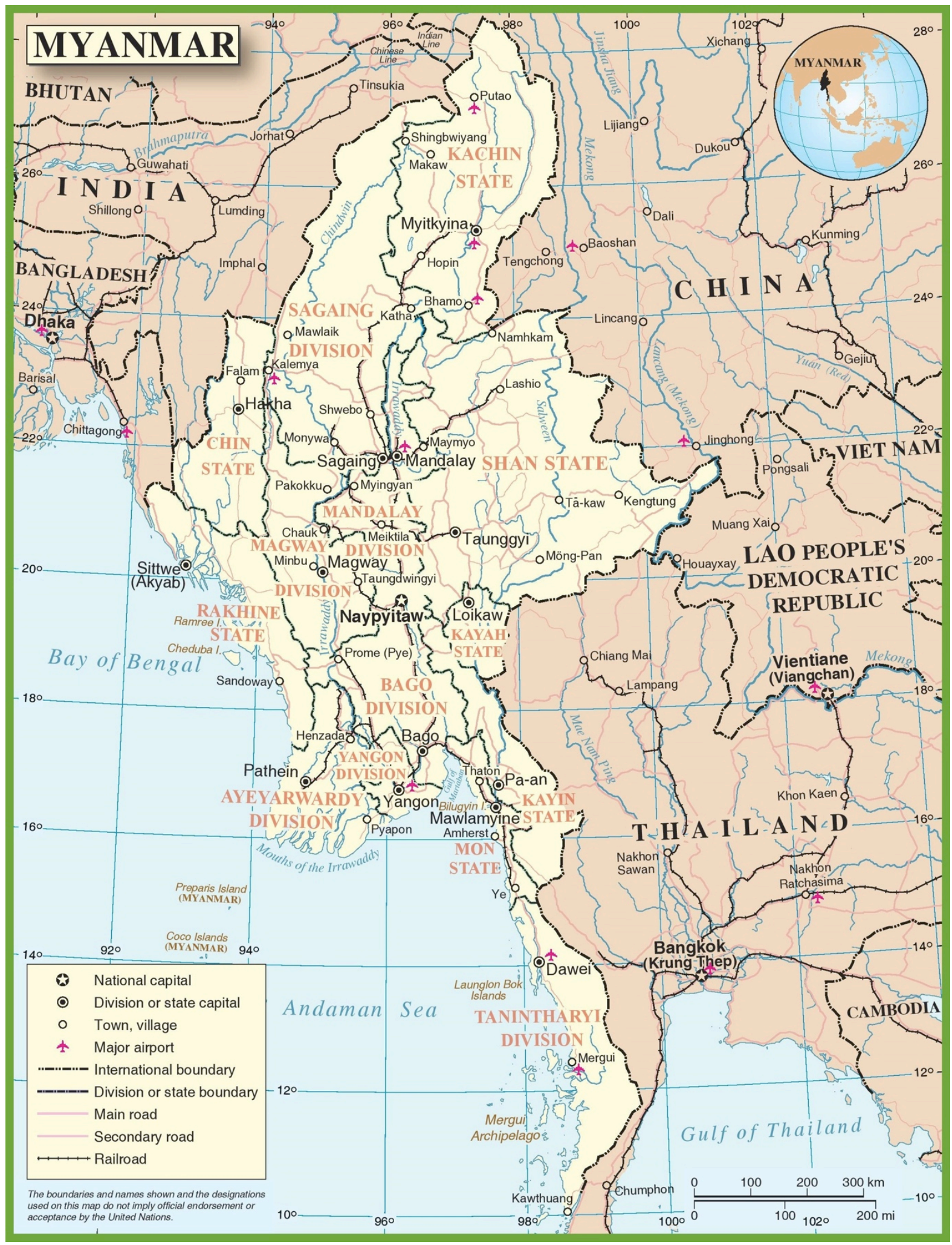

Map 2 - Myanmar (Source: 2012-2019 Ontheworldmap.com) 


\section{ACKNOWLEDGEMENTS}

This dissertation would not have been possible without the support of many people. First and foremost I would like to thank the Karen people who generously shared their stories and voiced their opinions throughout the duration of this project. They continue to be a source of inspiration in both their resilience and strength during challenging times. I would especially like to thank my research assistant, Saw Khu Htoo, for his tireless patience and invaluable insight. I am fortunate to have gained both a colleague and a friend in Khu Htoo and this research has been fundamentally improved by his involvement. I would also like to thank Saw Alwyn for his instrumental support, remarkable candidness and willingness to engage with this work. Additionally I want to thank Saw Hilton for being a wonderful neighbor, Poe Beh for his friendship and help with translations, and all the students and staff I met in Mae La who were endlessly kind and patient.

I would also like to thank the many colleagues and mentors I met in the field that helped shape this project including Dr. Shirley Worland at Chiang Mai University, Dr. Alexander Betts and Dr. Pia Maria Jolliffe at the University of Oxford as well as Dr. Ulrike Krause, Alexandra Kaun and Peter Trotter.

This research also would not have been possible without the generous support from Hunter and Stephanie Hunt. I am infinitely grateful for their assistance and support for this dissertation. 
I would also especially like to thank my advisor, Dr. Caroline Brettell, for her unwavering support, lightning fast response time and invaluable wisdom over the course of my time at SMU. I am eternally grateful to have had such a wonderful advisor and mentor throughout this process. I would also like to thank my committee, Dr. Nia Parson and Dr. Nicolas Sternsdorff-Cisterna from SMU and Dr. Ward Keeler from The University of Texas at Austin, for their thoughtful commentary, sage advice and willingness to support this project.

I am also grateful to be surrounded by an incredibly talented cohort at SMU and would like to thank Dr. Shay Cannedy, Dr. Carina Heckert, Dr. Kerri Brown, Dr. Joshua Dorfman, Jordan Wondrack, Sara Mosher and Katie Fox. I would also especially like to thank Dr. Ashvina Patel, whom I could not imagine going through this process without. Her humor, insight and friendship were invaluable from the classroom to the field and I will forever be thankful for the circumstances that led us to take this journey together.

On a personal note, I would like to thank my parents, JoAnne and Gary Hill, for always encouraging my curiosity about the world, my siblings, Chris and Rachel, for always cheering me on and my dear friends Courtney Fletcher and Stacey Verbeek for their humor and friendship over many years and many glasses of wine that have helped to keep me sane. Lastly, I would like to thank my husband, Simon Perkins, without whom this research would not be possible. Simon, thank you for your unconditional support, your never-ending patience with my tendency to destroy electronic devices, and your willingness to discuss all things anthropology and refugee repatriation with me over these last several years. This dissertation would not be possible without you. 


\section{Chapter 1}

\section{INTRODUCTION}

\subsection{The Thai-Myanmar Friendship Bridge}

Straddling the banks of the broad and muddy Moei River sits a fairly non-distinct bridge connecting the border towns of Mae Sot, Thailand and Myawaddy, Myanmar. I first visited the bridge in the late summer of 2015 with Nee Puh, a friend of mine who was currently working with an NGO based in Mae Sot. Nee Puh was from Hpa-An, a predominately Karen city in Myanmar about four hours west of Myawaddy. She had spent the last several years living in Mae Sot, working as a field guide and translator for an organization that transported educational resources to rural villages in Karen State. Earlier that day we had headed to the border by scrambling into the back of a crowded red songthaew, one of the local covered pickup trucks with two rows of seating along the back. The songthaew was full of men wearing the traditional Longyi I had grown accustomed to seeing in Yangon, and several women wore designs of yellowish thanaka paste on their cheeks. While we were technically still in Thailand, the border zone surrounding Mae Sot was an interesting mix of Thai, Chinese, Hmong, Lisu and Myanmar's majority Bamar population along with various ethnic minorities from Myanmar such as the Karen, Shan, Mon and Kachin. Sprinkled throughout the cultural mélange were NGO aid workers from the U.S., U.K., Australia and various regions in Europe. It was quite a cosmopolitan scene for such a small town and it was not uncommon to hear upwards of four to five languages in a 
single outing. Upon arrival at the bridge, Nee Puh and I found ourselves amidst a colorful hive of activity buzzing on the streets and overflowing into the adjacent Rim Moei market. Dotted beneath the bridge, nestled into the long grass and palm trees on the edges of the water were migrant settlements, whose makeshift roofs of blue tarpaulin and corrugated tin popped out amongst their bright green surroundings. As large trucks full of goods rumbled across the bridge towards the border crossing, steady flows of people crossed in cars, by foot and inside small wooden riverboats propelled across the coffee colored Moei with long wooden poles and humming outboard motors. "Busier than the Bangkok airport today!" Nee Puh remarked as we made our way down to the market.

The Moei River, a 200-mile long tributary of the larger Salween River, forms a natural border between Southeastern Myanmar and Western Thailand. Once the site of violent clashes between Myanmar's Tatmadaw and the armed wing of the Karen National Union, the region surrounding the Moei now sees more cross-border trade than civil war. Facilitating this trade is the Thai-Myanmar Friendship Bridge, a 420-meter long raised concrete highway where exports such as teak and jade from Myanmar cross paths with Thai shipments of consumer electronics, clothing and cars. The bridge is part of the greater Asian Highway Network, a sweeping infrastructure project which promises amongst other things to connect Myanmar to the rest of Southeast Asia. Recent estimates have put the value of the cross-border trade between Thailand and Myanmar at almost $\$ 420$ million usd for the 2018 fiscal year ${ }^{1}$, which is a sure indication of the tightening relationship between the neighboring governments.

\footnotetext{
1 As published in The Global New Light of Myanmar on July 30, 2018. The New Light of Myanmar is a government-owned newspaper published by the Myanmar Ministry of Information. Figures are provided by the Myanmar Ministry of Commerce.
} 
I often think of that trip to the bridge as an unofficial starting point for this project, as it made the concept of refugee repatriation into something more tangible. Here was the physical space in which official reentry back into Myanmar would occur; a place that so many had fled from but also spoken of returning to someday. A little over a year after that first trip, indeed it was at the friendship bridge in October of 2016, a bus emblazoned with an IOM logo brought 71 refugees back into Myanmar for the first official voluntary repatriation effort in over 30 years.

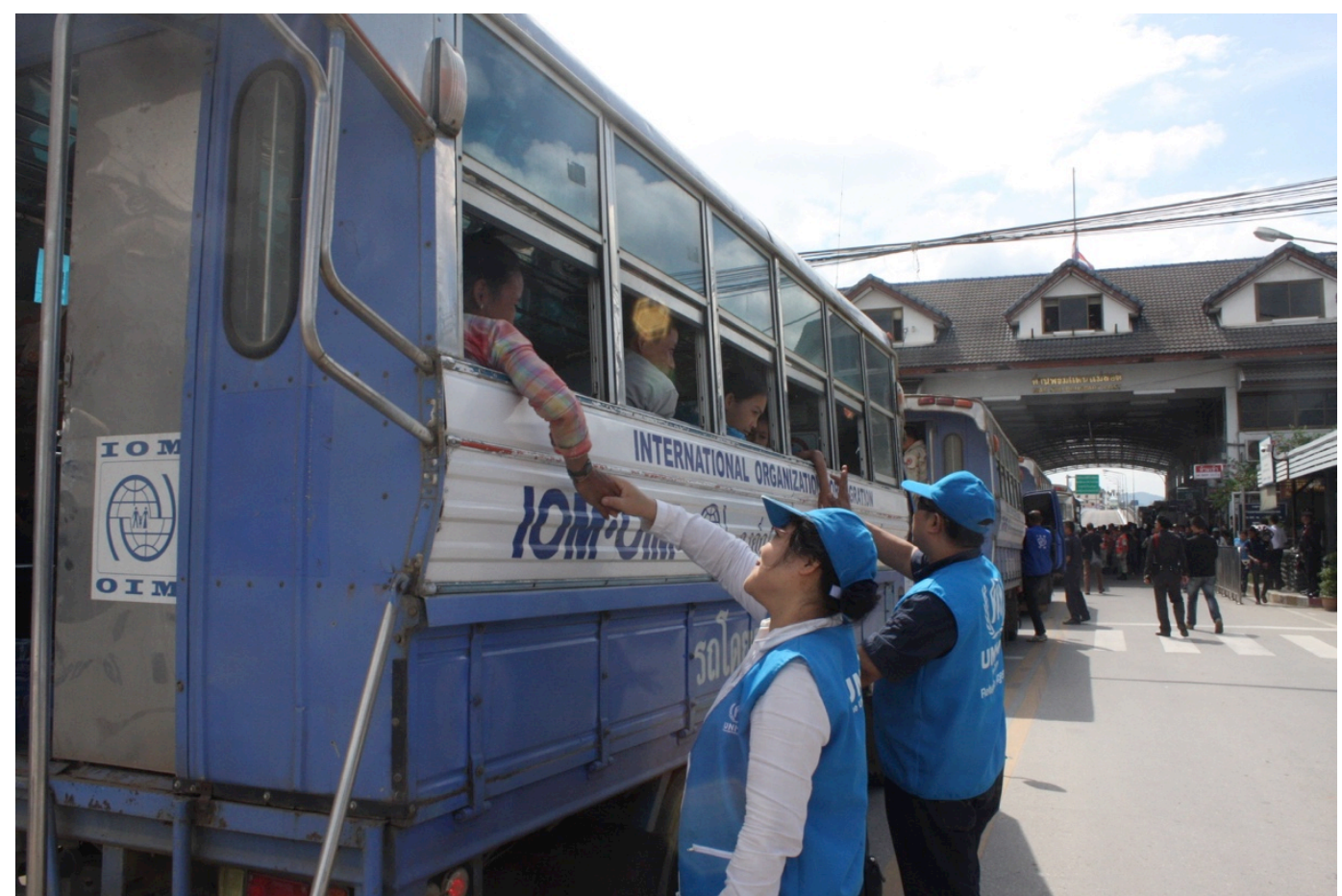

Photo 1- October 28, 2016: At the Mae Sot-Myawaddy border crossing, UNHCR staff based in Thailand say emotional goodbyes to the refugees returning to Myanmar after decades in exile. Source: UNHCR/Vivian Tan 
The year directly following that first voluntary repatriation is where my research begins. I wanted to know how those who had spent years and even decades as refugees in Thailand felt about the prospect of return. Would they in fact return 'voluntarily', as the program assured? Or would the time they spent in exile, waiting in various states of uncertainty and limbo, affect their willingness to reenter Myanmar once again? If they would not return voluntarily, how would acts of resistance manifest themselves in the confines of a refugee camp? What would be the specific concerns with return as the prospect of a facilitated repatriation had finally moved from the abstract into reality? Embedded within these questions were the practical issues of land rights, security and equitable access to employment, education and health care. Equally important were more subjective concerns surrounding rebuilding trust, creating autonomy, and renegotiating identity after years spent in a state of 'refugeehood'.

The foundations of this dissertation are very much rooted in the time I spent with resettled refugees in the U.S., many of whom came directly from Mae La Refugee Camp on the Thai-Myanmar border. For many years before this project was born, I listened to their stories of resettlement, containing within them memories of Burma and civil war and the reluctant yet comfortable familiarity with the refugee camps that became their homes. When the U.S. officially ended the large-scale resettlement program for refugees from Myanmar in 2014, I wanted to know what would happen to the tens of thousands of refugees who remained in the camps. Myanmar was in a state of rapid transition and no one could say with complete certainty how the protracted refugee situation along the border would end. This dissertation is an attempt to unravel how returning to one's country of origin is negotiated by not only the governments who decide, but also by the 
people who must make a choice. Those who have been stuck in the borderlands, confined to camps while they wait for solutions and hope for peace.

\subsection{Mae La}

On a sunny day in early June of 2017, almost two years after that first trip to the Friendship Bridge on the Thai-Myanmar border, I found myself in a dusty pickup truck barreling towards Mae La Refugee camp. That day was when I first met Saw Htoo Hay, a slender man in his mid-thirties with longish dark hair and a posture that hinted at the awkward boyishness that almost certainly characterized his late youth. He had come with the driver to meet me in town and act as my formal escort into Mae La, a gesture for which I was profoundly grateful. I would come to note that Saw Htoo Hay often flashed a slightly crooked smile that revealed his painful shyness and he was prone to offering greetings while simultaneously looking in the opposite direction of the person he was addressing. His English was near perfect as a result of several years of postsecondary education at a foreign seminary and he was well versed in the current geo-political situation unfolding in Myanmar. I liked Saw Htoo Hay immediately and went about enlisting his help for my research over the course of our hour-long journey north into camp.

The main road towards Mae La wove a path through alternating patches of farmland and dense green jungle that was broken up by various checkpoints manned by armed Thai soldiers. After about an hour of driving north from Mae Sot, I began to catch glimpses of the camp from the road. I had visited Mae La camp once before during my preliminary fieldwork in 2015 and was struck by the sheer vastness of it. For more than a mile along the main road you can see rows of tightly packed homes behind the tall fences topped with barbed wire. Upon arrival we swerved onto a small dirt road that led us to the 
southern entrance of camp. The road was riddled with the deep ruts and long gullies that resulted from the many years of heavy tires trying to navigate the muddy lanes during the relentless rainy season. As we bounced along at a slow pace, crossing a narrow makeshift bridge over a mostly dry creek bed below, I caught the first glimpse of Mae La that was not dominated by the packed housing visible from the main road. This section of camp seemed to sprawl out slightly and offer some space to breathe for those living here. The thatch roofed homes and small shops were punctuated with small kitchen gardens and the occasional pigsty or chicken coop spaced sporadically throughout the winding dirt lanes. The edges of the jungle, which were always hungry to regain their lost territory, inched around every corner, devouring footpaths with long green vines and tropical plants. We eventually made our way to the cluster of buildings that comprised the small school and were warmly greeted by a few students who had prepared a dinner of rice and vegetables for us. Over the next several months I would get to know them well, spending many days and nights practicing English, answering questions about Texas and learning to live within the confines of a refugee camp.

Over the next several months, my research for this dissertation would be profoundly impacted by my experiences living inside Mae La. The camp itself was a lesson in contrasts. The towering karst landscape provided a dramatic backdrop and ensured you never forgot you were indeed deep in the Southeast Asian rainforest. In the mornings, the limestone cliffs were enveloped in a foggy mist that snaked its way around the tall palms and thatched roofs that dotted the hillside. When late afternoon arrived, the cliffs were bathed in a golden sunlight while the distant sound of birds singing punctuated the thick humid air. By night, the jungle came alive and a chorus erupted from the insects and lizards 
that emerged from their hazy afternoon dormancy. Early in my stay at Mae La, a large Tokay gecko took up residency somewhere above my bed, taking advantage of the fourinch gap between the wall and the ceiling of my sleeping quarters. Every night around 3 a.m. he initiated his despondent mating call, loudly billowing his two-syllable chorus into the darkness, hoping to find his true love. One evening, feeling emboldened under the safety of my mosquito net, I made the very foolish decision to shine a light on the net to see which insects might be trying to make my acquaintance. A horror show of monstrous-sized moths and cicadas danced with each other above my head, punctuated by a large spider who seemed to be there just to complete the trifecta or perhaps mock my boldness. Eventually I reached an uneasy truce with the creatures that went about their nightly business, like disinterested roommates on different shifts who can largely ignore one another.

Aside from the realities of life in the tropics, daily life in Mae La felt simultaneously familiar and strange. The normal flow of meals and chores mixed with the typical melodramas that played out amongst the students attending the camp high school. Teenagers chatted about facebook and the latest youtube video making the rounds while young mothers tended to toddlers and children chased each other through the schoolyard. Soccer games and Sunday religious services felt natural until placed against the backdrop of confinement. The constant presence of armed guards and a population interspersed with landmine victims and those with traumatic scars not visible to the human eye provided a sober reminder of the civil war that raged not so long ago near the camp's Western border. The monthly line up to receive food rations offered another reminder of the other daily realities of camp life; that movement was restricted, working in Thailand illegal, and ones 
status as a refugee would continue to dominate the discourse surrounding their future. The following six chapters of this dissertation are a result of my time in Mae La and the surrounding region but most importantly, they are the result of the time I spent with the people I met along the way. This research is about their stories and experiences within the context of sweeping reform and international refugee policy.

\subsection{A Brief History of the Karen}

To start, it will be helpful to offer a brief history of the Karen in order to provide some essential context for the remainder of this dissertation. I would like to add two caveats before I begin. Firstly the use of the term Karen (or Kayin) to describe a singular ethnic group in Myanmar, while widely accepted, is a gross generalization. Amongst the Karen there is a substantial amount of internal ethnic diversity, where religious affiliations, customs and language can vary considerably according to region and village (Gravers, 2007). The term "Karen" refers primarily to people residing in southern and southeastern Myanmar and can include a number of individual Sino-Tibetan language-speaking ethnic groups. As Charles Keyes argued, "The Karen are an invention of the modern world, a product of Christian missionization, colonial and postcolonial ethnographic research, and policies regarding ethnic minorities adopted by the governments of independent Burma and Thailand" (2003:210). In this way, I recognize that using "the Karen" to describe the people this dissertation centers on has the potential to conceal their internal diversity. This is not my intent and throughout this work I will make every effort to offer adequate contextualization as to the Karen's heterogeneous makeup. Broadly, it can be said that when the Karen are categorized as a singular ethnic group, they comprise the second largest ethnic minority in Myanmar, with population estimates varying from 5 to 10 
million, accounting for roughly 7 percent of Myanmar's total population (Smith, 1991; South, 2011).

The second caveat I want to note is that I have found no definitive historical evidence that verifies when or how the Karen came to Myanmar. While oral histories maintain that the Karen originated from Mongolia, much of their early history has been a matter of dispute. This is complicated by the fact that much of the available early written history of the Karen has been filtered through Christian missionaries. While only an estimated 20 percent of Karen practice Christianity (with 65\% practicing Buddhism and 15\% practicing Animism) the access to education provided by Christian missionaries effectively created an upper class of "elite" educated Christian Karen. As a result, much of early Karen history has been summarized and reproduced by organizations such as the Karen National Association (KNA), which was formed in 1881 by “Christian Englishspeaking elites heavily influenced by American Baptist Missionaries" (Jolliffe, 2016:9). Thus I start with the history of the Karen in their own words, but with the note that the following history is as told by the KNA. I first encountered this reproduced cultural narrative as a component of a New Year Message by the Chairman of the "New Year Celebration Committee" tacked on the wall of a Karen bible school. The history reads as follows:

\footnotetext{
"We, the Karen people, are not an insignificant nationality. Racially, the Karens belong to the Sino-Thai family of language group, and come under the Mongoloid stock. According to history, our forefathers started to migrate in B.C. 2017 from Mongolia, passed through East Takistan and Tibet and reached the Yunan Province of China in B.C. 1385. Again, our forefathers started to migrate from Yunan in B.C. 1128 and the first wave reached the country now known as Burma in B.C. 1125. The second wave of migration left Yunan in B.C. 741 and reached Burma in B.C. 739. In counting the years of the Karen Era, that time of arrival was taken as the beginning. The early waves of migration coming into Burma finally settled down in Playloklo Delta (Irrawaddy Delta), the Gawloklo River Basin (Sittang River Basin) and the
} 
lower part of the Hkoloklo River Basin (Salween River Basin). Some following the Hkoloklo River went past the estuary and reached as far south as the southern part of Tenessarim regions and the adjoining areas in Thailand. Some remained as far north as the southern part of Shan State and the northern part of Thailand close to the Thai-Burma border. The majority of the Karen people live in the country known nowadays as Burma and form about $20 \%$ of the entire population of the country.

We, the Karen people, possess all the attributes of a nation. Our population is more than eight million. We have our own culture, history, tradition and literature. We have our own national anthem and national flag. Our national flag bears the rising sun and a bronze drum. Among them is the auspicious drum played on joyous occasions. The drum on our national flag is such a drum. It signifies prosperity, unity and cooperation. The rising sun signifies the rise of the Karen people for progress and dignity. The red colour signifies courage, the white colour signifies integrity and the blue colour signifies the honest and royal character of the Karen people." - Karen New Year Message, January $9^{\text {th }}, 1997$

This construction of history is noteworthy in that it situates Karen heritage in the territorial space of Burma while also constructing the Karen Nation as an "imagined community" (Anderson, 1983). It also encapsulates two distinct theoretical binaries core to anthropological inquiry: that of belonging and identity as well as territoriality and liminality. These are themes that emerge frequently in relation to repatriation and thus the above history provides an apt starting point in which to understand the modern history of the Karen.

In contrast to sparse accounts of the origins of Karen migration in Southeast Asia, the modern history of the Karen has been relatively well documented. During the colonial era of British rule from 1824-1948, the Karen developed a loyalist relationship with the British regime. As Kim Jolliffe notes, "the colonial state removed all traditional power structures and established a rationalized system of government, which favored the Karen for many military and administrative posts. Meanwhile, the Bamar were deeply 
marginalized, and sometimes subject to violent repression by Karen forces" (2016:9).

During this period, in exchange for favored treatment and increased economic and social mobility, the Karen assisted the British armies in the Anglo-Burmese wars². During WWII, the Karen fought alongside the British against Japanese forces as the British had promised to help form an independent Karen state in return. However, this promise never materialized and after the Japanese defeated the British in 1942, "the Japanese and the puppet regime they installed fostered reprisals against the Karen" (Keyes, 2003:213). The Karen were largely viewed as collaborators for their alignment with the British and were essentially ostracized as a result (see Guyot 1976, 1978).

In the aftermath of World War II, the British abandoned Karen nationalist interests as the Bamar (or Burman) majority began to work toward total independence from Britain. In February of 1947, leaders from the transitional Burmese government and representatives from three minority groups in Burma, namely the Chin, Shan, and Kachin, signed the Panglong Agreement, effectively creating the Union of Burma which became the first post-colonial government in 1948 (Walton, 2008). Notably missing from this agreement were signatories from other ethnic groups, most prominently that of the Karen and Rohingya. In 1947, a group of Karen politicians, lawyers, civil servants, and other educated Karen nationalists formed the Karen National Union (KNU) in an effort to advocate for greater autonomy for the Karen people in the context of Burma's new independence (Jolliffe, 2016). While the initial aim of the KNU was to obtain independence for the Karen people, in subsequent years they have instead begun to advocate for a federal

\footnotetext{
2 There have been three Burmese Wars or Anglo-Burmese Wars: First Anglo-Burmese War (1824); Second AngloBurmese War (1852); Third Anglo-Burmese War (1885). For an exceptional history, see George Bruce (1973) The Burma Wars, 1824-1886.
} 
union in Myanmar that includes adequate representation for Karen and regional self-

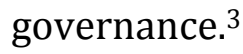

The Karen's history of conflict with the central Burmese government essentially began on January 31,1949, at the battle of Insein, where the Karen first launched their armed movement against the Burmese government. Today, the Karen still celebrate this day as Revolution Day and it has formed an important part of the Karen independence narrative. That same year, the KNU also officially declared the formation of the Karen Free State known as "Kawthoolei4". By 1952, they had secured an 11,600 square mile territory in the Southeast in what is known today as Kayin (Karen) State. However, less than one quarter of the Karen population resided within the territory when it was formed, and the major towns and roads were still controlled by the Burmese government.

Twelve years following the creation of Kawthoolei, the Burmese government was overthrown in a military coup d'état orchestrated by General Ne Win, who had expanded the military by nearly 100,000 troops. Jolliffe notes that General Ne Win and subsequent military regimes "became markedly ethnonationalist in their own character, envisioning a unified Myanmar based largely around Bamar Buddhist identity" (2016:12). This resulted in the systematic removal of local governance in ethnic states and the rise of violent conflict across the country. During this time General Ne Win implemented what is known as the

\footnotetext{
3 This point has been contested somewhat as Jolliffe (2016:11) points out that within the political context in which the KNU was formed, there was no choice between secession or unification. Agreeing that the KNU and its predecessors repeatedly voiced their aspirations for an independent Karen State, he argues it was consistently envisioned as part of a federation, which would also give them representation in central Burma, where many Karen people resided.

4 The first reference to the name "Kawthoolei" appears in the Karen history written by Saw Aung Hla, published in 1939. It can be translated as either 'a land without darkness' or alternatively, 'a land where the Thoo Lei flower grows': both translations are normally considered to mean a fertile land. The name has been adopted as synonymous with a free Karen homeland separated from Burma itself. (Source: College of Asia and the Pacific, Australian National University)
} 
"four cuts" strategy, which aimed to cut off the four vital areas of food, finance, intelligence and recruits from the armed ethnic groups through a campaign of relentless military harassment. The military declared vast amounts of ethnic land as "free-fire" zones, which resulted in the internal displacement of entire communities who were forced to relocate into highly militarized fenced areas. The destruction of thousands of Karen communities had a profound impact and the KNU was effectively pushed into the Bago Yoma region by the mid-1970's.

As the KNU resistance wore on, a new military regime came to power in 1988 known as the State Law and Order-Restoration Council. This led to the 8888 uprising of student democracy activists, protesters and politicians in central Myanmar who later fled to KNU controlled areas seeking refuge from the government forces. More than 10,000 students and politicians fled during the late 1980's and early 1990's, which significantly bolstered the KNU's position as the leading opposition group. During this time, the KNU operated as a de facto government and quasi state within Southeastern Burma. "The gate read 'Welcome to Kawthoolei' and the KNU comprised its own army, its own schools and hospitals, as well as its own townships, bureaucracy, and flag" (Horstmann, 2011:263; Rajah, 1990). However, an increasing division between Buddhist and Christian factions of the KNU came to a head in December of 1994 over disagreements concerning the construction of pagodas inside the effective KNU capital of Manerplaw. On December 11 $1^{\text {th }}$, 1994 the armed wing of the KNU (known as the Karen National Liberation Army or KNLA) clashed with Buddhist dissidents, which ultimately led to a permanent split in the organization. Consequently, the Democratic Karen Buddhist Army (DKBA) was formed on December 21st, 1994. 
The formation of the DKBA was significant in that it represented a substantial fracture of the KNU's consolidated power. Ultimately, the KNU capital of Manerplaw was overtaken by the Burmese military with the help of the DKBA. On January $27^{\text {th }}$ of 1995 , in a battle known as The Fall of Manerplaw, the KNU was effectively defeated leading to the loss of substantial territory in Myanmar as well as the loss of income they relied on from crossborder trade and local tax revenue. The Fall of Manerplaw also led an estimated 10,000 refugees to seek shelter along the Thai-Myanmar border, which had already begun to form sanctuary villages and camps for ethnic minorities during the previous ten years of violence propagated by the Tatmadaw.

In the two decades that have passed since The Fall of Manerplaw, the Karen in Myanmar have continued to suffer many documented cases of forced migration, forced labor, extrajudicial executions, land grabs, village destruction as well as rape and other forms of sexual violence, (KHRG, 2018; Davis et al., 2012; Centre for Peace and Conflict Studies, 2010; KWO, 2004; 2007; Human Rights Watch, 2005). The KNU and its armed wing, the KNLA, continue to operate in sections of Karen State, the Thai borderlands and various outposts in remote jungle camps. Notably in January of 2012, the KNU signed a ceasefire deal with Myanmar's military-backed civilian government. This step eventually led to the Nationwide Ceasefire Agreement (NCA) of 2015, which was signed by the KNU and several other ethnic opposition groups. However, peace has been fragile and approximately 85 percent of the 90,000 refugees still residing in camps along the ThaiMyanmar border are ethnic Karen (see map 3 below). 


\section{MAP: REFUGEE CAMPS ALONG THE THAI-MYANMAR BORDER}

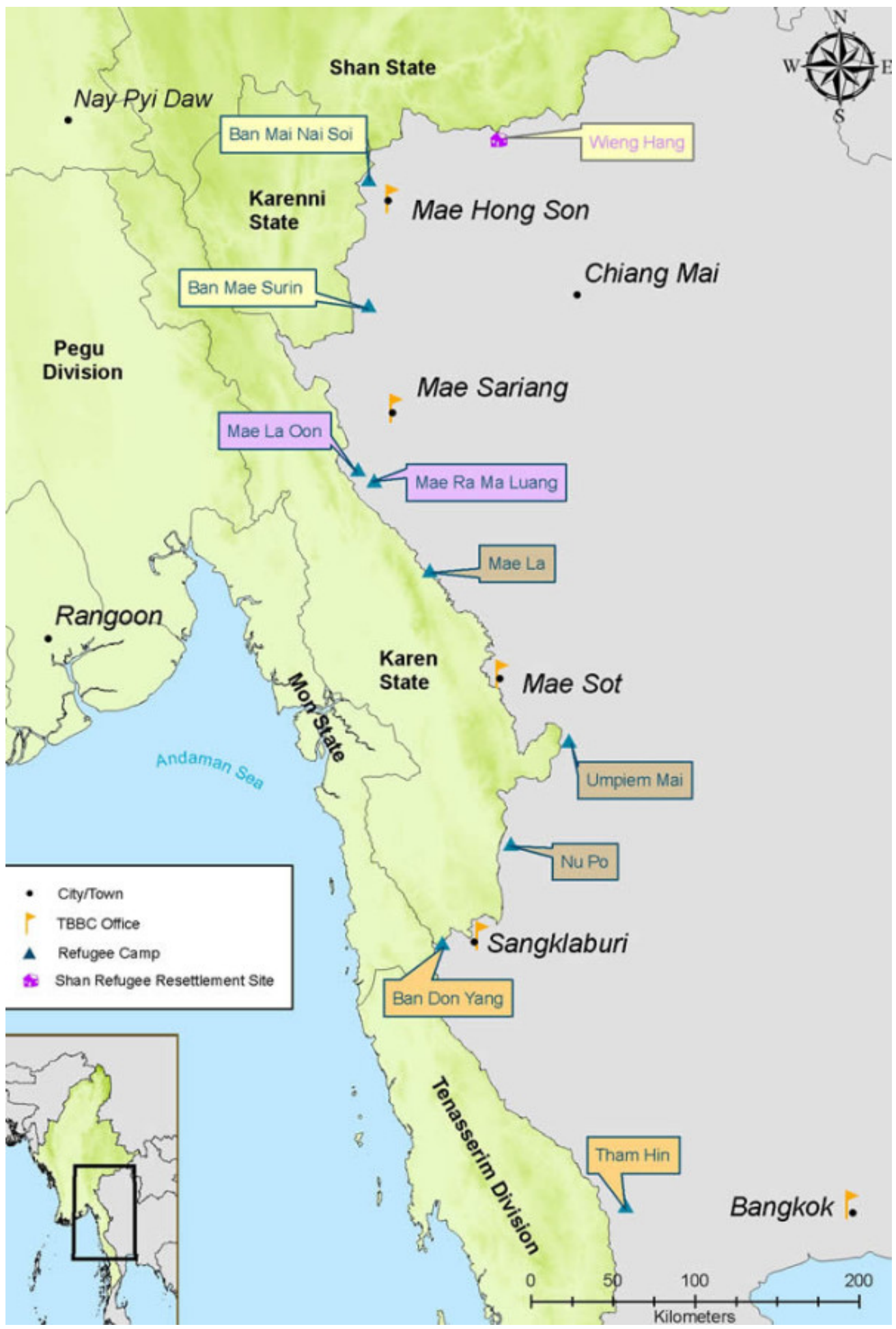

Map 3 - A map showing the nine camps on the Thai-Myanmar border plus the Shan IDP Settlement at Wieng Haeng in the far north. (Source: The Border Consortium 2017) 


\subsection{Overview of Theoretical Orientations and Contributions}

While anthropologists have long studied the causes and consequences of war as a component of cultural life, there is a new necessity for anthropologists to engage in research that addresses current global crises and the protracted refugee situations that follow. In the early 1980's as the field of Refugee Studies began to emerge, anthropologists were collating research surrounding forced migrants in the hopes that such research could "affect policy and make uprooting and readjustment less traumatic" (Hansen and OliverSmith 1982; Cernea 1985; Cernea and Guggenheim 1993; Morgan and Colson 1987 as cited in Colson, 2003:12). As ongoing civil wars and intense conflicts continued to expand across borders and cultures, the resulting mass displacement of people has become a defining moment in our shared cultural experience. As reported by UNHCR in 2018, there are now more than 68.5 million people worldwide who are either refugees or internally displaced persons, over half of whom are children.

In addition to the policy goals echoed in the early work of anthropologists in forced migration, anthropology is also particularly well suited to address the refugee experience by situating displacement within theories of time, (im)mobility and migration. In this way, research has sought to understand how refugees determine migration corridors, navigate life in refugee camps, manage host country integration and negotiate solutions such as third country resettlement and repatriation. While these processes are often deeply complex and nuanced, we can draw on past examples to help understand the current challenges refugee face in return.

My research is situated between the expansive bodies of literature comprising refugee studies and the anthropology of time. More specifically, I have drawn on literature 
in forced migration concerning repatriation, protracted refugee situations and policy development (see chapters 3,5,6) while drawing on the anthropological literature of temporalities related to waiting, liminality and exile (see chapter 4). Further, I have relied on literature concerning resistance, which has come from areas of migration, refugee studies, anthropology, sociology and political economy (see chapters 4, 5 and 6).

In general, this dissertation contributes theoretically to work in the anthropology of forced migration that is concerned with refugee repatriation and experiences of exile. More specifically, it analyzes the relationship between resistance and waiting by framing voluntary repatriation as a globally accepted durable solution to protracted refugee situations and as such, the preferred outcome of protracted displacement by the international refugee regime. Building on conceptualizations of waiting as an active strategy, I add resistance to this concept in the context of protracted refugee situations, showing how I will further develop this theoretical framework through my own ethnographic work. Since my contribution to this theoretical trajectory is to make 'waiting as resistance' central to an analysis of the repatriation framework, I will explain how holistic frameworks of return can guide effective policy implementation (Ch 7).

A common theme among anthropologists who study time and waiting is that the overabundance of time and unstructured waiting is both a symptom of social exclusion and a form of precarity. This dissertation adds ethnographic research that builds on these theorizations by showing that when indefinite waiting is interrupted, in this case by the emergence of a facilitated voluntary repatriation program, waiting can take on new meanings. Theoretically I argue that waiting is a multi-faceted experience that is capable of both encouraging and illustrating agency. Thus, waiting has been a way in which many 
Karen in Mae La can actively resist repatriation, strategize, and assert agency over their immediate futures. Therefore, this dissertation expands research concerning the conceptualization of waiting as being an active state, rather than a passive one, specifically in the context of a protracted refugee situation. Further, it also expands the conceptualization of 'waiting as resistance' in the context of forced migration and adds "waiting as strategy" to the myriad of responses associated with displacement. Expanding the conceptualization of 'waiting as resistance' in the context of protracted refugee situations is vital to both furthering the discourse in refugee studies as well as ensuring the principles of voluntary repatriation are respected in policy development. This dissertation also builds on repatriation theory in terms of adding ethnographic evidence as to the circularity of forced migration and the preference of many refugees to become economically self-reliant prior to or in lieu of return.

In this dissertation I also offer an applied contribution in the form of a policy recommendation for Thailand that suggests one avenue of resolution for the protracted refugee situation along the Thai-Myanmar border. Although the task of translating anthropological research into a tangible outcome can become complicated as ethical considerations arise concerning issues of objectivity and the role of advocacy, I argue that applied anthropology offers a framework to balance the core principle of "Do No Harm" with the responsibility that many feel to give back to the communities in which they conduct research. How Thailand resolves the protracted refugee situation along its Western border with Myanmar will have long lasting implications for global refugee policy. In fact, Thailand has a unique opportunity to demonstrate the power of transforming a perceived burden into an economic benefit while also maintaining a commitment to 
humanitarian principles.

In light of Thailand's growing support for regularizing labor migrants, I argue that it would be an ideal time to introduce a new solution for refugees who have lived in Thailand for extended periods of time. Within this vein and building upon the ideas I discuss in Chapter 6 surrounding self-reliance pending return, I suggest in chapter 7 that a hypothetical new category of status termed "Protracted Sanctuary Status" (PSS) for those living as refugees along the border be implemented. The framework for such a status would be similar to that of a "Temporary Protected Status" (TPS) in the United States. TPS provides freedom of movement and work rights for foreign nationals already in the United States from countries experiencing armed conflict, natural disaster, or other extraordinary circumstances that prevent their safe return. As Jill Wilson (2018: 2) noted in her recent analysis of TPS for the members of congress, "TPS is a blanket form of humanitarian relief. It is the statutory embodiment of safe haven for foreign nationals within the United States who may not meet the legal definition of refugee or asylee but are nonetheless fleeing_or reluctant to return to-potentially dangerous situations". There are a few key differences that I imagine would exist between the TPS model and the proposed PSS model (see table 5 in Chapter 7) primarily in the guarantee of protected status for refugees from Myanmar for a period of no less than 5 years, which may be renewable. While implementing regularized labor migration as a component of a durable solution is crucial, so too is ensuring adequate protection while acknowledging resistance to return. A policy that combines these elements within a recognizable framework may effectively offer a pathway by which protracted refugee situations can move from camps to communities. 


\subsection{Overview of Chapters}

I begin in Chapter Two by offering an overview of the research context for this project as well as a detailed description of the specific methodology employed to gather data. The chapter begins by describing the particular moment in time that characterized the region when research was carried out between the summer of 2015 and the fall of 2017. This includes a description of the recent political changes in Myanmar as well as a timeline of activity leading up to the commencement of UNHCR's voluntary repatriation program. This is followed by a summary of the preliminary research conducted in 2015 as well as its impact on the overall study. The next section goes on to describe the commencement of the primary research period beginning in January of 2017 with three months of archival work at The University of Oxford's Refugee Studies Centre. This section also includes a detailed description of the research site, Mae La refugee camp, located on the Thai-Myanmar border. The second half of the chapter offers a discussion of the methodology used in this study including descriptions of the project design, research population, recruitment and data collection, accuracy of data and methods of analysis. In the final section, a brief commentary is offered in regards to the ethical challenges faced in the field.

Chapter Three begins with an analysis of how Thailand's unique history of diplomacy, nationalism and independence has colored the current political landscape in regards to labor migration, as well as how it has intersected with current refugee policy. This is followed by a discussion of how the political and economic reforms happening within Myanmar are currently shaping diplomatic relations with Thailand and consequently affecting the fate of refugees residing in camps along the border. The chapter 
then offers a brief commentary on the emergence of special economic zones as a potential solution to both forced and irregular migration while offering a word of caution about the risks of development-induced displacement. The final section explores how refugees waiting in the confines of a camp are especially at risk of forming a new working underclass known as "the precariat" which may undermine attempts at creating economic security while derailing efforts towards voluntary repatriation.

Chapter Four begins with an overview of how anthropologists have approached the issue of time and temporalities in different cultures while also exploring how theoretical constructions of time intersect with experiences of waiting, liminality, and exile. This is followed by a discussion of the theoretical frameworks that conceptualize time as a tool of resistance and argue for its applicability to the protracted refugee situation along the ThaiMyanmar border. The next section focuses on refugee experiences of exile as well as illustrating how religion has played a role in transforming the exilic experience in the case of Baptist Karen refugees. In the final section, attention is focused on summarizing the importance of including experiences of time, waiting and exile within the broader literature of forced migration as well as why modes of resistance should always be considered in relation to repatriation design.

Chapter Five begins with a discussion of the internationally accepted protocol for resolving a protracted refugee crisis in relation to the Thai-Myanmar situation. This is followed by an explanation of the current voluntary repatriation program being implemented by UNHCR and an update on its status. The remainder of the chapter focuses on research outcomes regarding refugee perceptions of return. This includes both reported barriers to repatriation as described in interviews with refugees as well as other barriers 
identified through qualitative analysis and observation. In concluding remarks, I offer a summary of the impossible choice many Karen are currently facing in Mae La camp in relation to return.

Chapter Six begins with a discussion of how durable solutions have evolved in response to protracted refugee situations as well as an examination of what has recently been termed the 'fourth durable solution'. Following this is a brief commentary on the rise of strategies that seek to promote self-reliance prior to return and how they may aid sustainable forms of repatriation. In the final section, special consideration is paid to the notable emergence of a 'model village' to house returning refugees and IDPs in Myanmar in relation to its efficacy as a durable solution.

Chapter Seven concludes with a discussion on the theoretical contributions of this work to the anthropology of forced migration and the study of temporalities. This is followed by a discussion of the applied contribution to refugee policy and how we might imagine a protracted form of protection. Additionally an update on the events that have transpired on the border following the conclusion of fieldwork is provided as well as recommended directions for future research. 


\section{Chapter 2}

\section{RESEARCH CONTEXT AND METHODOLOGY}

\subsection{Introduction}

In order to provide context for the following chapters, it is important to note the particular moment in time that characterized the region when research was carried out for this project between the summer of 2015 and the fall of 2017. Over the past 33 years, in what has been one of the most protracted refugee situations of global record, the status of refugees along the Thai-Myanmar border has oscillated between 'crisis' to 'forgotten tragedy' to 'political predicament' to 'impending resolution'. As such, these characterizations often ebb and flow, like a cyclical changing of the tide as various governments, agreements, programs, and people come and go. The only constants that have remained are the camps themselves, symbolic spaces of a deteriorating peace process, and the people who are trapped within them, living in limbo between the revolving blades of "progress". It is a paradoxical fate to be both indifferent to change due to a lived experience of prolonged stasis, but also to experience perpetual anxiety at the uncertainty of the future. Thus when forced to live for decades confined to a small geographic space which requires dependency on foreign aid to survive, one becomes consumed with finding ways to 'move on', even if physical movement itself is impossible. It is within these confines that my research sits, albeit on the crest of one of the more promising waves of change. 
In the summer months of 2015, when the pilot research phase for this project first begun, change was brewing in Myanmar. The upcoming November general election would see Aung San Suu Kyi's party, the National League for Democracy (NLD), win a sweeping victory and a supermajority of seats in the combined national parliament. Widely regarded as the first openly contested election since 1990, the fervor of an open Myanmar, and a leader with a Nobel Peace Prize on her resume, created a palpable wave of hope both within the country and in the international community. By the end of 2015, sanctions on the country were being relaxed and global markets welcomed the entrance of a country rich in both natural resources and a population primed to consume modern commodities. It was within this sweeping optimism that support grew for attempting to finally reconcile the protracted refugee situation along the Thai-Myanmar border that had plagued both governments for more than three decades. Additionally, larger geopolitical forces, such as a vast refugee crisis unfolding in the Mediterranean Sea and Europe, further created a vacuum for both international attention and humanitarian funding. The confluence of a potential political solution with a state of decreased humanitarian funding for refugees on the Thai-Myanmar border, created both the will and the necessity to launch a formal repatriation plan. Indeed, all signs were pointing toward repatriation, as it gained both momentum and formalization with the passage of time (see table 1.1). 
Table 1 -Timeline of Repatriation Activity

\begin{tabular}{|l|l|}
\hline Date(s) & Timeline of Repatriation Activity \\
\hline 2012 - 2013 & $\begin{array}{l}\text { Steady decrease in funding, strict enforcement of camp } \\
\text { regulations restricting day labor work in Thailand, ad hoc } \\
\text { headcounts and military-led verifications fuel rumors of } \\
\text { repatriation }\end{array}$ \\
\hline July 2014 & Thai Government \& UNHCR conduct headcount in Mae La Camp \\
\hline March 2015 - & $\begin{array}{l}\text { UNHCR releases two documents titled “Strategic Roadmap for } \\
\text { Voluntary Repatriation" \& “Operations Plan for Voluntary } \\
\text { Repatriation" }\end{array}$ \\
\hline June 2015 & $\begin{array}{l}\text { Joint statement released by Thai \& Burmese governments } \\
\text { regarding future repatriation plans }\end{array}$ \\
\hline July - August 2016 & $\begin{array}{l}\text { Voluntary Repatriation Centers are established by UNHCR in 7 } \\
\text { camps }\end{array}$ \\
\hline $\begin{array}{l}\text { October 25 } \& 26^{\text {th }}, \\
2016\end{array}$ & $\begin{array}{l}\text { The first group of 71 refugees are voluntarily repatriated from Nu } \\
\text { Po and Tham Hin camps }\end{array}$ \\
\hline $\begin{array}{l}\text { January 2017 - } \\
\text { December 2017 }\end{array}$ & $\begin{array}{l}\text { Voluntary Repatriation Centers operate in camps as information } \\
\text { hubs and sign up locations. Initial engagement is low. }\end{array}$ \\
\hline May 2018 & $\begin{array}{l}\text { 164 refugees (50 households) repatriated from Mae La, } \\
\text { Umpheim, Ban Don Yang \& Ban Mai Nai Soi camps. Returned to } \\
\text { Karen State, Karenni (Kayah) State, Yangon, Bago \& Sagai }\end{array}$ \\
\hline June 2018 & $\begin{array}{l}\text { Myanmar government continues to conduct missions to } \\
\text { determine 'pre-nationality verification' in Mae La camp }\end{array}$ \\
\hline $\begin{array}{l}\text { July 2018 - October } \\
2018\end{array}$ & $\begin{array}{l}\text { 300 refugees now in process of repatriation from Mae La camp, } \\
\text { scheduled for October - November 2018 }\end{array}$ \\
\hline
\end{tabular}

Table 1 (Source: Developed by author using publicly available information from various news sources, in addition to reports published by UNHCR, RTG and the Government of Myanmar. Where possible, precise dates are given)

\subsection{Preliminary Research and Feasibility}

In the shadow of impending repatriation, in the summer months of 2015, I commenced preliminary research in both Myanmar and Thailand in order to gauge the feasibility of this project. I chose to first focus my efforts in Myanmar (Burma) within the former capital of Yangon (Rangoon), primarily for the access to both a diverse population 
as well as the proximity to an intensive Burmese language study program. In Yangon, I found myself thoroughly immersed into Burmese culture, having only experienced it previously through my work with the Burmese ${ }^{5}$ diaspora of resettled refugees in the United States.

Myanmar was still relatively new to tourism in 2015, with 2012 truly marking the increase of visitors to the country. At this time, rumors still swirled on the internet about the scarce availability of ATMs, credit card terminals and wifi service, while ominous warnings floated around about government surveillance of foreigners and exceptionally strict laws all visitors must follow. While there was a degree of truth in some of these things, in 2015 I found a population awash in smart phones, facebook, and excitement over the first western chain restaurant to open shop (which to my great dismay was a Kentucky Fried Chicken, furthering America's growing role as ambassador of a processed diet). Fluent English was almost non-existent, save for a few foreigners from Australia or the UK, or the odd NGO worker or academic around town. More often I was approached with a hodge-podge of English words, learned from American pop music or film, with the local Burman sometimes relying on a shy smile or a laugh with a confident "Hello, how are you?". More often than not, I was greeted with curiosity and a friendly, "Where you come from?" sometimes followed up with a cheeky "You need a tour guide?", which was more of a friendly attempt at trying the role on for size, rather than the persistent offers I had come to expect in some other tourist-laden Southeast Asian cities I visited.

\footnotetext{
5 "Burmese" is used here in a generalized context to refer to the many different ethnic groups that compose the diaspora of refugees originating from Myanmar. In my previous research, I have worked with the Karen, Karenni, Chin, Shan and Rohingya who have been resettled as refugees in Dallas, Texas.
} 
Portions of Yangon had the distinct feeling of stepping back in time, helped along by the decaying old colonial buildings, popping up like pastel-colored remnants of British colonial rule. Much of the architecture was now crumbling in the tropical humidity, seemingly stitched together with power lines and creeper vines in equal measure, reminders of the enduring battle between modernity and nature. And although this sleepy façade of historic relics seemed to demand a cold drink in the shade, the streets that connected the dilapidated government ministries to the filigreed railings of endless apartment buildings, were chaotic and colorful and afforded no time to stand still. Rather, change (and the turmoil and excitement that comes with it), was right at the surface, embodied in traffic jams and street vendors and loud speakers showering the city with Buddhist chants.

On my first ride into the city in the early summer of 2015, a taxi driver swerved onto the roundabout that encircled Sule Pagoda in the heart of downtown Yangon. He carefully pointed out the only synagogue in the city, saying cheerfully "This is where the Jewish go!", and I was indeed impressed. He went on to point out the neighboring Mosque, noting, "This is where the Muslims go." and then motioned to the golden stupa of Sule Pagoda, saying "This is where I go." while I murmured, "ah yes, for Buddhists". He ensured he had my full attention before finally pointing to a Christian Baptist church saying happily, "And this is where you go!". I smiled and nodded, noting to myself the instantaneous 'western-whiteAmerican' otherness that would perpetually color my interactions in this part of the world. This trip around the roundabout was a fitting foray into the significant demarcation of religious affiliation that characterizes Burmese society, and it only proved to intensify and become more relevant as the summer wore on. As such, the following day saw a 
demonstration downtown that concerned the growing anti-Rohingya and anti-Muslim sentiment in the country. Myanmar nationals and monks carried signs that read, "Bengalis, go back to Bangladesh where they belong” and “The BBC are doing a mistake, they don't know what is really happening here." The signs seemed to cement the national opinion that the minority Muslim Rohingya, largely concentrated on the western coast's Rakhine State, were not perceived as legitimate citizens of Myanmar, and should thus be deported and removed from their land immediately. I encountered the anti-Rohingya sentiment multiple times over the following six weeks in Yangon, which served as a window to observe how negative public sentiment towards minority groups played out in Myanmar. These observations were useful in a comparative context of the Karen's prior marginalization in Burmese society, and I often noted how easily propaganda made its way into casual conversation.

Overall, the goals of this first phase of my pilot research undertaken inside Yangon were not only to get a feeling for life inside Myanmar, but also to improve my language skills via immersion and intensive study. I also was attempting to answer the following questions:

1. How have Karen refugees who have returned to Yangon adjusted to repatriation?

2. How do current citizens living within Myanmar (Yangon) feel about Karen refugees returning to the country? Is the current climate in Yangon a hostile environment or a welcoming one?

I went about this in two ways. First, I cannot overstate just how valuable participant observation was at this stage. Trips through the multitudes of markets, my Burmese language classes, and observations of political demonstrations all provided insights into the effects of globalization and the arrival of the international media. Additionally, I was able to 
start gauging public perceptions of religion, violence, freedom and nationalism as well as getting a window into the social hierarchies and gender relations that guide everyday life. I was also incredibly lucky to be in Yangon during the third edition of the Human Rights Human Dignity International Film Festival, which brought 65 films to Yangon, both of national and international origin. Incredibly, all films included either English or Burmese subtitles depending on the language used, which served to make the films created in Myanmar rich sources of local information. In particular, films that dealt with national identity, internal displacement of minority groups due to international development, women's and LGBT rights, as well as rights for factory workers and those historically marginalized, especially stood out amongst the others.

However, to more specifically address the questions posed above, I turned to a strategy of semi-structured interviews with local residents of Yangon $(n=8)$, foreign nationals living in Yangon for more than 1 year $(n=3)$ and recently returned Karen refugees $^{6}$ in the region $(n=2)$. It was through these initial interviews that a larger story of resistance to repatriation began to develop, from both the host country community and the refugees themselves. Throughout interviews with locals in Yangon, all from the majority Burman group, there were open hostilities voiced concerning the Rohingya ethnic minority, and sentiments that ranged from indifference to dismissiveness concerning the approximately 90,000 Karen living as refugees on the Thai border. Many locals noted that they did not know what the word "refugee" meant, or insisted that the issue with the Karen was resolved long ago. Also telling was the sheer shortage of any returned Karen in the

\footnotetext{
6 The individuals interviewed in 2015 were not officially repatriated by UNHCR or the governments of Thailand and Myanmar. Rather, they spontaneously returned on their own accord and were attempting to live in the outskirts of the greater Yangon region.
} 
region to interview. Presumably, the majority of Karen would in fact return to the southeastern Karen State where they previously lived, rather than Yangon; thus, my assumption that some would seek out Yangon for economic opportunity was impossible to verify and most likely false. In the two interviews with returned Karen that I did manage to arrange in 2015, they both reported not being able to obtain citizenship paperwork from the Myanmar government, and were currently unemployed and living with relatives. Due to the fact that they had returned spontaneously, and without official sanction from UNHCR or the Myanmar government, they had received no monetary or logistical support. This greatly affected their feelings concerning return and placed them at odds with a highly bureaucratic system.

The second phase of preliminary research was carried out over 4 weeks in the late summer of 2015 in Thailand, in and around the border town of Mae Sot, as well as inside the proposed research site for the project, Mae La refugee camp (see detailed site description in following section). The goal of this phase was to speak directly to those facing repatriation and gauge their reaction at the prospect of returning to Myanmar. Specifically I was interested in the conceptualization of home in the context of this very protracted refugee situation, where many refugees had lived in camps for decades. Additionally, I wanted to understand what specific concerns they had with repatriation and if a "voluntary repatriation" as the UNHCR termed it, was indeed a possibility in the future. Over the course of these 4 weeks, I conducted 12 interviews with Karen refugees living either within Mae La camp ( $n=5)$ or living illegally in the neighboring town of Mae Sot $(n=7)$. Additionally, I interviewed 3 representatives from local NGOs who were all implementing either ESL or economic training programs in Mae Sot for Karen refugees. 
What became abundantly clear during this time was not only the seemingly universal resistance to return from both the Karen and regional NGO workers, but also the complexity of the situation. A cacophony of voices from CBOs, EBOs, NGOs, INGOs and government officials all collided with concerns, complaints, demands, concessions and refusals concerning the nine camps along the border. There were land rights issues, refugee vs. migrant status determination issues, issues with land mines, issues with economic development, and myriad other complexities that made the question of repatriation anything but straightforward. Rather at one point, a Karen leader I was interviewing mused dryly, "I'm glad you're here to sort all this out! Please send us your report when you finish." And as happens with much preliminary research, I was left with more questions than answers, but was confident of both the feasibility and significance of the project.

Overall, during the preliminary research phase in 2015, I conducted 28 interviews and participated in a variety of activities and daily life in both Myanmar and on the ThaiMyanmar border. Aside from confirming the feasibility of the project, this work proved to be especially helpful in cultivating strong research relationships with a variety of Karen community members, including those living in Mae La camp, as well as NGO workers in Mae Sot, and a handful of foreign academics conducting various research in the region. It ultimately helped form the foundation for this project, informed lines of inquiry, and guided thematic research. 


\subsection{Returning to the Field}

I officially began my fieldwork in January of 2017, spending the first 3 months of the year completing a visiting study fellowship at the University of Oxford's Refugee Studies Centre in the U.K. This fellowship specifically allowed me to immerse myself in the archival literature concerning the last 30 years of data on the plight of the Karen in Southeast Asia. The archives at the Refugee Studies Centre are some of the most comprehensive in the world concerning refugee literature, and include access to physical pieces of grey literature ${ }^{7}$ collected over the years by many researchers in the field.

Among the assortment of boxes filled with papers, photos, presentations, newspaper clippings and unpublished manuscripts, I came across several pieces of original correspondence from the late 1980's and early 1990's that painted a very complex picture of relations between Thailand and Myanmar concerning their handling of refugees. In my prior research, I often found Thailand portrayed in a mostly positive, sometimes even generous or heroic narrative, attributed mostly to their longstanding acceptance of refugees from Myanmar along their shared border. As is often pointed out by journalists and academics, Thailand is not a signatory to the UN's 1951 Refugee Convention, and thus, seemingly has no obligation to offer refuge or asylum to those seeking it from neighboring countries. In this way, the fact that camps have existed in Thailand for 30 years seem to be symbolic of Thailand's commitment to human rights and generosity of spirit, or so you might assume after reading much of the recent writing concerning refugees in this region. Notwithstanding Thailand's ratification of the 1966 Bangkok Principles on the Status and Treatment of Refugees (as discussed in greater detail in chapter 3), which lays out

\footnotetext{
7 Grey Literature can be defined as documents that are produced on all levels of government, academics, business and industry in print and electronic formats, but which are not controlled by commercial publishers.
} 
essentially the same sort of protections as the 1951 convention, Thailand has a much more complicated past of forcefully returning ethnic minorities to Myanmar or subjecting them to various forms of abuse.

In one press clipping from the May 1990 Issue Brief from the U.S. Committee for Refugees, several cases of refoulement ${ }^{8}$ by the Thai government resulting in death were reported. Quoting a report from Amnesty International, the issue recounts a group of 22 ethnic minority students who were forcibly repatriated to Myanmar after being rounded up by the Thai Police. As they noted:

"They are said to have repeatedly expressed fears for their safety and to have petitioned the Thai authorities not to be returned to Burma and eventually went on hunger strike. They are understood to have been forced to board a plane from Tak airport on January 6, 1989 by Thai army personnel."

It went on to say that the U.S. government agreed with the concerns of Amnesty International and the U.S. State Department subsequently released a press statement saying:

"We have received credible reports that a number of returned Burmese students who fled Rangoon after the September 18 military takeover were subsequently arrested and died while in the military regime's custody."

In another letter, addressed to the late Dr. Barbara Harrell-Bond on November 28 of 1991, a student writes:

"I have just returned from Bangkok where I find the situation even more pressing on the Burmese refugees. They have until 4 December 1991 to register with the Ministry of Interior for movement to the proposed "safe area". If they do not register, they will become illegal immigrants subject to arrest and possible deportation to Burma. It seems UNHCR at present has no

\footnotetext{
8 The principle of non-refoulement was first laid out in 1954 in the UN-Convention relating to the Status of Refugees, which, in Article 33(1) provides that: "No Contracting State shall expel or return ('refouler') a refugee in any manner whatsoever to the frontiers of territories where his life or freedom would be threatened on account of his race, religion, nationality, membership of a particular social group or political opinion."
} 
means of protecting these people though most of them have the status of "persons of concern" to UNHCR. In recent months two students have been killed allegedly by Thai Police. It is understandable that the Burmese students do not wish to go to the proposed "safe area" or camp. The border camps have proven to be long-term situations - some asylum seekers have lived more than ten years in this confinement. It seems UNHCR and the international community are not assured of any presence in the proposed "safe area" and reports on the conditions are inconsistent, and there has been no written documentation given to the public or to the agencies on this matter. Without some international presence, protection of the persons and human rights of the refugees and asylum-seekers will be difficult, even impossible. The coming seminar may find ways of using "good offices" to delay the implementation of the "safe area" proposal until there are guarantees of an international presence, and to negotiate with the Thai Government to allow proper documentation to be given to those Burmese recognized as refugees, and to allow UNHCR to carry out its major role of protection of "persons of concern" and asylum-seekers. Currently there are some 100 Burmese detained in the Police Academy in Bangkok. Some are students arrested for trespassing after the protest to draw attention to the attempted refoulement, sentenced for 60 days on 3 July 1991 and still being detained."

In another handwritten correspondence, subsequently dated February $24^{\text {th }}, 1992$, a

Burmese refugee writes directly to the head office of UNHCR in Switzerland, in what appears to be an attempt to tell someone - anyone - what is happening. She writes:

"The Thai government has planned, and is proceeding to keep all the Burmese Refugees in a camp. We don't want to be kept in a camp, totally controlled by the Thai Authority. Because we had never been kept like this before. We, altogether 107, arrived Ranong, Thailand in the evening of $18^{\text {th }}$ September 1988 after the military took up the power in Burma. They arrested and camped us in a village called Hut Sun Pan near Ranong. They kept us in a building that was surrounded by barbed wire. They did not let us out beyond that. We assumed it was a camp and it was heavily guarded by Thai police and military personnel. We got food and a few other things through them. They took some of them. We made the meals by ourselves. Before we had our meals they often came to take what they wanted to eat. The guards were fond of drinking. They were drinking the whole day. When they did not have money to buy drink, they took our rice and exchanged with drinks in the market. One night before we went to sleep, a guard kicked Ko Htun Win in the face. Ko Htun Win was unconscious. When we protest about that, they nailed all the doors closed and aimed the guns at us. We asked the governor to solve that problem when he came to visit. But he left the problem unsolved. The leader of the military took our pictures twice. But we never 
saw the pictures. We suspected that he sold the photographs to Burmese agents. The place we were kept is very much look like the camp the Thai government is going to. But the present one will be worse. We were barely kept two months. In that short time, nearly half of our group went back to Burma because they could not tolerate the behavior of the guards and being kept under detention. If it were longer then two months, we were not sure to keep our anger under control. So we do not appreciate and strongly object the plan to keep all the Burmese Refugees in a camp that is totally under the control of the Thai Authority. These are the names, UNHCR registration numbers and signatures of us on the next page."

Through these letters, field reports and press clippings, a more nuanced history began to emerge. This history was often tense, predicated on political maneuvering between two governments, and frequently exacerbated by the presence of international agencies attempting to intervene. It is also a history of alternating narratives of Thailand as both savior and tormenter, refuge and snake pit; a complicated history that would ultimately lend clarity to the complexity of the current state of affairs. Thailand's complex history with refugee protection is given additional consideration in chapter 3 , especially in relation to its influence on the current political climate surrounding repatriation.

Upon completion of my time as a visiting study fellow at the Refugee Studies Centre, I began to prepare for an extended stay in Southeast Asia. In the late spring of 2017, I returned to the Thai-Myanmar border to begin the ethnographic portion of this research project. For the first two months I stayed in and around Mae Sot, the closest border town to my chosen research site, Mae La refugee camp. During this time I was able to reestablish contact with informants and colleagues from my preliminary research, as well as establish contact with the local UNHCR field office to update them on my research concerning their voluntary repatriation program. During this time I was also able to reconfirm entrance into Mae La camp with the assistance of two colleagues from universities in the U.K. and 
Thailand. Ultimately, I was put in touch with a school operating inside the camp that was willing to sponsor my stay in exchange for my services as an English teacher.

The research site for this project, Mae La Refugee Camp, is located in the Tha Song Yang District of the Tak Province in Northern Thailand, approximately $8 \mathrm{~km}$ west of the Myanmar border. Mae La is the largest of the nine camps along the Thai-Myanmar border, with a population of 36,708 (TBC, 2018). Mae La is also known as 'Beh Klaw' or 'cotton fields' in the Karen/Kayin language, which refers to the agricultural activities around which Karen leaders originally negotiated permission for refugees to cross into the area (TBC, 2014). While official maps of the camp are notoriously rare, the map below displays recent satellite imagery captured by Google Earth in 2019. Nestled in the shadow of a large karst limestone cliff sits the sprawl of bamboo and thatch roof homes that make up the camp's 455 acres, split across four zones (zones A,B,C,D).

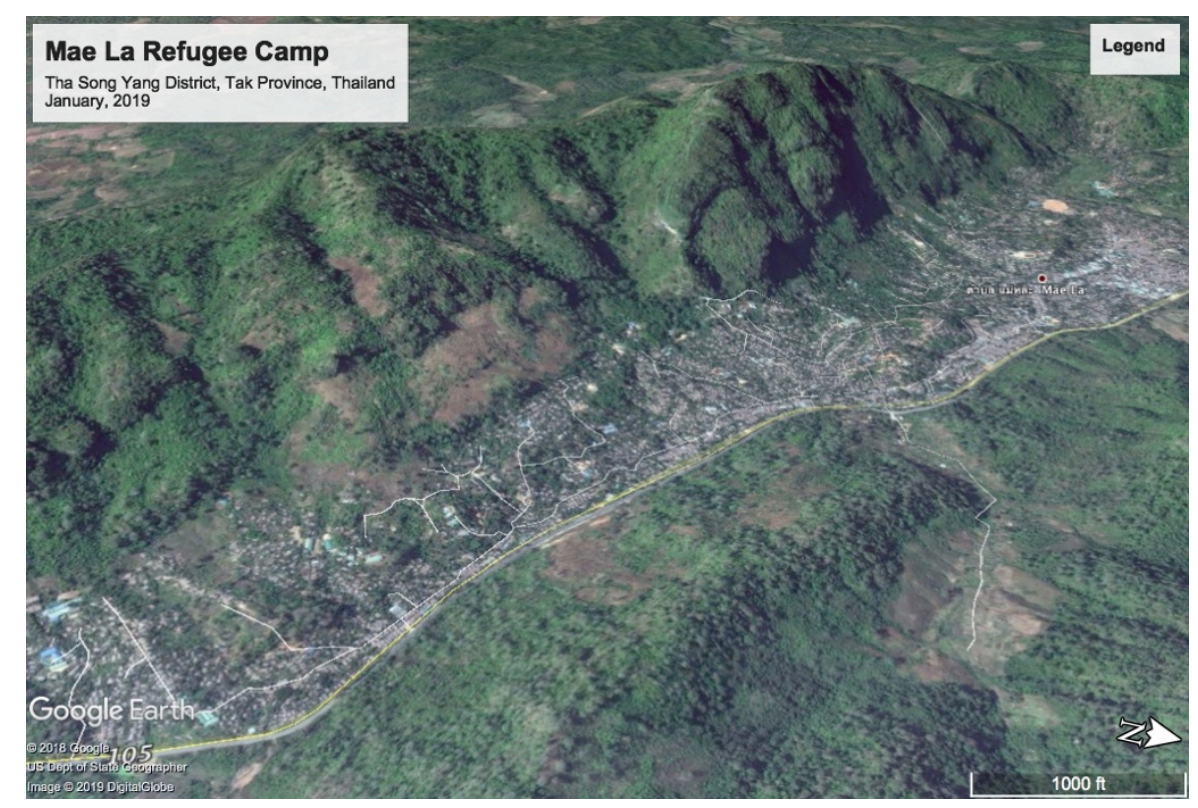

Map 4 -Mae La Refugee Camp, Source: Google Earth, 2019 
The camp was originally established following the fall of a Karen National Union (KNU) base near the Thai village of Mae La on the border in 1984. In January 1995, numerous camps were attacked in cross-border raids and the Thai authorities began to consolidate camps along the border to improve security and reduce the risk of shelling. Mae La was designated as the main consolidation camp in the area and thus in April of 1995, Mae La increased in size from 6,969 to 13,195 due to the closure of five camps to the north: Mae Ta Waw, Mae Salit, Mae Plu So, Kler Kho and Ka Mawlay Kho and the move of Huay Heng later in October of the same year (TBC, 2014). Over the next 3 years, the camp nearly tripled in size as refugees continued to stream across the border and additional camp closures continued including both Huai Bone and Shoklo camps. Today approximately 85\% of the refugees in Mae La are ethnic Karen (TBC, 2018), most having fled due to the constant fighting between the Myanmar military and the Karen National Union's (KNU) armed wing, the Karen National Liberation Army (KNLA).

Due to its size, age and visibility, Mae La has become both a place to access healthcare and education for refugees. The camp's medical clinic at Mae La is run by the international NGO Première Urgence-Aide Médicale Internationale (PU-AMI), which trains health workers and provides healthcare to the refugees. Additionally, there are several schools in Mae La providing children within the camp access to primary and secondary education. The schools are also attended by a few thousand students living inside Myanmar, who do not have access to educational facilities within their villages. These students are thus registered as temporary inhabitants of the camp.

Over the past two decades, researchers from varying academic and practical disciplines have conducted a limited number of research projects in the camp. Researchers 
have addressed areas such as alcohol abuse and partner violence (Ezard, 2009),

experiences of LGBT individuals within the camp (Forced Migration Review, Iss. 42, 2013), dietary assessments (Banjong \& Menefee, 2003), HIV prevalence (Plewes \& Lee, 2008), community-based camp management (Thompson, 2008) and human rights abuses and the protection of children (Chia, 2012). However, there is a dearth of academic research concerning the lived experiences of the refugees on the border, especially in regards to living within states of limbo, waiting and biding time. Additionally, how these experiences affected their acceptance (or non acceptance) of voluntary repatriation programs remained to be seen. As Mae La refugee camp is both the oldest and most prominent camp along the border, it served as the most relevant site to carry out this research project.

\subsection{Methodological Approaches}

The primary focus of this project was to understand how Karen refugees living inside Mae La coped with the long periods of uncertainty and waiting inherent to living in a refugee camp for extended periods of time. It also aimed to explore how they negotiated their agency, resistance and strategic decision-making when faced with impending camp closures and voluntary repatriation programs. As such, this project addressed the following three objectives:

Objective 1- To understand which factors may affect the acceptance or nonacceptance of voluntary repatriation programs offered to Karen refugees living in Mae La camp.

Objective 2- To determine if experiences of indefinite waiting and uncertainty alter decision making in regards to individual migration strategies.

Objective 3- To identify the specific barriers to voluntary repatriation perceived by both refugees and governmental stakeholders. 
To achieve the specific objectives above, the project employed a five-phase research design that included both qualitative and quantitative elements (described in detail below). In addition to ten weeks of preliminary research carried out in the summer of 2015, I spent approximately three months conducting archival research at the University of Oxford, three months conducting research and community-centered interviews with stakeholders within the Mae Sot region of Thailand, and approximately five months living inside Mae La refugee camp in order to enable both in-depth interviews as well as participant observation of the every day life experienced in a refugee camp. This access was facilitated by a small school within the camp that provided sleeping quarters and daily meals. As such, during this time I only had access to the same facilities and resources as the refugees themselves, including limited running water and electricity. In order to mitigate any costs associated with my stay in the camp, I made monthly donations to cover the cost of food and other expenses. Additionally, I taught an English class at the school for the duration of my stay.

\section{Project Design}

The project's first phase was centered on community engagement in Mae Sot and renewing contact with informants and study participants identified in the pilot study, undertaken in May-June of 2015. During this phase, interview questionnaires were developed, pre-tested and revised based on informant feedback. In the second phase, I entered the camp and began teaching English for the school that hosted my stay. This phase also entailed conducting systematic observations of camp life recorded in detailed field notes as well as hiring a research assistant. The third phase centered on conducting taped, semi-structured interviews with a purposive sample of 40 individuals, related to lived experiences in the camp and feelings regarding returning to Myanmar. Questions posed 
during interviews ranged from inquiries about personal histories ("Can you tell me about your journey to Mae La camp?"), life in camp ("Can you tell me about your life in Mae La?" "How do you spend your day?" "What do you do in your free time?" "Do you feel that there is too much free time, not enough free time, or just enough free time?"), and questions concerning repatriation ("Have you heard about the voluntary repatriation program?" "How do you feel about returning to Burma?" "Do you know any friends or family members who have returned or are planning on returning soon?'). Additionally, I always closed each interview by asking the participant if they had any questions for me or anything else they would like to add. This more casual and conversational tone proved to add a valuable compliment to the semi-formal interview and often gave additional insight into their previous answers. For reference, a complete copy of the interview guide can be found in the appendix of this dissertation. The project's fourth phase entailed two months of on-site preliminary data analysis in order to improve the validity of study results and share findings with project partners before leaving the field. During this phase I conducted a public presentation in camp with my initial findings, which I opened up for a long Q\&A session afterwards. The project's fifth and final phase involved the full transcription of all audio files, intensive data analysis through Atlas.ti, a qualitative software program, and conducting any required follow up interviews with research participants.

\section{Research Population}

The population for this study was comprised of Karen refugees, both men and women, residing in Mae La refugee camp. Respondents were limited to those refugees who have lived within the camp for more than five years, so as to fully explore questions concerned with extended periods of time residing within camp walls. In the interest of 
collecting a diverse sampling of data, I interviewed only one person per household.

Additional interviews were conducted with local camp leaders and representatives from UNHCR, TBC and KRC.

\section{Recruitment}

Recruitment of participants was facilitated through both community engagement and assistance from my local research assistant. Through the preliminary research I conducted in the summer of 2015, I successfully built a small network of both local and international NGO employees within Mae La camp who expressed enthusiasm for my project. This network ultimately helped with several referrals for research participants. Other recruitment methods included identification of probable informants during participant observation, daily life in Mae La and the use of a chain-referral sampling technique. Chain-referral sampling (Goodman, 1961) is best explained as a non-probability technique where existing study subjects refer potential informants to the researcher from among their friends and acquaintances.

\section{Data Collection}

Data collection was primarily performed through the use of taped semi-structured person-centered interviews and participant observation. Interviews with refugee informants took place within Mae La camp while interviews with NGOs were typically conducted at an arranged site within the Mae Sot area. Semi-structured interviews with informants were facilitated through the use of prepared interview guides and administered in person along with my research assistant, who would also act as translator if the need arose. Each interview lasted approximately 45 minutes to 1 hour. I recorded each interview with the participant's consent for future transcription. Due to the research parameters 
agreed upon between myself and the SMU Institutional Review Board, I did not conduct any interviews with persons under the age of 18.

In each interview session, I verbally explained the need for informed consent while also explaining the details of the research study, including the purpose, study procedure, foreseeable risks, and benefits. Prior to conducting the interviews, I allowed the participant to ask any questions before consenting. In the case of interviews with refugee informants that did not speak English or Burmese, my research assistant acted as translator for the S'gaw Karen dialect to explain the informed consent process. On three occasions, a second translator was made available to translate the Pwo Karen dialects for both the purposes of consent and interview. As previously agreed upon between myself and the SMU Institutional Review Board, I requested that written consent be waived in lieu of verbal consent, as the only record linking the subject and the research would be the consent document and the principal risk would be potential harm resulting from a breach of confidentiality.

Myanmar has recently become a democratic country as of 2011, however due to the history of military and government oppression, there still remains a degree of uneasiness about being identified as having certain opinions or political beliefs. Previous anthropologists working in Myanmar have noted their informant's request to destroy any interview transcripts due to this uneasiness of their name being linked to the information they have provided (Fink, 1996). Thus the only record of the name or other identifying information of the subject would be the signed consent form and knowledge of an individual's participation or information provided could lead to potential social harm. It is 
for this reason that I requested a waiver of signed informed consent and instead obtained verbal consent.

In addition to the 28 interviews gathered in 2015 during the preliminary phase of this project, data collected in 2017 included 40 semi-structured person-centered interviews, 2 community meetings, 3 months of archival research, 8 months of participant observation and ongoing analysis of local publications, media, art and music related to repatriation and refugee experiences along the border (see table 2 below for additional detail). 
Table 2 - Summary of Interview Data Collected (2017)

\begin{tabular}{|c|c|c|c|c|}
\hline Gender & Age & Religion & Note & $\begin{array}{l}\text { Length of time } \\
\text { in camp }\end{array}$ \\
\hline $\mathrm{M}$ & 35 & Christian & Camp Leader & 20 \\
\hline $\mathrm{M}$ & 50 & Christian & Camp Leader & 27 \\
\hline $\mathrm{M}$ & 40 & Christian & Camp Leader & 19 \\
\hline NA & NA & NA & NGO Group Interview & NA \\
\hline $\mathrm{F}$ & 24 & Christian & NGO Staff Member & 22 \\
\hline $\mathrm{M}$ & 33 & Christian & NGO Staff Member & NA \\
\hline $\mathrm{F}$ & 38 & NA & NGO Staff Member & NA \\
\hline $\mathrm{M}$ & 46 & NA & NGO Staff Member & NA \\
\hline $\mathrm{M}$ & 51 & Buddhist/Animist & Refugee & 17 \\
\hline $\mathrm{M}$ & 78 & Christian & Refugee & 32 \\
\hline $\mathrm{F}$ & 52 & Buddhist/Animist & Refugee & 11 \\
\hline $\mathrm{M}$ & 31 & Christian & Refugee & 8 \\
\hline $\mathrm{F}$ & 42 & Christian & Refugee & 9 \\
\hline $\mathrm{M}$ & 38 & Christian & Refugee & 11 \\
\hline $\mathrm{M}$ & 31 & Christian & Refugee & 8 \\
\hline $\mathrm{M}$ & 43 & Christian & Refugee & 12 \\
\hline $\mathrm{M}$ & 28 & Buddhist & Refugee/Monk & 10 \\
\hline $\mathrm{M}$ & 52 & Christian & Refugee & 8 \\
\hline $\mathrm{F}$ & 27 & Christian & Refugee & 10 \\
\hline $\mathrm{F}$ & 47 & Christian & Refugee & 10 \\
\hline $\mathrm{F}$ & 72 & Buddhist/Animist & Refugee & 15 \\
\hline $\mathrm{F}$ & 44 & Christian & Refugee & 10 \\
\hline $\mathrm{F}$ & 48 & Christian & Refugee & 9 \\
\hline $\mathrm{M}$ & 21 & Christian & Refugee & 21 \\
\hline $\mathrm{M}$ & 20 & Christian & Refugee & 20 \\
\hline $\mathrm{F}$ & 50 & Buddhist & Refugee & 26 \\
\hline $\mathrm{F}$ & 39 & Christian & Refugee & 27 \\
\hline $\mathrm{M}$ & 24 & Christian & Refugee & 24 \\
\hline $\mathrm{M}$ & 39 & Buddhist & Refugee & 17 \\
\hline $\mathrm{M}$ & 31 & Christian & Refugee & 8 \\
\hline $\mathrm{F}$ & 28 & Christian & Refugee & 25 \\
\hline $\mathrm{F}$ & 18 & Christian & Refugee & 18 \\
\hline $\mathrm{F}$ & 27 & NA & Refugee & 24 \\
\hline $\mathrm{M}$ & 56 & Buddhist/Animist & Refugee & 19 \\
\hline $\mathrm{M}$ & 42 & Christian & Refugee & 9 \\
\hline $\mathrm{M}$ & 36 & Buddhist & Refugee & 12 \\
\hline $\mathrm{F}$ & 39 & Buddhist & Refugee & 14 \\
\hline $\mathrm{M}$ & 18 & Christian & Refugee & 18 \\
\hline $\mathrm{F}$ & 36 & Christian & Refugee & 20 \\
\hline M & 59 & Buddhist & Refugee & 17 \\
\hline \multicolumn{5}{|c|}{ Summary Totals and Averages for all Interviews (2017) } \\
\hline $\mathrm{M}=23$ & \multirow{5}{*}{$\begin{array}{c}\text { Avg } \\
\text { Age }=39 \\
\text { years old }\end{array}$} & Christian $=26$ & Camp Leader $=3$ & \multirow{5}{*}{$\begin{array}{c}\text { Avg } \\
\text { Time in Camp = } \\
16 \text { years }\end{array}$} \\
\hline $\mathrm{F}=16$ & & Buddhist $=6$ & NGO Staff $=4$ & \\
\hline \multirow[t]{3}{*}{$\mathrm{NA}=1$} & & Buddhist $/$ Animist $=4$ & NGO Group = 1 & \\
\hline & & $\mathrm{NA}=4$ & Refugee $=31$ & \\
\hline & & & Refugee $/$ Monk = 1 & \\
\hline \multicolumn{5}{|c|}{ Summary of Additional Data Collection (2017) } \\
\hline \multicolumn{3}{|c|}{ Archival Research } & & \\
\hline \multirow{2}{*}{\multicolumn{2}{|c|}{$\begin{array}{l}\text { Participant Observation } \\
\qquad 8 \text { months spent living within region (Yangon, Mae Sot and Mae La Camp) } \\
\text { Focus Groups and Community Meetings }\end{array}$}} & & & \\
\hline \multirow{2}{*}{\multicolumn{5}{|c|}{$\begin{array}{l}\text { Focus Groups and Community Meetings } \\
\qquad 2 \text { sessions conducted in Mae La Camp (June } 2017 \text { and Oct 2017) }\end{array}$}} \\
\hline & & & & \\
\hline \multicolumn{5}{|c|}{$\begin{array}{c}\text { Analysis of local publications, media, art and music related to repatriation and refugee experiences along the border } \\
\text { Ongoing analysis Facebook, Karen News, KRC newsletter, Burmalink, Teacircle }\end{array}$} \\
\hline
\end{tabular}




\section{Accuracy of Data}

The accuracy of data collected from refugee populations can sometimes be problematic as has often been discussed within the literature of refugee studies. It has been argued that refugee informants may have an interest in obscuring or falsifying data in relation to a perceived connection to the success or failure of bids to receive aid or resettlement (Mulumba, 2007; Dunlop 2011; Satterthwaite \& A Rosga, 2008). With knowledge of the reported challenges of gathering qualitative data from refugee populations, I felt more equipped to deal with this issue by being more cognizant in this regard. Further, before each interview I explicitly explained that answers would in no way affect their personal situation in regards to resettlement or aid distribution. Additionally, my extended presence in the camp prior to conducting semi-structured interviews helped alleviate any initial distrust that might have potentially affected the accuracy of any data collected.

The time spent living in camp also worked to refine and improve the accuracy of data I collected through participant observation. I generally stuck to a strategy of saying yes to any invitation extended my way which led to observing a camp-wide soccer tournament, two funerals, multiple religious ceremonies, many shared meals and a host of other opportunities to engage with the population. This engagement offered multiple lenses in which to view the dynamics of daily life and community interaction, furthering strengthening my analysis. The data I collected during participant observation was also strengthened tremendously by the input I was able to receive from my research assistant and fellow teachers inside the camp. 
In regards to the accuracy of data collected while interviewing officials and representatives from international and community-based organizations, I consciously made an effort to communicate my neutrality at all times. As the protracted refugee situation along the Thai-Myanmar border is deeply political, some have argued that western researchers often present a biased representation that sides with Karen activists (Horstmann, 2011). With this in mind, before interviews with any organization, I made every effort to review all public information about their work and any potential biases that may be present.

\section{Data Analysis}

The results from the data collection methodologies described above were analyzed primarily through the use of Atlas.ti, a professional software application used in the analysis of qualitative data. Additionally, I drew from the literature on forced migration to inform my top-down coding methodology in regards to both specific words and themes. All audio recording from semi-structured interviews was transcribed first into Microsoft Word, and then uploaded into Atlas.ti. Within Atlas.ti, I created several key words such as "agency", "resistance", "repatriation", "time" and "waiting" to identify themes and assign them to related sections of text. Through this coding I was able to see emerging themes in the data and determine which ideas were predominant among the community. This strategy of analysis is rooted in grounded theory (Soulliere et al. 2001), which is a way of conceptualizing data that creates an interplay between data collection, coding and analysis that involves coding, constant comparison, theoretical sampling and verification. 


\subsection{Concluding Remarks about Ethical Challenges in the Field}

Working with refugees or other marginalized groups can often present ethical challenges concerning power dynamics, properly informed consent and culturally appropriate representation amongst other things. I found all of these challenges present in my fieldwork although in the context of living inside a refuge camp, some proved more difficult than others. As a rule, I decided prior to entering the camp that I would not interview any of the students at the school where I would be living and teaching an English course, even if they were over the age of 18 . In my previous research experience, I have encountered response bias, where I felt my informant was potentially giving answers that they assumed I wanted to hear. I was acutely aware of this risk being greater when there are both an age and cultural difference present, and I felt adding an additional layer of status (ie teacher v. student) would potentially invalidate any data collected. However, what I did not anticipate was the ethical challenge inherent in presenting myself authentically and unbiased, as a researcher and anthropologist, amongst the community I was living in. To be more specific, the school that agreed to host my stay was religious in nature with a core curriculum that was heavily reliant on scripture and Christian ideology. Personally, I do not claim membership in any religion, although I certainly do not disdain others for theirs. I knew the organization was religious before agreeing to stay and felt I had alleviated any conflicting interest by noting some concerns up front. I communicated that I was happy to teach English (which I believed to be a very neutral subject) but noted I could not teach any religious classes as I would need to interview people in camp from all religious backgrounds and did not want to be perceived as biased. This was agreed upon prior to entering the camp, and indeed, I did not need to teach any religious courses over 
the duration of my stay. However, there were several times when I felt it was assumed I was a practicing Christian and I chose in those instances not to overtly correct the assumption. At other times I felt it was necessary or polite to participate in a routine religious activity as an active member of the school staff. Participating in these activities sometimes felt deceptive or inauthentic, although I often found myself weighing the cost of othering myself further from a community I was trying to become a part of. Ultimately I decided that the conflict was not significant enough to warrant concern, as I was not actively recruiting research participants from the school's student population. I eventually resigned myself to minimal participation in any activities that felt disingenuous on my part and a general avoidance of the topic concerning my personal faith. I would describe this as an uneasy truce and imperfect solution. I must also mention that at all times the leadership and fellow teachers at the school were incredibly gracious and respectful to me, and I am eternally grateful for their kindness.

Upon reflection, I felt it was important to discuss this experience in the context of research challenges, as there are often many obstacles no amount of graduate courses can prepare us for in the field. According to Goffman's theory in The Presentation of Self in Everyday Life (1959), the social actor may take on an already established role, with preexisting fronts and props with the main goal to keep coherent and adjust to the different settings offered him. In this way, I felt the role of visiting westerner had previously been played to the "audience" in camp by a missionary or religious leader. Thus, they assumed I would also fulfill that role which made it easier to slip into due to a desire to fit in. In this sense I would offer a word of advice to future researchers should they follow a similar path into fieldwork: Taking conscious inventory of the ways in which your identity may 
intersect with your research population is an important step in preparing for the field.

While we often discuss cultural relativism as anthropologists, we are sometimes lacking in asking how we will negotiate our own faith, gender identities, sexual preferences or even political leanings until we are confronted with presenting ourselves in the field. The personal dimensions of our lives, and which ones we choose to share, can have implications to our integrity as researchers. Finding a balance that feels right is sometimes as challenging as it is personal. 


\section{Chapter 3}

\section{POLITICS AND THE PRECARIAT}

"The Thai people, I think they look down on us. You know because we are just refugees, we can't do anything. My life here, it's like the bird or the pig, just living in the garden, in a cage. It's like a prison. No job, no place to earn money or stand and walk by myself. But there is no place for Karen people to go and live peacefully. There is no security, no life to return to. So we are stuck."

$\sim$ Saw Htoo Hay, 31, Mae La Camp

\subsection{Introduction}

On a hot day in mid-September, I found myself tagging along for a trip out of the refugee camp and into the border town of Mae Sot. One of the teachers from the school, Poe Taw, a refugee himself who had grown up in Mae La, invited me to come along for the hourlong journey full of bumpy roads, Thai talk radio and stunning views of the surrounding jungle. This was an opportunity I happily jumped at, relishing the chance to find a store in town where I might pick up some bread or chocolate- rare commodities in camp. We piled into a pick-up truck, one of the vehicles used for official school business, and set off excitedly for this unexpected day trip into town to buy some supplies and medicine. The school hosting my stay had over the years reached a sort of informal agreement with the armed Thai guards who stood constant watch over the entry and exit points of the camp. When we arrived at the gate, Poe Taw presented them with a typed letter, signed by both 
the school's dean and the section camp leader; they glanced at it and waved us on our way. “They know us, it's ok." Poe Taw explained, passing me the letter so I could get a better look. The letter listed the names of the three teachers leaving camp that day, with a brief paragraph noting that they were acting as official representatives of the school and asked that the Thai government please grant them permission to travel to Mae Sot for the day. What the letter didn't mention, was the mutual understanding that upon our return, we might happen to bring the guards a bit of lunch or another small token to show our appreciation for their generosity.

It struck me at this point how abnormal this process of asking for permission to leave actually was, while at the same time being entirely routine for my travel companions. Early in my stay at the camp, I wrote in my field notes about how easy it was to forget sometimes that this was a refugee camp rather than a crowded village. There were 40,000 people living across the 454 acres that comprised the four sections of Mae La, and it was possible to wander around for the entire day without seeing a fence or barbed wire. What I failed to grasp however was just how deeply engrained the knowledge becomes that your freedom of movement is restricted. You may not see the fence but you know it is there. You may not see the guards, but they are watching. And you may even be able to leave for the day, but it is a temporary departure. Those who have dared to leave the camp unofficially, sneaking under fences to seek out day labor jobs in order to supplement meager food rations, risk fines, arrest, imprisonment and even possible deportation. Thus the lack of legal status for the Karen to live in Thailand outside of a camp has put them at an extreme disadvantage, both socially and economically. Their confinement and subsequent inability to work legally in Thailand has perpetuated a culture of aid dependency while also 
encouraging an illegal labor market prone to exploitation. Figures from 2017 estimate there are nearly 2 million irregular migrants from Myanmar working in Thailand (IOM, 2017) with many refugees and migrants employed on the western border in factories, construction sites and agricultural zones. These are jobs that rely heavily on migrant labor because most Thais are unwilling to fill them. Due to the Karen's precarious legal status, they are often paid less than minimum wage and have no recourse should they be injured or taken advantage of. Still, the numbers of migrants and refugees unofficially crossing the border into Thailand continues to rise, and more than half of the refugees I interviewed ${ }^{9}$ noted that staying in the country was indeed a preferred option to formal repatriation back into Myanmar. In that vein, it's worth exploring here what impact the emergence of this illegal working class may ultimately have on how Thailand deals with refugees from Myanmar, as well as its effect on attempted voluntary repatriation efforts.

In this chapter, I will start with a discussion of how Thailand's unique history of diplomacy, nationalism and independence has colored the current political landscape in regards to labor migration, as well as how it has intersected with current refugee policy. This is followed by an analysis of how the political and economic reforms happening within Myanmar are currently shaping diplomatic relations with Thailand and consequently affecting the fate of refugees residing in camps along the border. Additionally, I will offer a brief commentary on the emergence of special economic zones as a potential solution to both forced and irregular migration while offering a word of caution about the risks of development-induced displacement. In closing I will discuss how refugees waiting in the

\footnotetext{
${ }^{9}$ Qualitative analysis of semi-structured interviews conducted with refugees living in Mae La Camp produced $n=21$ respondents who listed "remain in Thailand", "find work in Mae Sot" or "stay with relatives in Thailand" as the answer to the question, "What would you do if Mae La camp closed in the near future?"
} 
confines of a camp are especially at risk of forming a new working underclass known as "the precariat ${ }^{10 "}$ which may actually work against creating economic security while derailing any attempts as sustained voluntary repatriation.

\subsection{From Siam to Thailand}

Thailand, known as Siam until 1939, has always been somewhat of an outlier in Southeast Asia, most notably in its status as the only country to never officially be colonized by European powers. Although it could be argued that forced land concessions to the French in the late $19^{\text {th }}$ century effectively amounted to foreign invasion, Siam never completely lost autonomy as a nation. Siamese kings quickly realized that actions such as mapping fixed borders, consolidating power to a geographic center such as Bangkok, and promoting a homogenous Siamese culture gave them a much better position from which to negotiate. In doing this, they effectively emulated a typical European nation-state, which created a way for their governing system to be familiar to outsiders, thus reinforcing the validity of their claim to sovereignty. In the late $19^{\text {th }}$ century, when Siam's territory was being encroached upon by the British from the west and the French from the east, the Siamese kings were able to effectively sustain their independence by leveraging the less than friendly relations between the British and French. In an important diplomatic feat, the Siamese Ambassador to Europe at the time, a member of the ruling Chakri dynasty, was able to quietly appeal to the British and their desire for a "buffer zone", or neutral space between their colonized territory of Burma and the French occupied Laos and Cambodia.

\footnotetext{
10 "The precariat" is a term first coined in 2011 by British economist Guy Standing. A combination of the words "proletariat" and "precarious", it describes an emerging class of people facing insecurity by means of precarious work. The precariat is often characterized by social exclusion, irregular or temporary migrant work and participation in informal economies.
} 
The closed door meetings that took place ultimately led to the Anglo-French Declaration of January 1896, which effectively guaranteed that neither the British nor the French would move to colonize Siam (Jeshurun, 1970). This cemented Siam's autonomy and ensured the Chakri dynasty remained in power for the next three decades as the ruling house of the Kingdom of Siam.

\section{Map 5 - Southeast Asia during the high colonial age, 1870 - 1914}
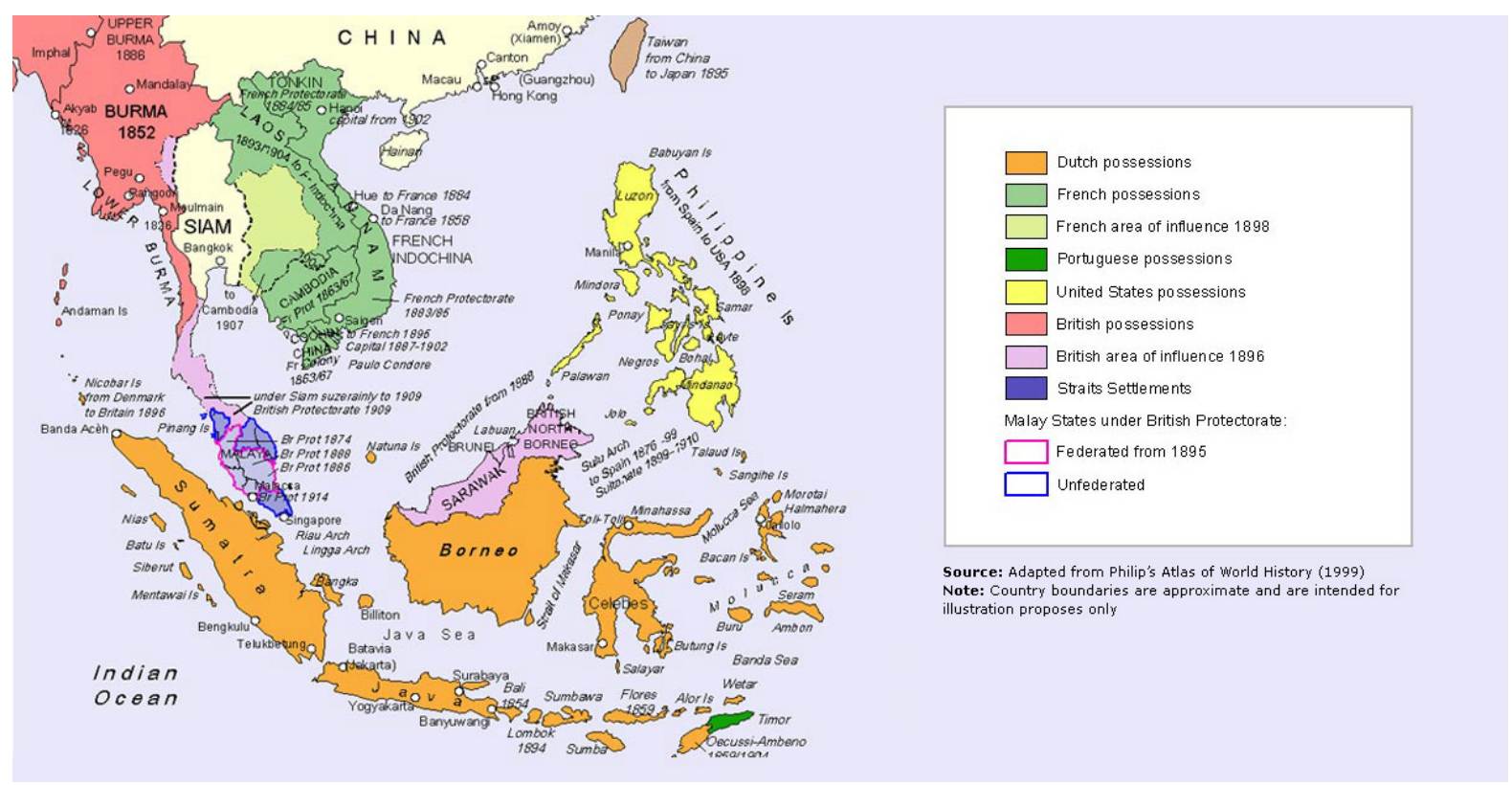

Source - Adapted from Philip's Atlas of World History (1999)

By 1927 however, a Siamese army officer by the name of Phibun had established the radical People's Party, which would go on to lead a coup against the ruling Chakri dynasty. In 1932, they were successful and a western-style parliamentary democracy was created. By 1938 Phibun had taken charge as a dictator, with an agenda of modernization and nationalism. He changed the country's name to Thailand in an effort both to highlight Thai culture as unique and to modernize the country's image. His slogan, "Thailand for the Thai" was largely seen as anti-Chinese, as there was a substantial population of Chinese in the 
country, many of whom owned prosperous businesses. Phibun drastically decreased the level of legal immigration from China and instead redirected funding toward governmentbacked Thai businesses. Additionally, he promoted the widespread use of the Thai language, especially in ethnic minority regions, and demanded that Mandarin in Chinese schools only be spoken for a maximum of two hours a week.

Phibun's idea of nationalism culminated in a plan he called "Ratthaniyom" (loosely translated as "state convention") which he rolled out between 1939 and 1942. The idea behind Ratthaniyom was to compel the people of Thailand to adopt the behavior, dress and etiquette of "civilized people" through a series of twelve cultural mandates ${ }^{11}$. These included how often people should eat (no more than four times daily), which products they should consume (always make an effort to buy Thai goods) as well as what to wear in public (inappropriate dress includes wearing only underpants, wearing no shirt, or wearing a wraparound cloth). More importantly however, were the cultural mandates that aimed to unite the country as one unit. For example, Mandate 2.2 stated, "Thai people must never reveal anything to foreigners that might damage the nation. These actions are a betrayal of the nation." Mandate 3 specifically targets the practice of referring to fellow Thais as 'Northern Thai' or 'Muslim Thai' reading, "Cease referring to Thai people inconsistently with the name of the nationality, or according to the preference of the group. Use the name 'Thai' to refer to all Thai people, without subdividing them." In March of 1940, perhaps the most strongly worded mandate (\#7) was issued, which explicitly urged the Thai people to help build the nation. This Mandate states, "Every Thai person must help build the nation. Every able-bodied person must work at a stable career. Any person without a

\footnotetext{
11 Each of the twelve cultural mandates were published in The Royal Gazette, volumes 56-59 between June of
} 1939 and February of 1942. Archives are readily available online at ratchakitcha.soc.go.th 
career is unhelpful to the nation and is not deserving of respect from the Thai people."

Collectively, these mandates not only solidified the importance of individual contributions

to nation building but also effectively created an in-group mentality for Thais.

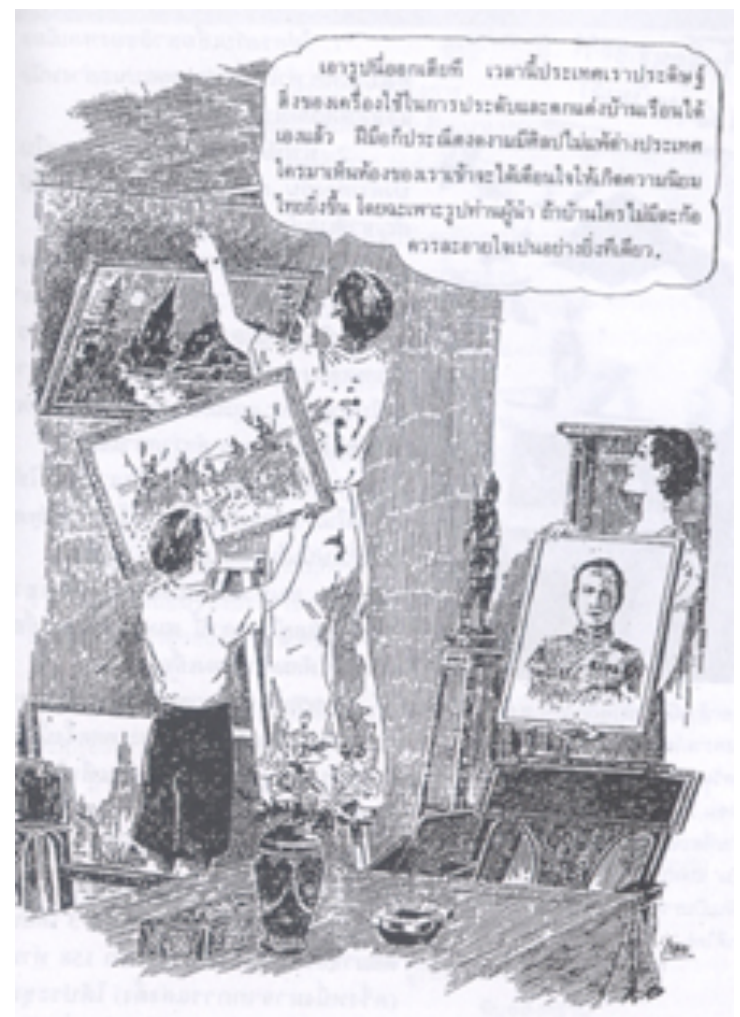

Figure 1. An illustration highlighting the cultural mandates of Phibun's Ratthaniyom. Note the father is removing a picture of a European landscape, while the son is holding a battle scene typical of the military engagements of the Ayutthaya period and the mother is holding a portrait of Phibun. The father is saying, "It's about time we had this picture removed. Thailand is now able to produce decorations for the home that are as good as those produced overseas. Any houseguest should always be reminded to buy only Thai goods. As for the Leader's portrait... any home that lacks one should be ashamed." (Source - P. Klykoom, Nation-building and the Pursuit of Nationalism under Field Marshal Plaek Phibunsongkhram, 2004)

The impact of the twelve cultural mandates has been profound and greatly shaped life and political discourse in Thailand. You can see their legacy as recently as 2018, when the Thai government launched a campaign called "Thai Niyom" (or "Thai-ism"). This campaign, aimed at reinforcing the idea of "Thai exceptionalism", includes twelve core values, which echo many of the ideas present in the original mandates. In this way, a strong 
sense of nationalism and diplomacy has not only been a way of life for the Thais, but rather a means of pride that is deeply embedded in their identity. They are skilled negotiators, adept at foreign relations, and project the confidence of a nation with both a loyal population and a proficient army. However, it is this relationship with nationalism and quiet diplomacy that often makes policy decisions confusing or less than transparent to foreign onlookers.

In the years that followed Phibun's takeover, Thailand became an ally of the United States and joined in anti-communist measures including participation in the Vietnam War. At the same time, internal conflict regarding economic instability plagued the Thai government and led to several uprisings and resulting coups. After a coup d'état in 2014, Thailand's constitutional monarchy was overturned and Thailand has been under the rule of a military organization called the National Council for Peace and Order (NCPO) ever since. Over these last four years, Thailand's stance on immigration has shifted somewhat as a result.

Directly after the coup, the general consensus along the Thai-Myanmar border was that restrictions were tightening and the military would begin cracking down on anyone living or working illegally in Thailand. Additionally, employers caught hiring an undocumented foreign worker could also face hefty fines. Internal negotiations between Thailand and its three largest migrant sending nations (Myanmar, Lao and Cambodia) resulted in the 2017 announcement of a new Royal Decree on Managing the Work of Aliens, which purportedly aimed to register and give legal status to all 3.8 million migrant workers in Thailand. However, the policy effectively excluded all those who lacked proper national identity documentation, such as many stateless Karen. In contrast to the push to officially 
register all economic migrants, the policy on refugees remained ad hoc and offered no suggestion of a plan to regularize their status or provide a path to obtaining work rights. Rather, refugee policy continued to be vague and risk of refoulement often overshadowed any sustained efforts at improving protections. As a 2017 report from Amnesty International noted:

"Thailand has paid lip service to improving protections for refugees, but this has not translated into real actions. Authorities continue to do foreign governments' bidding and send refugees back to countries where they could face torture and other human rights violations. These callous actions fly in the face of Thailand's international obligations and must be stopped immediately." (A. Gaughran, 2017)

Complicating the matter is that Thailand is not a signatory to the 1951 UN Refugee Convention and thus has not agreed in this way to uphold international standards of protection. Indeed, Thailand has no domestic laws governing refugees and their policies regarding treatment over the years have often been inconsistent and concealed from international scrutiny. However, it is fair to say that Thailand has in fact been offering some degree of refugee protection for decades and has spent significant time considering the impact of housing large populations of refugees along their shared borders. Certainly the international visibility of the protracted refugee situation along the Thai-Myanmar border has created pressure for Thailand to accede to the 1951 convention. However, Thailand has thus far rejected signing the convention and perhaps unsurprisingly, has preferred to address the refugee situation as an internal issue, free from the input of western governments. 


\subsection{Negotiating Refugee Status in Thailand and the Case of the Missing Bangkok Principles}

While much of the world was focused on the widespread refugee crisis unfolding in the Mediterranean in 2015, the protracted refugee situation on the Southeastern border of Myanmar and Thailand surpassed its third decade in existence. It has remained a point of contention for the Thai government, which has signaled multiple times over the years that it does not wish to be an indefinite host for the persecuted minorities crossing the border since 1984. Over the course of my fieldwork in 2017, I occasionally would spend a few days in the border town of Mae Sot to chat with local NGOs or the regional UNHCR field staff. On these days I found myself having conversations about the role of the Thai government in the fate of the nine camps along the border and mulling over both Thailand's cultural obligations and political exposure. Time and again, the fact that Thailand is not a signatory to the 1951 UN Convention came up as a sort of boilerplate explanation for their ambivalence towards protecting refugee human rights to an international standard. This was disconcerting though, as I and a few of the practitioners in the region did indeed recall reading at some point about The Bangkok Principles of 1966, which generally laid out similar guidelines to the UN Convention for the treatment of refugees and asylum seekers. I recalled that these principles, created in collaboration with the Asian-African Legal Consultative Organization (AALCO), were a sort of affront to adopting a westernized approach to forced migration. Instead, they argued that guidelines for the region should be imagined and realized by the countries themselves, a concept that truly nods to the power of self-governance in developing nations. However, over coffee in Mae Sot with regional NGO staff, the details seemed foggy and we agreed that they were seldom mentioned in any formal talks concerning Thailand's refugee policy. Was this historic regional coordination 
concerning the treatment of refugees an imagined occurrence? Or why had the literature on forced migration so thoroughly ignored it as to make their mention seem an obscure bit of trivia? I made a note to do some additional digging and headed back to camp.

The 'Bangkok Principles'12 were originally created in 1966 by the Asian-African Legal Consultative Organization (AALCO), an international governmental body based in New Delhi. Among the 47 member states of the AALCO are several South and Southeast Asian countries that are not signatories to the 1951 UN Convention, including: Myanmar, Bangladesh, Brunei, India, Sri Lanka, Nepal, Indonesia, Malaysia, Singapore and Thailand. Many of these countries refrained from ratifying the 1951 UN Convention out of a perception that it was a Cold War instrument which privileged political refugees over others in need of protection. Further, it would give UN agencies excessive license to interfere in their internal affairs while also shifting the economic burden to developing countries (Abrar, 2001). After decades of debate by the member states concerning regional obligations and the specific definitions assigned to 'asylum', 'refugee' and 'forced migration', the final text of the AALCO's 1966 “Bangkok Principles on the Status and Treatment of Refugees" was officially adopted on June $24^{\text {th }}, 2001$ at the AALCO's $40^{\text {th }}$ session in New Delhi. Within these finalized documents, we find the definition of a refugee very much in line with the UN 1951 convention and described as:

"A person who, owing to persecution or a well-founded fear of persecution for reasons of race, colour, religion, nationality, ethnic origin, gender, political opinion or membership of a particular social group:

12 AALCO'S 1966 Bangkok Principles on Status and Treatment of Refugees" as adopted on 24 June 2001 at the AALCO's 40 $0^{\text {th }}$ Session, New Delhi 
(a) leaves the State of which he is a national, or the Country of his nationality, or, if he has no nationality, the State or Country of which he is a habitual resident; or,

(b) being outside of such a State or Country, is unable or unwilling to return to it or to avail himself of its protection;

The term "refugee" shall also apply to every person, who, owing to external aggression, occupation, foreign domination or events seriously disturbing public order in either part or the whole of his country of origin or nationality, is compelled to leave his place of habitual residence in order to seek refuge in another place outside his country of origin or nationality"

Further of note are mutually agreed upon terms of asylum, guidelines for non-refoulement, minimum standards of treatment, discussions of international burden sharing and even the right to compensation from the State when refugees are forced to flee.

Such a comprehensive agreement negotiated and agreed upon by both sending and receiving countries of refugees in Southeast Asia (i.e. Myanmar and Thailand) highlights the question of why the international refugee regime continues to push for accedence with the 1951 UN convention while disregarding the Bangkok Principles entirely. Perhaps it was the long period of time where the document sat in limbo, being debated and pushed back and forth that caused its relevance to wane. Or perhaps it is the lack of support from wealthier, more developed nations. Backing such a regional initiative may be antithetical to other agendas that support the advancement of programs administered by global humanitarian aid organizations, and subsequently the financial funding that comes with them. While much of the literature concerning refugee policy for South and Southeast Asia does often suggest that there should be regional collaboration to create formal structures for refugee protection (Abrar, 2001; Davies, 2007; Sharma, 2015;), there is no significant recognition of existing frameworks, such as the Bangkok Principles, as viable solutions. Rather, in an age of proposed new ideas delivered via viral TED talk, it seems far easier to 
suggest a new idea rather than revisit an old solution. This leads to incoherent policy advice while also sending the message that the countries of the Global South cannot be trusted to achieve their own frameworks for dealing with refugee flows.

While it is aptly pointed out that the Bangkok Principles carry no actual weight as being legally binding, (they are 'declaratory and non-binding in character' and aim inter alia at inspiring Member States to enact national legislation regarding the status and treatment of refugees) the same can be said for the 1951 UN Convention. While the convention is technically legally binding, there is no monitoring body to oversee compliance, nor a mechanism to report violations. It is essentially just a social contract. Alas, neither the 1966 Bangkok Principles nor the 1951 UN Convention has had much impact on how Thailand shapes its refugee policy.

Thailand's treatment of refugees has been largely inconsistent over the years and is often influenced by the current state of geopolitical relations. A recent example can be seen in the 2015 deportation of 109 asylum-seeking Uighurs back to China. The Uighurs, a Turkic-speaking, Muslim ethnic group of approximately 10 million, have been subject to widespread persecution for decades in their region of northwestern China. When Thai authorities transferred custody of the 109 Uighurs to Chinese authorities in 2015, rather than allowing them to travel on to Turkey, they faced intense international backlash. The response from Thai President Prayuth Chan-O-Cha seemed to sum up the role politics played in the decision, telling journalists:

"It is not like all of a sudden China asks for Uighurs and we just give them back. China asked for all Uighur Muslims in Thailand to be sent back but we said we could not do it... Thailand and Turkey are not rivals and we do not want to destroy trade and commerce with Turkey. At the same time, we do not want to destroy the relationship between China and Thailand." (Reuters, 10 July 2015) 
While Thailand has been host to the nine refugee camps along the Thai-Myanmar border for more than thirty years, and certainly have shown a commitment to protection by doing so, they have also often violated international standards such as the principle of nonrefoulement ${ }^{13}$. In 1979, in perhaps one of the lowest points of Thailand's treatment of refugees, Thai soldiers forced approximately 42,000 Cambodian refugees at gunpoint through an active minefield in the mountainous region of Phnom-Dong-Raik. This forced movement back across the Thai-Cambodian border resulted in their subsequent capture by the Vietnamese soldiers waiting there (Chan, 2004). Throughout the years, reports have also surfaced regarding the forcible return of Vietnamese, Lao Hmong, and multiple ethnic minorities and political asylum seekers from Myanmar. Thailand also has a welldocumented and long-standing practice of using naval forces to repel boats carrying thousands of Rohingya refugees and Bangladeshis seeking asylum, as well as other documented forcible returns of refugees and asylum-seekers to China, Turkey and Pakistan (Amnesty, 2017). The forcible return of these individuals to places where they risk torture or death amounts to a serious breach of international standards and severe human rights violations.

In light of these violations, and the subsequent backlash from UNHCR, Amnesty International and international media, Thailand's ruling NCPO has recently committed to implementing new laws and policies to protect refugees. Notably, in January of 2017, Thailand's Cabinet passed a resolution authorizing the development of a system for

\footnotetext{
13 The principle of non-refoulement was first laid out in 1954 in the UN-Convention relating to the Status of Refugees, which, in Article 33(1) provides that: "No Contracting State shall expel or return ('refouler') a refugee in any manner whatsoever to the frontiers of territories where his life or freedom would be threatened on account of his race, religion, nationality, membership of a particular social group or political opinion."
} 
screening refugees and irregular migrants. If successful in implementing a screening mechanism that is both fair and in accordance with international law, the NCPO will have made a major step forward in the protection of refugee rights.

However, the situation on the Thai-Myanmar border and Thailand's handling of the refugees who reside there, has become much more complex as political and economic reforms in Myanmar are shaping diplomatic relations. As Myanmar's economy has begun grow, so has their embarrassment at the unresolved refugee situation along the border with one of their largest trading partners. Complicating the issue however, is how Myanmar conceptualizes a successful return of ethnic nationals. In the past they have taken the position that they can only accept returns from 'Myanmar citizens', a category generally denied those of ethnic origin. They have largely been unwilling to acknowledge responsibility for the refugees encamped along the Thai border (Lang, 2001). However, the refugees along the border have now become a visible political reminder of Myanmar's failure to provide security for those born within its borders. Just as Thailand did in the late $19^{\text {th }}$ century, Myanmar is actively trying to nation build. This means securing their borders, homogenizing language and culture, and regaining control over ethnic conflicts.

\subsection{A New Myanmar, a New Outlook on Refugees?}

"My brother and his wife left the camp last year to find work in Thailand. They worked at this farm about one hour away from here. But the man they worked for was not good. One day he said he would not pay them, and they had no choice but to leave because they were afraid he might just kill them or report them if they complained. They had heard rumors of this happening before. So they had to leave and now are looking for work."

$\sim$ Poe Baw Ku, 25, Mae La Camp 
The economic reforms taking place in Myanmar over the past six years, such as the revamping of the foreign investment law in 2012, have had a profound effect on the nation's monetary growth and international standing. Subsequently, its attitude towards repatriating the thousands of ethnic minorities that have sought refuge in neighboring countries has softened somewhat. Improving diplomatic relations with neighboring states, supplying a profitable workforce for industries along the border and ensuring sanction-free international investment are all strong incentives to resolve the country's longstanding ethnic conflicts. However, the path to democracy and economic security in Myanmar has been anything but smooth since 2012. Human rights abuses carried out by the government coupled with a lack of transparency and accountability has colored much of the coverage surrounding Myanmar. The following section will look at what has transpired both economically and socially since 2012 , and how these changes may ultimately impact the return of refugees along the border.

In the wake of the foreign investment law change of 2012, Myanmar found itself awash in new visitors and potential projects. The country's former capital, Yangon, and its northern archaeological gem, Bagan, began to appear on top ten travel lists everywhere. The Telegraph touted Myanmar as "The Trip of a Lifetime!" and in late 2012, Forbes urged readers to "Consider Myanmar" for investment. Indeed, after a record 8.43\% growth in 2013, Myanmar's GDP has hovered between a 5\% - 7\% growth rate, making Myanmar one of the fastest growing economies in Southeast Asia. 


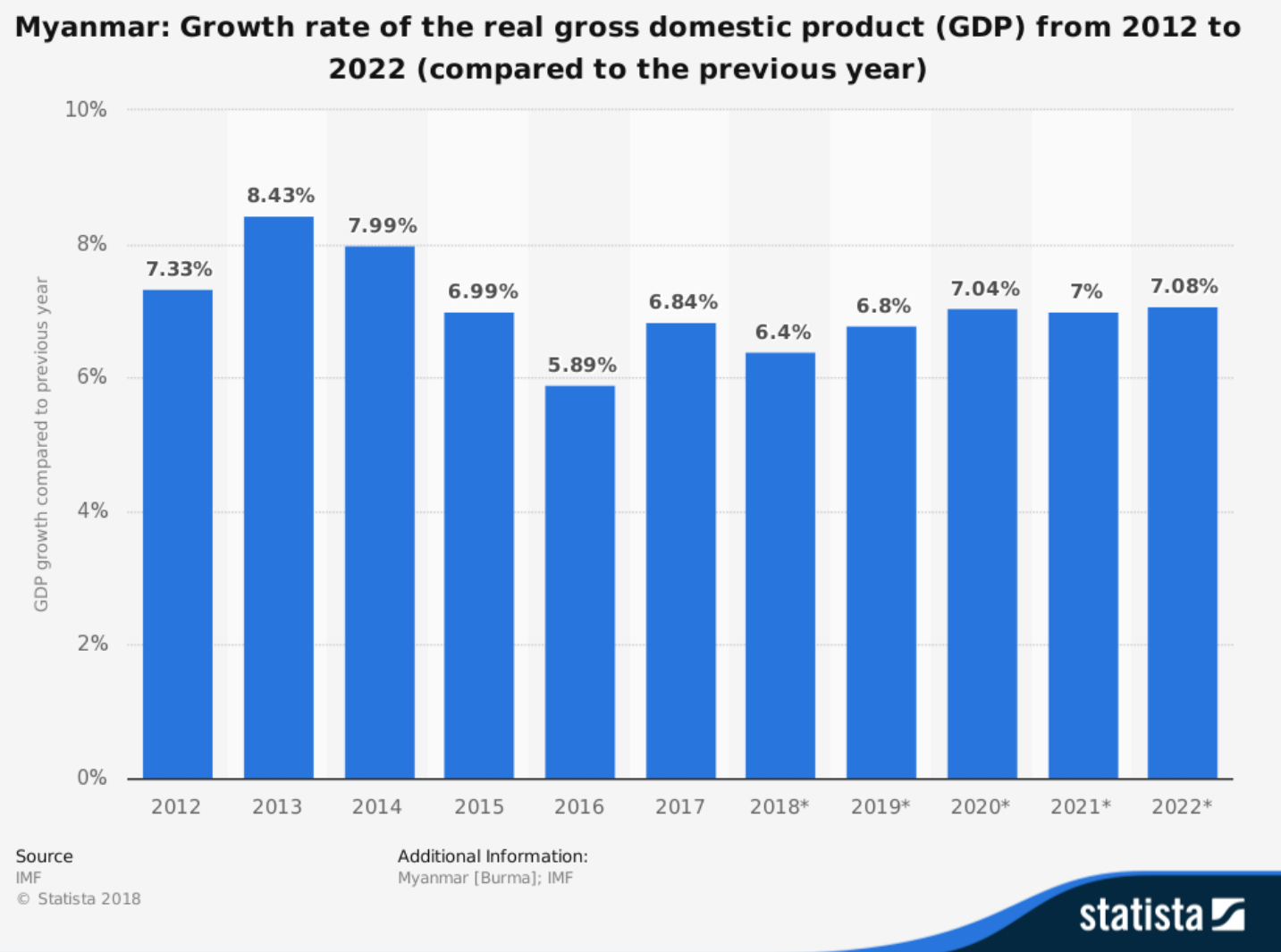

Figure 2: Myanmar GDP Growth 2012-2022 (est) source: IMF 2018

Foreign investors began flocking to Myanmar in 2012 due to its natural resources, relatively young workforce and the positive changes to laws concerning business and investment. Foreign-funded projects from China, Korea, Thailand and the U.S. ranged from energy production to retail and served to start modernizing a country that was largely isolated for decades. However, the question of how Myanmar will ultimately adapt and develop future policy within these new economic realities still remains to be seen, as does whether Myanmar's growth can be sustained. A substantial portion of Myanmar's population still live in staggering poverty while human rights violations against ethnic minorities have continued both on the eastern and western borders. The success of Myanmar's economy may ultimately hinge on addressing the growing political and social 
concerns, as the European Union and the U.S. are currently debating new trade sanctions in relation to the Rohingya crisis, potentially stripping the country of tariff-free access to the world's largest trading bloc (Reuters, 2018).

The complex relationship between Myanmar and Thailand, and their future policies concerning refugees, is deeply entwined with the economic success of the region. Myanmar must resolve the protracted refugee situation along the border with Thailand, maintain ceasefire agreements with ethnic groups across the country, and address the growing Rohingya crisis. So far, none of these areas have been particularly successful, and there is speculation that Myanmar's trajectory could mirror that of the failed democratic policies of post-communist Cambodia.

Myanmar and Cambodia share many historical and political similarities, and it would be fair to say Myanmar could look to Cambodia as a cautionary tale in its own transition to democracy. Among their most obvious commonalities are state managed transition plans to capitalism and democracy as well as having natural resources and rice production at the center of their economies (Jones, 2014). In the 1980s, Cambodia was similarly sanctioned and isolated by the West. In response to aid cuts in 1986, the government pursued a state managed transition to capitalism. This transition meant privatizing state assets into the hands of various state sponsored groups and their allies, and the patronage networks thereby established became the basis for the Cambodian People's Party (CPP) (Hughes 2003). Today, the CPP is largely regarded as responsible for perpetuating a one-party state, rife with nepotism and corruption. The question will ultimately be how Myanmar will be able to differentiate its political and economic 
transition from that of Cambodia, given their similar low levels of development, Chinese economic influence and ongoing human rights violations.

Prior to the Myanmar elections of 2015, most analysts drew strong comparisons between the Cambodian People's Party (CPP) and Myanmar's Union Solidarity and Development Party (USDP), which as a result of rigged elections in 2010, was the dominant party in both chambers of Myanmar's national parliament and all but one of the regional assemblies. The USDP had strong military support, given its large ex-military membership and thus was able to combine political, state and business power to harness its control of the economic interests in the country. Like the CPP, the USDP secured voters in rural areas through promises of local development projects.

However, in 2012 as part of the ongoing reforms in Myanmar, by-elections were held to fill 48 vacant parliamentary seats. As a result, Aung San Suu Kyi's recently reregistered party, The National League for Democracy (NLD), won 43 of the 44 seats they contested which ultimately began the process of easing Western sanctions on Myanmar. As noted by former Secretary of State Hillary Clinton in 2012:

"The results of the April 1st parliamentary by-elections represents a dramatic demonstration of popular will that brings a new generation of reformers into government. This is an important step in the country's transformation, which in recent months has seen the unprecedented release of political prisoners, new legislation broadening the rights of political and civic association, and fledgling process in internal dialogue between the government and ethnic minority groups."

Following the by-elections, the focus on sustainable economic reforms in Myanmar took center stage in the government's Framework for Economic and Social Reform (FESR) that was presented to the international donor community in early 2013. The framework 
emphasized ten priorities in the government's economic strategy: fiscal and tax reforms, infrastructure, private sector development, monetary and financial sector reforms, liberalization of trade and investment, health and education, food security and agricultural growth, governance and transparency, mobile phones and internet access, and effective and efficient government.

While all of the areas listed above were indeed critical to the future development of Myanmar, examples from Cambodia and other developing countries showed that figuring out what needs to be done is far easier than determining how to do it. Thus, achieving transformative change in Myanmar will require not only strong leadership to overcome vested interests, but also the balancing of competing objectives, and ensuring the appropriate sequencing of policy change (Nehru, 2015).

The landmark elections in 2015 were perhaps the most promising sign that Myanmar was forging a new path to democracy and true economic growth. In November of 2015, Aung San Suu Kyi's party, The National League for Democracy (NLD) won a landslide election victory gaining enough seats to control the next parliament and choose the next president, ending decades of military-backed rule. However, in what the military termed "Disciplined Democracy", the military-drafted constitution still guaranteed that unelected military representatives would occupy $25 \%$ of the seats while also holding the power to exercise a veto over any constitutional change. Nonetheless, the overwhelming defeat of the USDP, and more so their acceptance of defeat, sent an important message to the international community that Myanmar was making meaningful progress.

Complicating the path to success for the NLD however, has been a failure to continue progress on policy reforms as well as a fall from grace for their leader, Aung San 
Suu Kyi. The NLD previously enjoyed tremendous popularity among the people and often was touted as a symbol for change and freedom in Myanmar. In the years leading up to the 2015 elections, the NLD often made large sweeping statements about the need for change, without offering a solid plan to achieve such goals. Thus a political commentator noted in 2014 , “...by constraining itself to statements of principle, the NLD continues largely as a symbolic, elite opposition party - albeit one with a popular figurehead, rather than the vanguard of a counter-hegemonic bloc driving a new agenda" (Jones, 2014).

In the long transition period after winning the 2015 elections, indeed Suu Kyi and the NLD failed to offer specific policy details, beyond a broad manifesto. Faced with serious economic challenges that desperately needed tangible solutions in addition to staggering rates of poverty, in early 2016 the NLD turned to the development of three special economic zones ${ }^{14}$ (SEZs) in Arakan State and Rangoon divisions. Special economic zones, which have been linked to both positive economic development as well as problems related to land confiscation, forced relocation and the internal displacement of people, seemed to offer a potential solution. Under the premise of promoting economic growth, the NLD worked to encourage the development of special economic zones, as well as the resulting increased industrialization, by inviting direct foreign investment into the country. In recent months, there has been worry that negotiations on future SEZs will stall, as Aung San Suu Kyi's international reputation has plummeted due to her complicity in a state-sponsored

\footnotetext{
14 The Special Economic Zone Law was enacted in 2014, and its Implementing Rules were published in 2015. The law has paved the way for Special Economic Zones (SEZ) in Myanmar. Special Economic Zones consist of Free Zones and Promotion Zones, which carry various tax benefits. Under Chapter 1, section 3 of SEZs Law 2014, Free Zone shall be deemed to be situated outside the country. A Free Zone is primarily focused on export-oriented markets and includes manufacturing, transportation, and wholesale areas that are entitled to custom duty and other taxes exemption relating to the goods in the SEZs and the goods imported to this Zone. Promotion Zones are primarily based on the domestic market and the market in SEZs. In this zone, investment can be made in manufacturing, housing, departmental stores, banking, insurance, schools, hospitals and recreational places.
} 
campaign of ethnic cleansing against the Rohingya. However, the international interest, especially that of Singapore, China and South Korea, of creating special economic zones both within Myanmar and on its borders continues to drive conversations about Myanmar's future.

This path to economic growth is problematic for Myanmar, as the government must be able to find the balance between foreign investment and sustainable economic development. Further, the emergence of special economic zones as a potential solution for securing legal status and employment for refugees and migrants along the border may lead to further marginalization and exploitation. Looking to the past experiences of both Cambodia and Thailand, there are many examples of communities suffering the negative impacts of rapid industrial development and the promotion of economic growth via foreign investment, by governments that ignore both local livelihoods and the protection of the ecological system (Snaing, 2016).

In Thailand for example, rapid industrialization has led to lead and cadmium contamination of agricultural areas such as paddy fields and grazing land, deeply impacting the economy and health of local populations (Parkpian, 2003). In Cambodia, foreign investment has led to the unmitigated development of four coastal provinces (Sihanoukville, Kep, Kampot and Koh Kong), which has caused serious environmental pollution along the coast. Faced with these challenges, Myanmar must swiftly develop policies that promote sustainable solutions for economic growth that also protect workers and the environment.

In 2016, at a public seminar in Yangon entitled “Myanmar's Special Economic Zones (SEZs): Opportunities or Threats to Local Communities", a plan was laid out by regional 
development specialists to encourage the NLD to embrace sustainable solutions.

Overwhelmingly, the most often cited component offered for future policy development was the suggestion that the NLD should encourage the people's participation in conjunction with promoting economic investment.

"It is very important, because the outcome of economic development [affects] the livelihoods, the happiness and the security of the nation and the people. So the Myanmar government should not make its own decisions without the people's participation. If the government is open to this, they will reduce conflicts in the country in the long term." - Penchom Saetang, Director of Ecological Alert and Recovery Thailand, 2016

Further, regional development specialists cautioned that the NLD should enact laws that protect the environment, control pollution, and ensure the people's health before rapidly promoting economic and industrial growth. As seen in Cambodia and Thailand, foreign investors, especially from large industrial companies, are primarily concerned with earning the highest profits possible, not ensuring quality of life for the local people. Along this same vein, regional development specialists suggested that sustainable development should at all costs be transparent, and within a democratic system (Snaing, 2016).

As such, creating trust in a population that has historically held very low confidence in its government is critical for the country to move forward. One factor that has the potential to bolster confidence among the people is the injection of foreign money aimed at sustainable development. In March of 2016, the government of Finland signed a 4 million Euro fund agreement with The United Nations Development Programme (UNDP) to support the agency's work in Myanmar in the areas of democratic governance, local development and environmental sustainability. Among other things, this funding recognizes the economic impact of rural women involved in agricultural work through the formation of the Rural Women's Network. If Myanmar is able to embrace these types of 
foreign partnerships with transparency and fair democratic governance, they will be in a much stronger position to advocate for the return of refugees and demonstrate a commitment to human rights. If they fail, and resort to only policies concerning the expansion of foreign investment, it may well lead to the further marginalization of irregular migrants and refugees.

Special Economic Zones (SEZs) and other policies aimed at economic development have recently been posited as potential solutions for protracted refugee situations. Most notably in 2016, the Jordan Compact was signed which gave Syrian refugees in Jordan the right to work while promising to turn a crisis into a development opportunity. More specifically, the Jordan Compact is a ten-year deal that employs SEZs as a mechanism for attracting direct foreign investments. It allows Jordan to access the EU's market tariff-free, as long as the products being exported are produced within the SEZs by a labor force that is at least 25 percent Syrian by 2019 (Mellinger \& Berlo, 2016). Thus the idea (originally put forth by Paul Collier and Alexander Betts out of the University of Oxford), is that Jordan would gain economically by foreign investment and entrance into the EU market, while Syrian refugees would be able to become self-sufficient through acquisition of legal work rights. While the agreement seemed like a win-win on the surface, in practice the results were mixed.

In 2018 the Overseas Development Institute released their findings on the impact of the Jordan Compact. Among other positive outcomes, they noted that, "by building on existing political capital between donor governments, international organisations and host governments, as well as economic and political incentives such as trade deals, a restrictive policy environment can be opened up and funds can be mobilised in a short space of time." 
However, they also pointed out that while progress was made on the number of work permits issued, critical sectors and self-employment remained closed to refugees. Subsequently, they found that the Compact's design "did not integrate refugee perspectives at the outset; as such, it has been slow to improve their daily lives." In this way, the Compact failed miserably and many Syrians remained unemployed with no significant improvement in their situation.

As early as 2014, talks about creating SEZs along the Thai-Myanmar border began between the Thai Chamber of Commerce (TCC) and the Union of Myanmar Federation of Chambers of Commerce and Industry (UMFCCI). In August of 2018, Thai Deputy Prime Minister Somkid Jatusripitak confirmed that government agencies were drafting plans to develop border regions. These plans have promised to both increase exports and provide jobs that would narrow the urban-rural inequality gap. What has not been addressed, however, are the stateless refugees and irregular migrants along the border who often make up the workforce, but are unable to obtain legal status as migrants. Without possession of identity documents from Myanmar, it is impossible to register legally in Thailand. Thus, a new precarious working class will emerge to meet the new labor demands, one that is made up primarily of ethnic minorities from Myanmar. When faced with little to no alternative options, stateless refugees will be drawn to an exploitative labor market that will employ them in the shadows, forced into informal economies and rampant wage discrimination.

Some of the earliest commentary on how we conceptualize precariousness in relation to labor came from Rodgers and Rodgers (1989) who developed four dimensions of precarious jobs for the International Labour Organization (ILO): (1) uncertainty over the 
continuity of employment; (2) a lack of individual and collective control over wages and conditions; (3) low or no levels of social protection against unemployment, discrimination, etc.; and (4) insufficient income or economic vulnerability. Not included here are those individuals working without legal status who also face the threat of deportation back to abusive regimes. Standing (2011) argues that this additional layer of precarity in addition to exclusion from a more structured labor market will ultimately lead to an underclass termed 'the precariat'. Along the same vein, Clement et al. (2009) have noted that systems that exclude particular groups of migrants from the right to work or access to social services create vulnerability to both precarious employment and unemployment. Further, a combination of these factors may push them into the informal (and thus unregulated) economy to find an income (Community Links and Refugee Council, 2011). These are substantial risks to weigh as both Thailand and Myanmar work to increase trade, and the subsequent labor market, across their shared border. Creating a mechanism to give legal status to those without documentation from Myanmar will be the first step in achieving a sustainable, human-rights centered approach to economic development.

\subsection{Conclusion}

While refugee movements are often initially the result of civil war, they ultimately become protracted due to a confluence of factors from both ones country of origin and ones country of asylum. Ongoing violence, political impasses, policies restricting employment and freedom of movement all work against the long-term resolution of a protracted refugee situation. In this way, Thailand's unique history of independence and fierce nationalism has colored its approach to regularizing labor migration as well as limiting its policies towards 
refugees. Similarly, economic growth in Myanmar and a desire to increase development along the border has incentivized improving diplomatic relations with Thailand. Whether this will incentivize a sustainable resolution for refugees or lead them instead to join a precarious working class remains to be seen. What remains clear, however, is that understanding the sociopolitical and economic environments of both sending and receiving countries will provide an important context for imagining solutions.

In the next two chapters, I begin to look at how resistance to repatriation has started to develop through strategies of waiting, shared cultural narratives and experiences of exile. Additionally, I will give an overview of the internationally accepted protocol for resolving a protracted refugee crisis in relation to the Thai-Myanmar situation as well as an explanation of the current voluntary repatriation program being implemented by UNHCR. The second half of chapter five focuses on research outcomes regarding refugee perceptions of return, including both reported barriers to repatriation as described in interviews with refugees as well as other barriers identified through qualitative analysis and observation. In concluding remarks, I offer a summary of the impossible choice many Karen are currently facing in Mae La camp in relation to return. 


\section{Chapter 4}

\section{WAITING: Experiences of Exile and Protractedness}

\subsection{Introduction}

"Sometimes it feels like my mind can never have a rest. Everyday we do the same things. Cooking food, cleaning the house, sometimes I see my friends and play soccer. Once a month we go to get the rations, the charcoal and rice, and bring it back to the house. But I am always thinking about the next day. So always we live like this. Just waiting." - Cho

Htway, 24, Mae La Camp

On a hot July afternoon, I quickly trudged down a sandy dirt path towards a sea of thatched roofs that made up a particularly dense section of housing in camp. Armed with only a few basic directions and running late for my scheduled interview, I felt the familiar flush of agitation spread over my cheeks. I hated being late. The arrangement of homes felt like part of an impossible labyrinth and I finally resorted to calling my research assistant for help. “Hi Htoo, sorry to bother you again! I went left at the small shop but I didn't see the path that goes towards the river. Am I in the right place?" I quickly blurted out in equal parts exasperation and embarrassment. Htoo, who had kindly offered to escort me to the home of my interview participant that day, even though he had soccer practice, laughed good-naturedly at my navigational defeat. "Yes Thramu, keep going. The path will be to the right just before the small farm. The house is the second one there with the blue sign. I told you I would go with you!" After insisting earlier that day that I could manage on my own, I 
had clearly overestimated my general sense of direction. “Ok, thanks Htoo. I think I see it. I hope they are still there! I'm late now." I said. "It's no problem," he replied assuredly, "of course they will be there".

Finally locating the home, I called out a greeting and waved to the faces peering down at me from the bamboo platform above. After motioning for me to come in, I slipped off my dusty rubber sandals and inched my way up the short wooden ladder. Seven members of the Khun family resided here, including three generations of women and two adult sons. No one seemed overly concerned that I had arrived ten minutes after our agreed upon time and I felt a wave of relief at the relaxed atmosphere. After a quick exchange of greetings, the eldest daughter sat back down in the corner and continued to grind a piece of thanaka wood into a creamy yellowish paste while her grandmother filled a kettle with water. "I'm sorry I'm late." I exhaled, still feeling flustered while unpacking my notebook and settling in on the floor. "It's no problem, you're not late" one of the adult sons absentmindedly reassured me while making faces to a smiling baby girl on his lap.

I still hadn't quite adjusted to the pace of life in camp and often had to remind myself to relax. The unhurried pace made me feel restless, as if somehow I was wasting time and the lack of an overly scheduled calendar made me feel idle. While I knew my anxiety was irrational, it was difficult to feel at ease when I was used to so thoroughly conflating my personal contentment with being productive, or at least busy. I came to understand that time moved slower in Mae La and its passage was more often counted by the rhythmic changing of the seasons than by the strict daily scheduling of meetings or engagements. I also came to understand that for refugees living in Mae La, this slowness of time mixed with an uncertain future created a different sort of anxiety--an anxiety that has 
been described by Griffiths as the result of the "instability and precarity created by living with a dual uncertainty of time, one that is simultaneously endless but that can also bring change at any moment" (2004:1991)

The study of time in relation to various cultures is not a new concept in anthropological research (see Adam, 1994; Brown, 1998; Fabian, 1983; Munn, 1992). How different cultures experience time has periodically been explored especially in the context of small-scale and static societies (Mauss, 1950). However, there is a paucity of research that asks how one experiences time in the context of forced migration, exile or transience. This chapter aims to first provide an overview of how anthropologists have approached the issue of time and temporalities while also exploring how theoretical constructions of time intersect with experiences of waiting, liminality, and exile. This is followed by a discussion of the theoretical frameworks that conceptualize time as a tool of both strategy and resistance and argue for its applicability to the protracted refugee situation along the ThaiMyanmar border. Further, the chapter will also focus on refugee experiences of exile as well as illustrating how religion has played a role in transforming the exilic experience in the case of Baptist Karen refugees. In concluding remarks, attention will be focused on summarizing the importance of including experiences of time, waiting and exile within the broader literature of forced migration as well as why modes of resistance should always be considered in relation to repatriation design.

\subsection{Time, Waiting and (Im)mobility}

In perhaps one of the most comprehensive and admirable attempts to summarize the breadth of anthropological research related to time, Nancy Munn (1992) compared the 
task to Borges's infinite "Book of Sand": as one opens the book, pages keep growing from it. It has no beginning or end. As she aptly points out, "the topic of time frequently fragments into all the other dimensions and topics anthropologists deal with in the social world" (pg. 93). In this way, time is both universal and subjective in its relevance to specific areas of inquiry and should be approached thoughtfully in regards to its multidimensionality. Munn points out that the challenges of conceptualizing time in anthropology have been related to how our theoretical understandings of temporality "hinge on the way we conceptualize its connections to space, action, and actor" (p.116). Thus without a thorough theoretical examination of the basic sociocultural processes which create temporality, time often becomes oversimplified and loses part of its qualitative and social nature, or perhaps what Wagner (1986) would describe as losing the 'presence of time'. Munn proposes this could be resolved by using a lens of "temporalization" (pg, 104), where time is understood as a symbolic process continually being produced in multiple forms within everyday practices. Additionally she argues that temporalizations will allow for the recognition of time's simultaneous embodiment of the past, present, and future, meaning that the way in which we operate in the present is always infused with both the past and an imagined future.

Laura Bear (2016) has built on Munn's 'temporalizations' by arguing that anthropological research has recently taken a more significant temporal turn and should be conceptualized within the framework of timescapes. Similar to Munn's temporalizations in their embodiment of the past, present and future, she describes timescapes as incorporating techniques, knowledges, and ethics of time as being both 'in' and 'of' time. She points out that this temporal turn within our discipline is largely the result of anthropologists in their field sites who have increasingly encountered temporal insecurity 
or conflicts in time as a crucial element of experiences of inequality (Comaroff \& Comaroff 2001, Mains 2007, Vigh 2008, Auyero 2012). Bear argues that, "this social reality gives urgency to the temporal turn in anthropology. By paying attention to time, we can critique and measure inequality in new ways. A focus on the varying ability to plan a life across classes, genders, and racial groups has much potential" (p. 488-489). Thus, Bear's assertion that anthropological research on time has created another lens in which to view experiences of inequality further strengthens its applicability to understanding refugee experiences of exile and protractedness. However, in order to effectively relate anthropological conceptualizations of time to refugee experiences, it is helpful to first offer some historical context of the discipline's engagement with the subject.

To offer a brief overview of how anthropologists have approached the issue of time and temporalities, I begin with Emile Durkheim, who was the first to conceive of a "social time" and argued in 1912 that time was a fundamental category of human thought. For Durkheim and his colleagues, time centered on "social diversity, qualitative heterogeneity, and a conceptual segmentation that nonetheless remained connected to activity or motion" (as quoted in Munn, 1992:94-95). Durkheim viewed time as a "collective representation" or "categories" which used a system of symbols with a commonly shared meaning within members of a social group or society. These categorical divisions allowed Durkheim to imagine time in qualitative and diverse ways. Durkheim believed that society ultimately created the categories in which he could understand time, and that people understood time differently because they were products of different types of societies. He justified this position in the basic argument that different people use different measures of time. In this 
way he rejected Kant's transcendentalism by noting that "the categories of understanding are never fixed; they change according to place and time" (1912; 1960:21).

Malinowski (1927) introduced a functionalist approach to time by introducing "time reckoning" among the Trobriands which he described as a practical necessity in every culture to coordinate activities, plan dates in the future, place events in the past and measure time spans (p. 203). Munn (1992) colorfully summed up Malinowski's rather boring conceptualization of time as putting on "mundane, empiricist clothing, instead of the "qualitative, myth-ritual dress of Durkheimian representations" (p. 96). Evans-Pritchard (1940) built on Malinowski's time reckoning with his account of the Nuer, and the presence of what he describes as a microcosmic 'oecological time' (p. 94-101). Evans-Pritchard 's notion of 'oecological time' centers on how environmental circumstances create 'timeconceptualizations' and understanding how societies adapt to them. He gives an example of Nuer society as revolving around what he termed the "cattle clock", which meant that daily tasks such as cattle herding, and milking the cows served to order the way they experienced and understood time.

Edmund Leach (1961) went on to describe "cyclical and linear" processes of time, in which he theorized that the concept of time combines two "basic experiences" of human life. The first experience he noted as being "that certain phenomena of nature repeat themselves" and the second as understanding that "life change is irreversible"(p 125-127). As such, he argued that the experiences of cyclical and linear processes are at odds in that there cannot be repetition and irreversible change at the same time. The only circumstance in which cyclical and linear time can co-exist, is within the context of religion, where one believes death is only a phase of life. 
While early theorizations of time were essential to building the framework for future anthropological inquiry, they were also problematic to two key areas that relate to understanding time in the context of forced migration. First, early theorizations did little to recognize and explain personal experiences of time. Through collective representations and functionalist frameworks, individual experience was largely neglected. To rectify this, anthropological research began to reflect a temporal turn towards micro-geographies and individuals. This was essentially the result of the growing trend towards a more politically engaged anthropology, which began to explore notions of how time intersected with personal experiences of inequality. As Bear (2016) noted, "research begin to provide subtle accounts of how people ethically engaged with the concrete inequalities of spatiotemporal relations and attempted to rebuild senses of agency" (p. 494) (Mole, 2010, Auyero 2012, Bolt 2013, Millar 2014, Nielsen 2014, Kwon 2015).

The second way in which early theorizations of time were problematic was the way in which their conceptions of time were based on perceiving societies as static and thus reflecting what Malkki later termed, a "sedentarist bias" (1995:508). In this way, early theorizations of time needed to be developed and built upon to allow for both societies and individuals who were dynamic and mobile actors. As the field of migration studies within anthropology began to expand in the 1970's, “...anthropologists progressively rejected the idea of cultures as discretely bounded, territorialized, relatively unchanging, and homogeneous units" (Brettell, 2014:148). As such, theorizations of time also developed to accommodate the temporalities inherent in migration such as life course trajectories and longitudinal studies. Among the early attempts to theorize time in relation to migration was the work of geographer Torsten Hägerstrand (1982), who introduced the concept of 
'Time Geography', noting that, "we need to rise up from the flat map with its static patterns and think in terms of a world on the move, a world of incessant permutations" (p. 323).

By the 1990's as the field of migration studies continued to expand and levels of mobility increased across the globe, more scholars and practitioners in fields such as sociology, anthropology, geography and economics began placing a higher degree of importance on the impact of the movement of people. In anthropology, this "mobilities turn" (Adey et al 2012; Cresswell 2006; Greenblatt 2009; Harvey 2000; Kaplan 1996; Urry 2007) led to incorporating new ways of theorizing how mobilities were "at the center of constellations of power, the creation of identities and the microgeographies of everyday life" (Cresswell, 2011: p.551). Subsequently, as anthropologists wrote about how the world was transformed by the movement of people, so too they recognized the importance of understanding the impact when this movement was restricted. Thus the concept of immobility (Adey 2006, Urry 2007, and Sheller, 2008) emerged as its own unique framework. As priority is often given to mobility in much of the contemporary anthropological research on migration and transnationalism (Hannam et al 2006; Salazar 2012), the recognition of immobility has created an important bridge between anthropology and refugee studies by offering a lens with which to view experiences of forced migration and exile. In this context, immobility can relate to one's geographic confinement in a refugee camp or country of asylum as well as to feelings of being "stuck" or living in a state of in-betweenness. Anthropology can offer new, ethnographicallygrounded theorizations of how time and waiting are experienced by refugees in exile, while also speaking to the overall impact of protracted refugee situations on people and places. 
Some of the earliest research to specifically highlight the experience of time and waiting in refugee camps came from studies of the Vietnamese in Hong Kong from the mid 1970's to the late 1990's (Bousquet 1987; Hitchcox 1990, 1993). Bousquet describes a state of "limbo" and periods of endless waiting as characteristic of the way Vietnamese refugees viewed their lives in camp. As she wrote:

"Their lives revolved around waiting: for interviews, for news of their families in Vietnam or relatives already resettled in another country, to see the list of boat people arriving in Hong Kong, and for word that they had been approved for immigration"(pg. 47).

Bousquet drew on the work of Victor Turner to help her frame the experiences in refugee camps, noting that camp life resembled what Turner called liminal periods, which are inherent to many rites of passage (1969). Turner argued that individuals undergoing a rite of passage are "divorced from their past under conditions which break old patterns of behavior so that they may reenter their communities in new roles" (pg. 34). What Turner did not consider, however, was what would be the outcome of residing in a liminal space for an extended and often indefinite period of time.

Other early descriptions of refugee camps as places of liminality or limbo have come from research with refugee women in Hungary (Huseby-Darvas, 1994) and Vietnamese refugees in camps along the Thai-Kampuchean (Cambodian) border (Reynell 1989). Additionally, Peteet's ongoing research with Palestinian refugee camps in Lebanon (1991, $1995,2005,2015)$ addresses the impact of perhaps the most protracted of all refugee situations. The Palestinians, who have been spatially constrained in a liminal state for upwards of six decades, have had to live within a constructed environment that 'bears the hallmarks of permanency' (pg. 216). In this way, the notion of temporariness has become distorted. As Peteet explains: 
“To equate camps with Auge's depiction of 'non-places' (1995: 78) as the 'fleeting, the temporary and ephemeral' exemplified by spaces of hypermobility such as the airport, is belied by the sheer longevity of these camps and the enclaves' indeterminacy. People pass through Auge's non-places. People live in camps and enclaves. With no end in sight, the camps and enclaves may be permanently temporary." (2015: p. 216)

A similar context of 'permanent temporariness' is illustrated by Mansouri and Cauchi (2007) in their research with asylum seekers in Australia. They show that increased levels of depression and trauma are linked with the indefinite and yet temporary nature of the asylum process ${ }^{15}$. They argue that Australia's temporary visa regime has created a "uniquely liminal state, which keeps refugees in a space of ambiguity, marginalization, and transition" (pg. 127).

In recent literature, experiences of time and waiting have more often been explored in relation to broader categories of marginalized people-prisoners, economic migrants, the unemployed or underemployed, the homeless-- rather than refugees specifically. For example, research on transnational migrant workers has centered on themes of uprootedness and liminality while also addressing the immobility of family members that migrant workers leave behind. In Brettell's (1986) work in the Portuguese village of Lanheses, she found that as many men left the village to seek out work in Spain, Brazil or Southern Portugal, they often left behind waiting fiancés and wives. While the intent of their economic migration was initially temporary, in practice they were often gone for

\footnotetext{
${ }^{15}$ A similar situation is currently unfolding along the U.S. and Mexico border, as asylum seekers are being held indefinitely at detention centers in the U.S. The Trump administration announced in December of 2018 that it would make asylum seekers wait in Mexico while their court cases are resolved in the United States, further exacerbating the problem. Many have called the move a clear violation of the standard international protocol of non-refoulement, as well as an unnecessary political tactic. The human cost has continued to rise as on December 8, a 7-year-old Guatemalan girl named Jakelin Amei Rosmery Caal Maquin died of dehydration in U.S. Border Patrol custody after she and her father were picked up in a group of 163 migrants who'd crossed illegally near Antelope Wells, New Mexico, a particularly remote stretch of the border.
} 
extended periods of time or in many cases, they never returned at all. In these instances she describes the women essentially becoming "widows of the living" (p. 193) as they were unable to remarry and their husband's deaths were never recorded in the local parish. In a similar theme, Kwon's (2015:481) ethnography of the spouses of Korean Chinese transnational migrant workers suggests that waiting is an "immaterial, but nonetheless important, form of unwaged, profit-producing labor". As spouses wait years or sometimes decades for their partners to return, their loyalty and commitment to waiting ensures they receive remittances, thus securing some form of economic stability.

Another common theme among contemporary researchers of time and waiting is that the overabundance of time and unstructured waiting is both a symptom of social exclusion and a form of precarity (Kwon 2015). Griffiths (2013) has referred to these phenomena as "enforced idleness" (pg. 22) and argues that the negative impact of prohibiting work for asylum seekers is profound. A relevant example of this can also be found in Mains' work (2007) with young men in urban Ethiopia who are dealing with unemployment rates as high as 50 percent. As he describes, Ethiopian youth with too much unstructured time report having introspective thoughts about their futures and lack of ability to progress in life. This has become a source of both unease and distress leading to depression, boredom and shame. Another example of enforced idleness related to unemployment is found in Jeffrey's work $(2008 ; 2010)$ with educated young men in India who are forced to wait indefinitely to find employment. Jeffrey uses the term "timepass" to describe the sense of having nothing to do other than waste time. In some instances, this 'wasted time' or the experience of time passing slowly has been linked with emotional suffering (Flaherty et al., 2005). Additionally, O’ Neill (2014) has noted in his work with 
underemployed Romanians that they have suffered from "a brutal kind of boredom" (pg. 9) without any social security net. He argues that boredom is a persistent form of social suffering largely as the result of the economic downturn in post-Communist Bucharest.

While research concerning experiences of time and waiting are often focused on the negative social consequences, some have argued that the act of waiting may also produce positive economic and social outcomes. As described previously, Kwon's research with Korean Chinese transnational migrant workers led to an assessment that waiting can actually be a form of profit-producing labor. In this way, Kwon notes that "waiting is not a completely passive, powerless, and unproductive condition, or a mere consequence of structural violence" (pg. 492). Rather as Jeffery (2010) argues, the act of waiting can sometimes be appreciated as an acquired skill and source of knowledge. With an abundance of free time in the city, young, educated but unemployed males became knowledgeable on the particulars of urban life. This allowed them to act as social intermediaries and interpreters for rural friends and colleagues. In this way, "Timepass was not a passive activity: It offered an opportunity to convey a youthful adaptability to circumstances" (g. 474)

In summary, there is a diverse array of literature that grapples with how time is embedded in the social processes of movement, immobility and migration. In an increasingly technology-driven world, speed has become fetishized while stillness and passivity are often perceived negatively (Bissell and Fuller 2011). Individual experiences of time have shown that living in liminal spaces or having too much time can lead to mental distress, social exclusion or boredom. Alternatively, research has also shown the ability of people to transform periods of waiting or stasis into opportunities for social and economic 
growth. However, there is a need for a more comprehensive understanding of how time is conceptualized in relation to refugees and those living in protracted states of exile. While work concerning the experiences of Palestinian refugees has many direct correlations to other protracted refugee situations, the case of refugees along the Thai-Myanmar border presents a unique context. The recent act of UNHCR facilitating voluntary return has publicly demonstrated a degree of mobility in a previously immobile space, thus adding an additional layer of complexity that alters individual relationships with waiting. While waiting in a refugee camp with no viable option for return may have previously been associated with 'feelings of powerlessness, helplessness, and vulnerability' (Crapanzano, 1985), the introduction of facilitated returns may transform the act of waiting into an active form of strategic planning or resistance ${ }^{16}$.

\subsection{Waiting for Change: resistance in its many forms}

"I look around here and I don't believe they will ever close this place. We have heard this word 'repatriation' many times before but it is just a rumor, you know? For us, we cannot go back to Burma. So if they close the camp, I will decide then what we will do. But for now, I will just wait and see what happens." - Saw Blu Ma, 39, Mae La Camp

The construction of the Voluntary Repatriation Center (VRC) in the late summer of 2016 created somewhat of a watershed moment for many Karen living in Mae La camp. Prior to the erection of this physical embodiment of the promise for a safe and orderly return to Myanmar, the idea of repatriation had existed mostly as a rumor. Easily dismissed

\footnotetext{
${ }^{16}$ It is important to note that resistance in this context does not necessarily employ the same meaning as more western-centric notions of resistance as heroic narratives regarding speaking truth to power. While it may certainly take on that meaning at different times, resistance as applied to the Karen choosing not to repatriate is more closely aligned with active and strategic decision-making.
} 
or simply forgotten, the phrase "facilitated voluntary repatriation" sounded like the hollow words often batted around by politicians or international aid workers for many years prior. Early in my stay at Mae La, I interviewed a man in his late sixties who had lived in the camp for more than twenty years. Lounging back against the bamboo wall in his home while he prepared some betel nut, he had stated to me rather matter-of-factly, "This camp will never close, even if all of you leave, we will still be here." The Karen had grown used to hearing vague threats about the camp closing and had become somewhat desensitized to its possibility. The events leading up to the construction of the VRC had largely been approached with skepticism rather than as signals of the progress being made towards finally ending one the world's longest running refugee situations. The steady decreases in funding, ad-hoc head counts and finally the official statements released by UNHCR, the Royal Thai Government and the Government of Myanmar all signaled that something was different this time. Ultimately, the presence of the building right in the center of the camp's 'C zone' provided irrefutable proof that this time, something might actually change. Signs displaying the familiar UNHCR logo were hung outside, as well as informational sheets that gave basic details about the program. The condition of voluntariness was heavily emphasized with the goal of allaying fears about a forced return or triggering a widespread panic about the camp closing. In the early months of the VRC's arrival, only a handful of people visited during its opening hours ${ }^{17}$, often choosing instead to satisfy their curiosity by stopping by at night to glance over the information tacked outside. To bridge the gap, various workshops, focus groups and community information sessions were held at the

\footnotetext{
17 In a recorded interview with UNHCR staff in Mae Sot, they roughly estimated 14-15 visitors per week to the VRC in Mae La during the initial months after construction. Additionally, they estimated over 30 informational sessions and focus groups were held with camp residents. The interview was conducted on August 25th 2017.
} 
VRC to discuss the details of the program and encourage people to visit. By October of that same year, the first group of 71 refugees from the Nupo and Tham Hin camps officially repatriated to Myanmar.

When I arrived in Mae La camp in the early summer of 2017, the VRC had been in operation for less than a year. Already there was a growing resistance to its presence, or at least what it had come to represent. The chorus of voices warning that the time was not right to return to Myanmar had intensified in recent months and outlets such as Radio Free Asia, Karen News, The Irrawaddy and Burma Link circulated heavily shared videos and articles reporting on the lack of security and resources currently available in Karen State. In October of 2017, which also marked the same month the first facilitated return was carried out, the Karen Human Rights Group (KHRG) published an extensive 291-page report detailing the past 25 years of reported human rights violations, militarization and village agency in southeast Myanmar. The report, titled "Foundation of Fear: 25 years of villagers' voices from southeast Myanmar", detailed the multiple concerns IDPs and refugees currently had with the notion of return.

The increased output of narratives against repatriation clearly highlighted a type of resistance strategy being employed by some Karen living along the border and within camps. Interestingly, it was reasonable to equate the relative success of this messaging to the assistance of several international humanitarian organizations either through the amplification of audience reach or financial assistance. In his extensive research along the Thai-Myanmar border, Horstmann (2014) noted how the Karen have previously been successful in mobilizing international humanitarian support to further their cause. As he describes, the Karen have worked to operationalize KNU controlled space on the border 
and establish access corridors into Myanmar through partnerships with groups such as the Free Burma Rangers and the Back Pack Health Workers. These access corridors have enabled resistance in Karen State by facilitating the "consecutive re-entering of the conflict zone in Burma to establish civil society structures and to politically organize people, villages, and schools in a space that remains inaccessible for international NGOs" (pg. 59). Other forms of political resistance have been described from within refugee camps along the Thai-Myanmar border, namely in relation to an assortment of 'formal and informal activities that aim to shape the conditions of camp life or achieve more long-term goals such as elections, protests, and engagement in community-based organizations (CBOs)' (Olivius, 2017:292).

Indeed many scholars have noted similar forms of resistance in situations where one group has substantially less power than another (Adas, 1981; Mullen, 1972; Scott 1976, 1979, 1985; Wolf, 1969). Most notably, James Scott (1985) focused on "everyday resistance" such as foot-dragging, non-compliance, slandering, etc. rather than outright revolution. Similar tactics were reported in the early 2000's concerning life inside a heavily militarized Burma. Tax evasion, the leaking of information or rumors to outside agencies, and the slandering of junta leaders (Fink 2001, Skidmore 2004) all served to undermine the Burmese military regime. In one particularly poignant narrative, Malseed (2009) describes how elderly women, who have often been appointed as village heads in contested regions of Myanmar, have been able to exploit the reverence for mother-figures in Burmese cultures.

"...they scold or challenge the young military officers who give the orders, and whose sense of power and authority becomes confused in their presence. In written orders it is very common for Tatmadaw officers to address village headwomen as 'Mother' and refer to themselves as 'Son' (KHRG 2002, 2003). 
In late 2005, a village headwoman in Papun district confronted an officer who had ordered her to send villagers as 'guides' for a military patrol. She told him, 'You know I cannot ask my villagers to walk in front of your troops to step on mines'. He replied, 'It is my duty and these are orders from above, you will have to do it or your village will be punished'. She said, 'Then take me instead. I will go. But on one condition. I'm afraid of mines, and I'm sure you're afraid of mines too. So let's walk in front together, hand in hand. If I step on a mine or you step on a mine, we'll both die together. I can be content with that'. The officer eventually responded, 'I'll think about it, go home Mother and I'll tell you my decision later'. The demand didn't come again. She knew that the officer had impunity to kill her on the spot or detain her indefinitely without charge, yet she was confident enough in her maternal authority to gamble against this possibility (Malseed, 2009: 375-376).

To understand strategies of resistance, many scholars have turned to theoretical frameworks that center on the impact of power relationships. Malseed (2009) and Olivius (2017) have both remarked on the relevance of a Foucauldian perspective in relation to understanding how resistance is developed and performed by refugees on the ThaiMyanmar border. Understanding that, "where there is power, there is resistance" (Foucault, 1990:95) has framed the actions of the Karen not as particularly anomalous, but rather a natural response to marginalization or oppression. Malseed makes the salient point that "reports on Burma often document repression and suffering without exploring civilians' responses, but a growing literature has shown in other contexts that recognising and acknowledging responses and the agency behind them is crucial if people are to have a role in negotiating their own political, social, and economic future"(pg. 373). In this way, his argument can be built upon to include a reckoning of how resistance is employed in response to repatriation specifically. While the growing output of narratives from the Karen against repatriation may represent one form of resistance, I argue that the act of waiting itself represents another. 
There is a substantial difference between being forced to wait for something and transforming waiting into an expression of resistance. The latter requires the recognition of agency as an inherent characteristic of all people, regardless of their race, class, gender or present condition as an oppressed person or refugee. Additionally, the context surrounding why one waits offers a lens in which to understand how passive forms of waiting may be transformed into active ones. For example, Appadurai (2013) has argued that in the context of marginalization, hope can be seen as "the force that converts the passive condition of 'waiting for' to the active condition of 'waiting to'"' (pg. 126). In this way, the hope of resettlement or a job opportunity elsewhere transformed the experience of waiting in Mae La into something more positive. One male respondent in his mid 60's described his aspirations of resettlement as "I will wait to go join my daughter and her husband in Australia when it's possible, but it takes a long time. We have a lot of family there now and I also have a new granddaughter." Or in another interview a young man of 19 said, "We are waiting to see if the rations stop. If there is no more rations or money I will just go to live in Mae Sot. There is a school there and my friend is a teacher so he will get a job for me." This builds on the argument previously put forth by Corcoran (1989) which noted that the act of waiting "...suggests strong and purposive action: to keep watch, to lie in wait, to stalk a prey, to take by surprise"(pg. 517). Lakha (2009) took this idea forward by applying the metaphor of hunting to Indian migrants who were waiting to return home and noted that migrants were following opportunities that emerged in their homeland like hunters who stalk 'prey'. He argued that opportunities such as policy changes in the Indian government that would allow for dual citizenship sparked considerable activity rather than passivity. 
A good example of how waiting has been operationalized as a resistance strategy can be found in Harms' (2013) research with residents of an urban neighborhood in Ho Chi Minh City. Under the context of development-induced displacement, he describes how residents have been left to choose between accepting government relocation compensation or living surrounded by the rubble of demolished houses while waiting for the long process of eviction to begin. In describing the residents who refused relocation, Harms notes:

"Subjected to enforced waiting by project authorities, they respond by doing nothing, asserting themselves without exerting themselves, by simply being. Their "weapon" is a cool indifference to time that redirects the disruptive effects of waiting back onto project planners themselves. This indifference threatens project authorities because the Thu Thiem project must pay four billion dong (about $\$ 200,000$ ) in interest on loan obligations each day." (Harms, 2013:357)

Much like the residents described in Ho Chi Minh City, the Karen in Mae La can assert themselves simply by staying put. As one man in his late seventies explained, "I have been here in Thailand for thirty years. They cannot make me go back. I will stay here for the rest of my life". Their position has been bolstered by both a sizable population as well as the international visibility afforded through the involvement of UNHCR, and its corresponding mandate to never forcibly repatriate refugees. For the Karen, the act of waiting is a rejection of repatriation. It is a rejection of the notion that a 'safe and dignified' return is currently possible and it is a rejection of the narrative that they are merely passive recipients of aid. Rather it is a non-confrontational strategy to exert agency over their immediate futures and provide space to weigh all available options.

There were many times that I observed forms of agency that played out under the context of camp confinement in Mae La. The periodic bribing of guards or other Thai authorities acted to usurp formal power structures and open additional opportunities for 
mobility and access to resources. Additionally, the proliferation of inexpensive smart phones and sim cards facilitated increasing interconnectedness among the younger generation of Karen and I can attest to witnessing more than a few new romances budding by way of Facebook or LINE. Anecdotally, I heard stories from the days of the mass resettlement programs about refugees trading names and registration cards between families, often joking about how western aid workers couldn't tell the difference between male and female names. There were many times when the economics of camp life were laid bare to me and a thriving real estate market was described where one could "purchase" a property in Mae La for close to the same price as in a neighboring Thai village. Agency was everywhere, as it often is when dealing with human beings. During an interview one morning with a 26-year-old Karen man in Mae La, he explained to me, "It's a waiting game right now. We have to wait and see what the government in Burma will do. If they really want a ceasefire, we will see." And in this way his natural agency transformed the condition of waiting into something more active: a waiting game. It implied the active monitoring of a situation and then determining ones counter move. It implied both self-determination and strategic positioning. In a word, it implied choice.

In summary, waiting has been a way in which many Karen can actively resist repatriation and assert agency over their immediate futures. While waiting has often been transformed into something more positive, such as waiting for family reunification or a job opportunity, it still may represent a hardship. These are not mutually exclusive, as often people recognize something as being difficult or unpleasant but still actively engage with it due to the perceived potential outcome. In these situations, coping mechanisms have become a way in which the burden of waiting is eased while one strategically waits for a 
more positive option. For many Christian Karen in Mae La, the church has provided this outlet. In the following section, I ask how coping through religious expression might have an impact on resistance to repatriation and how time in exile is ultimately understood.

\title{
4.4 Refugee Experiences of Exile
}

\section{Lord Hear Our Weak and Humble Prayer}

Music and Lyrics by:

Dr. Wado, Mae La Camp, 2017

\author{
Father in Heaven \\ Sing this song in the foreign land \\ We are displaced and homeless, not wanted in Thailand \\ Unwelcomed in Burma, where do we go? \\ Over 30 years we are praying and the answer is No \\ And where do we go?
}

Oh Lord, we pray for freedom

Lord we pray for hope

Please remember us, deliver us

Set us free from this exile

Give us a better desirable future

Oh Lord we pray, Oh Lord we pray

Oh Lord, hear our weak and humble prayer 
Upon the first few weeks of arriving at Mae La Camp, I began getting to know the small school that was to be my home for the next several months. Operating primarily as a Baptist seminary, the school was largely made up of staff and students who were both Christian and from the Karen (Kayin) ethnic group. Aside from the core theological curriculum there were many other activities and events that spoke to the deeply religious nature of the space. These included morning devotionals, Sunday sermons and the occasional visiting missionary who might give a guest lecture or sermon. In exchange for my services as an English teacher, I was graciously provided with room, board and a neverending supply of choral hymns that wafted around campus like a divine soundtrack. Although entirely pleasant, I often felt the ubiquitous singing provided somewhat of an odd backdrop for the realities of life in a refugee camp. On days when the temperature soared and electricity, water and patience were all on short supply, the cheerful chorus had a way of making it all seem surreal. "How on earth can anyone be so cheerful right now?" I would say to myself while dripping in sweat and wallowing in my own self-pity. What I would later come to consider were that these expressions of faith and joyfulness in the context of confinement were actually a powerful tool for coping. I observed that they had the distinct ability to boost both morale and self-confidence within the community. Coping was important because indulging in self-pity or anger inside the camp was akin to letting a wound fester and the consequences of doing such could be severe. Depression, alcoholism and substance abuse were all well documented problems, and in 2017 the International Organization for Migration released a report stating the number of suicides in Mae La was more than three times the global rate. In an interview with a young man who had lived in Mae La since birth, he recalled the recent tragedy of a young couple that committed suicide 
together. "You know they just drank the poison, it's like pesticide. She was pregnant and her husband's mother would not accept her. So they drank the poison and died. It's very sad for the family."

In the face of accelerated rates of depression and suicide, Christian faith has become a way in which many Karen refugees in Mae La are able to cope and make sense of their circumstances. Visiting missionaries and pastors who give guest sermons often find biblical analogies to help explain the suffering the Karen have endured. On more than one occasion during my fieldwork I was told how the plight of the Karen mirrored that of the Israelites. In one interview, a young woman recounted a conversation she had with a western missionary who visited the camp several years earlier: "One of the women who came to stay here thought the Karen people were the lost tribes of Israel. Many people think like this." Through this comparison, a narrative developed that suggests the Karen will ultimately be rewarded for their suffering in exile with eternal life in the 'promised land' if they remain faithful. Aside from this ideological motivation, there are also more practical reasons why many Karen in exile have turned to the Baptist church. As Horstmann (2011) argues:
"In a hostile environment, and harassed by the state, unable to return home in Burma, the Baptist church provides a key location for mobilizing the resources for a better life, solidarity with other refugees and a vision. Far from being passive recipients of humanitarian aid, refugees make careers in the church and emphasize their aspirations by actively participating in evangelical efforts." (pg. 270)

In this way, membership in the Baptist church has allowed the Karen to strategize about their future while also connecting them to a global community. These sorts of connections have led to increased mobility and have the potential to greatly affect the decision making surrounding repatriation. In the following sections I will focus on refugee experiences of 
exile as well as discussing how religion has played a role in transforming exilic experiences in the case of Baptist Karen refugees.

Conceptualizing experiences of exile within the social sciences can largely be traced back to the wave of intellectual scholars who fled to the United States in the 1930's escaping persecution by the Nazi regime. The New School for Social Research in New York (also known as the University in Exile) became the academic home for great European intellectuals such as Hannah Arendt, Franz Boas, Emil Lederer, Erich Fromm and Leo Strauss. This new academic base significantly increased publishing on topics of social, political and intellectual exile by way of the New School's journal, Social Research, as well as many subsequent books and articles. However, Camurri (2014: 2-3) has noted that many of the works on exile published after 1945 focused on the "refugee scholars," which was a concept promoted by the institutions engaged in their rescue (as cited in Duggan-Dry, 1948). As such, these experiences of exile focused more on assimilation and the "appeasement of American public opinion, showing the high level of integration and rapid Americanization of the refugees" (p.3). In subsequent decades, refugee experiences of exile have mostly been subsumed into the broader field of "refugee studies", which began to grow in the 1970's and 80's as its own area of academic inquiry. Malkki (1995) has rightly criticized the inclination of researchers to generalize the "refugee experience" and has argued for the importance of differentiating exile in refugee studies from other literary forms of exile. As she reasoned:

"Into the contrast between "refugees" and those "in exile" is built a whole history of differences, not only of race, class, world region, and historical era but of different people's very different entanglements with the state and international bureaucracies that characterize the national order of things. [...] "Exile" connotes a readily aestheticizable realm, whereas the label 
"refugees" connotes a bureaucratic and international humanitarian realm. “ (1995: 513)

In the two decades that have followed Malkki's argument, scholars of refugee studies have at least in some part attempted to incorporate a more nuanced and contextualized understanding of exile. This has been achieved largely through recognition of the intersectionality of Malkki's aesthetic and bureaucratic realms of exile in spaces such as refugee camps. In a refugee camp, individual exilic experiences are accompanied by prolonged periods of confinement that have been perpetuated by bureaucratic and international humanitarian regimes. In this way, the legality of one's status as a refugee, and the subsequent loss of work rights or freedom of mobility, has the power to shape the experience of exile into something quite different than traditional interpretations of exile as simply banishment or expulsion. Norum et al. (2016) have linked individual experiences of exile to experiences of time and uniquely noted that, "...it is possible to focus on exilic temporal experiences as processes of becoming and unfolding, rather than periods of stagnancy, stasis and being "caught in time."” (p.74). More commonly however, periods of exile experienced by refugees have been linked to experiencing time slowly or the experience of a 'fracture, displacement from the motherland, or alienation lived as a loss' (Camurri, 2014). Additionally, exilic narratives where time is experienced as standing still or stopping entirely have been explained as a suspension of the typical life stage progression. When confined in a refugee camp, activities or rites of passage associated with becoming an adult, such as going to college, getting a job, getting married or having children, can become reordered or impossible to achieve. Castree (2009) has argued that a feeling of time being stopped in exile is related to the inability to produce goods or labor and engage with the market economy. Moreover, refugee experiences of exile have also led 
to a loss of social status (Jansen, 2008) or a reconceptualization of manhood and masculinity in in the context of refugeehood (Suerbaum, 2018).

For the purpose of this work, I argue that it is important to understand Karen refugee experiences of exile within their own unique spatiotemporal contexts. Throughout the course of three decades in exile, many Karen have started new families or cultivated new identities and communities of belonging. For many Christian Karen, exile has been as much a process of 'becoming and unfolding' (Norum et al., 2016) as it has been a space for reconstituting national identity (Horstmann, 2015). Specifically in the case of Baptist Karen refugees, the exilic experience has been transformed to unite ethnic Karen through a narrative of shared suffering while enhancing political mobilization within the KNU and redefining the terms for voluntary return.

\subsection{Christianity and the Karen}

It has been nearly 200 years since Baptist missionaries first introduced Christianity to Myanmar. Beginning as far back as 1830 , missionaries were successfully converting many Karen and building large religious networks in the Southeast. While there are an estimated twenty different subgroups of Karen, the majority of people come from two main groups. These are the Sgaw Karen, who have a prominent Christian representation and mainly inhabit the hill areas; and the Pwo Karen who are predominantly Buddhist and reside in the lowlands. Gravers (2007) points out that it is important to contextualize the process of Christian conversion and see it from a Karen point of view. He argues that Christian conversation is not seen as a change of culture or custom, but rather a new ritual practice. In this way, Christianity has been converted into a genuine Karen tradition, 
replacing former rituals and prayers (pg. 232). While only an estimated $20 \%$ of Karen practice Christianity (the majority of Karen are Theravada Buddhists who also practice animism), Karen Christians have generally achieved higher levels of both income and education. This is due in large part to their connections with other international Christian organizations that have sent both financial and material support. Additionally, both the Baptists and Seventh-day Adventists have established a strong presence within the camps along the Thai-Myanmar border and have helped to open several schools. While the refugee camps rely heavily on international humanitarian aid, they also utilize an internal management system run by the Karen Refugee Committee (formerly the Karen Christian Relief Committee), a primarily Christian-led organization with strong ties to the KNU. As such, power held within the Karen refugee community has largely been consolidated within Christian networks and camps have become centers for proselytization (Dudley, 2007; Gravers, 2007; Horstmann, 2011).

The impact of Christianity on the Karen refugee community cannot be overstated and its influence can be measured both economically and socially. Throughout the course of my fieldwork in 2017, three key areas in which Christianity affected repatriation began to surface. Firstly, I noted that Christian leaders have played a pivotal role in the messaging surrounding repatriation in the Karen Refugee community. As such, pastors and camp leaders have constructed visions of 'Kawthoolei' as both a 'promised land' and independent state. Thus, Christian leaders in the KNU and KRC have been loud proponents for obtaining inherent sovereignty and self-rule in Karen State as a condition for return. This has historical roots as Gravers (2007) noted:

"In 1946, being a Christian Karen, in their own self-identification, signified that the ethnic group had reached a level of civilization qualifying them as a 
nation in their own right with the right to claim their own state. Christianity became part of an ethnic opposition and confrontation with the Burmese." (pg. 227)

However, the requirement of sovereignty in Karen State may present a challenge in negotiating conditions for a voluntary repatriation. ${ }^{18}$

The second area in which Christianity affected repatriation was in that it legitimized the creation of a shared narrative of suffering and exile. In addition to comparisons of the Karen to Israelites in exile, Horstmann (2011) also notes metaphors of refugees being 'saved on Noah's ark', or part of 'God's mysterious plan' being extensively used by Christian leaders to encourage each other. During my fieldwork I was introduced to a song that was widely circulated at the Baptist church in camp, written by a late Karen pastor. The lyrics stated: "I am not ashamed to be a refugee. For I know my Lord my Master my Savior was a refugee long, long before me... I am glad to be a refugee for I am always reminded that my eternal home is in heaven and not on the earth. But I know that for the time being, Satan is trying to enslave me." Further, to "read the Bible through Karen eyes" (pg. 263) is to facilitate this shared narrative of suffering by suggesting the Karen's fate is biblically tied to exile. Ultimately this narrative promises the Karen will be rewarded for their suffering with eternal life in the Promised Land if they remain faithful. Thus, rejecting repatriation can coincide with accepting a fate of exile.

Finally, the third area concerns how membership in the church has increased opportunities for mobility and education through access to a global community. Mobility has been increased by way of private visa sponsorship programs, which are administered

\footnotetext{
18 For a more detailed discussion on this topic, see Chapter 5 in relation to the incongruence of stipulations between the Karen and the Myanmar Government as a barrier to repatriation.
} 
by religious organizations in foreign countries such as Canada and Australia. Additionally, the participation in Christian missionary networks has the potential to open up theological educational opportunities through access to a global community. Many of the young adult Karen I met who spoke English had been educated in foreign theological schools. Managing without official identity paperwork, many Christian Karen students make their way over land borders into India or Thailand to study in religious schools. As one young man explained to me in an interview, "I don't have the Burmese passport, but it is not a problem. I went to Nagaland by bus to study in seminary school. This is like a sponsorship program,

it was a very good opportunity. I stayed there for three years. So now I have come back and I try to give back to my community and share what I learned". As Horstmann (2011) also noted, “...refugees make careers in the church and emphasize their aspirations by actively participating in evangelical efforts" (pg. 270). In this way, repatriation is resisted in lieu of strategically working towards a better option for ones future.

\subsection{Conclusion}

In summary, understanding experiences of time, waiting and exile in relation to repatriation and resistance allows us to examine the issue from multiple vantage points. Conceptualizing how waiting can be transformed from something passive into something active illuminates the power of agency inherent in all humans. However, protracted refugee situations must be understood within their own unique cultural and spatiotemporal contexts. In the case of the Karen living in refugee camps along the Thai-Myanmar border, additional attention must be given to aspects of time, confinement, governmental power, religion, and international interventions. While all of these areas have the potential to 
significantly impact voluntary repatriation, a final area should be noted. The creation of a Christian-centric identity in the Karen refugee community suppresses the internal ethnic diversity of the Karen in Myanmar, where religious affiliations, customs and language vary substantially according to region and village (e.g. Gravers, 2007). Said (2003) has argued that, "exiles feel an urgent need to reconstitute their broken lives, usually by choosing to see themselves as part of a triumphant ideology or a restored people" (pg. 47-64). Perhaps those who write about groups in exile also have an inclination to create binaries between the righteous and the ruthless. Western researchers have had a noted tendency to both generalize the Karen as Christian and well as produce arguably biased work that leans toward the policy goals of the KNU (Horstmann, 2011; Rogers, 2004). In order to truly understand how repatriation can ever be voluntary, both a comprehensive and honest assessment must be delivered. One that acknowledges both the power and hardship contained within a heterogeneous Karen refugee community. 


\section{Chapter 5 \\ NEGOTIATING RETURN: Strategies, Compromise and Barriers}

\subsection{Introduction}

"Many things need to change before we would consider returning. We need our own land to farm and we also need security. The Tatmadaw are still in the mountains around Karen State and the military can never be trusted. They never do what they say. So we worry about our security if we go back there because we don't know the truth. We cannot see someone's heart, we can only see their face." Saw Doh Moo, 56, Mae La Camp

On a cool and cloudy day in late September I decided to wander down to the small sports field that was neatly tucked away between the school's rear entrance and the bank of a small river that ran though the center of camp. It had been raining nonstop for the past several days and the dirt lanes that snaked their way through the bamboo and thatch roofed buildings had turned into a series of treacherous mud puddles. I carefully made my way down the path to the field, all the while grasping at tree branches and sheepishly smiling at the group of women who were watching nearby in amusement as I tried not to fall. By now the rainy season was well upon us and any break in the torrential downpour was a welcome opportunity to spend a bit of time outdoors. I settled in on one of the small cement stoops in the periphery of the field and unpacked a bit of fruit and a book I had stashed in my bag. Across the way a group of boys were hitting a small rattan ball back and 
forth over a volleyball net using everything but their hands. They played barefoot while wearing shorts and each time they hit the ball it delivered a satisfying hollow thud. While I watched them one of the students I recognized from another school in camp came to sit with me. Saw Bu Reh was Karenni and had grown up in Ban Mai Nai Soi refugee camp, which was located several hours north of Mae La with a population of approximately 10,000. Like many young people in Mae La, he had come here specifically to attend school. “Hey Bu Reh, how are your studies going?” I asked. Always eager to practice English, although ignoring my original question, he replied happily, "Thramu, you like this game? This is called chinlone." I laughed and said yes, pointing out how impressive it was that they could keep the ball off the ground for so long without using their hands. 'Thramu', a term used for a female teacher, had come to replace my given name almost immediately after I arrived. I liked the familiarity it seemed to bring to conversations and always smiled at its use, even though it was a thoroughly generic term. We chatted for a while about sports and school and eventually landed on the topic of what Bu Reh wanted to do after he finished his studies that year. "Will you go back to Ban Nai Soi to be with your family?" I asked gently, knowing the question might be a difficult one. He thought for a moment and replied, “No, I don't think so. Maybe I will stay here. Or maybe I can go to Canada...” his voice trailing off. The answer was one that I was familiar with. Bu Reh had limited options to weigh and what he wanted to do was not necessarily what was possible. It was an answer full of frustration and uncertainty but also hopefulness. I looked at Bu Reh and nodded in agreement, "Yes, maybe."

The mixture of frustration, hope and uncertainty colored many conversations I had with refugees in Mae La about the prospect of returning to Myanmar. People noted several 
factors that needed to be considered or options weighed before concrete plans could be made. Often, the barriers preventing return seemed so insurmountable that people ruled out repatriation entirely. In these instances I considered how difficult it might be to describe the absolute paradox people faced when confronted with the words: "voluntary repatriation". Each interview seemed to capture only a brief moment in a continually evolving mental negotiation. Strategies changed with the ebb and flow of information coming from Karen State, the KNU, or friends and family. What someone planned to do if Mae La closed today might be completely different next month if there were rumors of a new resettlement program or work visa. The environment felt both idle and in constant flux at the same time.

More than 15 years ago Colson argued that if anthropology continued to rely on ethnography it would have to focus on "people in transition, who are uneasy about themselves in a world that ignores their desire and need for continuity. It will have to deal with responses to processes of displacement and arrival. Ethnographic time horizons will change: the one-shot time exposure will have to be supplemented by longitudinal research" (2003). I asked myself what might be gained from research that captured only a brief moment in time with strategies that were mostly contingent on continuously changing factors? Would the data be outdated and useless by the time I left the field? Or could the information be seen as the micro-level threads that form the fabric for longer-term social change on the Thai-Myanmar border? The challenge would be to define how strategic decision-making under conditions of constant flux could actually underpin the social change inherent in a mass repatriation should it come to pass. Barbara Harrell-Bond famously championed the use of anthropology in studying refugees in that it "offers the 
chance to record the processes of social change, not merely as a process of transition within a cultural enclave, but in the dramatic context of uprootedness where a people's quest for survival becomes a model of social change." (Harrell-Bond and E. Voutira , 1992).

In this way it became important for my research to be situated in the context of the Karen's transitional existence as refugees, and how not only strategic decision-making, but also the related experiences of exile can help form cultural narratives that drive change; or resistance to it. Additionally, situating the Karen displacement within anthropological theories of time, mobility and migration (see Ch. 4) help to understand how strategies for migration corridors develop, resistance strategies are employed and solutions such as third country resettlement and repatriation are decided. In this chapter I will focus on the latter, looking specifically at the current program of voluntary repatriation being offered to refugees along the Thai-Myanmar border. First, I discuss the internationally accepted protocol for resolving a protracted refugee crisis in relation to the Thai-Myanmar situation. This will be followed by an explanation of the current voluntary repatriation program being implemented by UNHCR and an update on its status. The remainder of the chapter will focus on research outcomes regarding refugee perceptions of return. This includes both reported barriers to repatriation as described in interviews with refugees as well as other barriers identified through qualitative analysis and observation. To conclude, I will offer a summary of the choice many Karen are currently facing in Mae La camp as well as introduce the potential solutions to be discussed in the next chapter.

\subsection{Durable Solutions}

The goal of refugee protection is ultimately to find a long-term solution for displacement that allows refugees to live their lives free from persecution in peace and 
dignity. The universally accepted standard to achieve this goal is the protocol developed by UNHCR for resolving refugee situations. This protocol entails three primary options known as 'durable solutions' which include: (1) integration into the country of first asylum, (2) third-country resettlement, and (3) voluntary repatriation. It is worth taking a moment to discuss each of these individually in regards to their history, efficacy and how they relate to the situation on the Thai-Myanmar border. While the enactment of durable solutions are often deeply complex and rooted in their own geo-political contexts, past examples often provide the best lens to understand the current challenges refugees face in return. By no means is this an exhaustive review of the role that durable solutions play in global refugee policy ${ }^{19}$. Rather it is a brief overview to help explain both the framework of available options as well as their relevance to resolving the protracted refugee situation along the Thai-Myanmar border.

(1) Integration into the country of first asylum:

The first durable solution proposed by UNHCR is local integration into the host country where a refugee first sought asylum. As refugee situations become more protracted and camps linger for decades across international borders, this option often becomes increasingly desirable. Displaced groups naturally become more emplaced in their geographic location with the passage of time, often getting married, giving birth to children and raising families on foreign soil. In the anthropological literature, Feld and Basso (1996) have defined emplacement as 'the way in which people encounter places, and invest them with significance' while Jacka (2005) notes emplacement as 'a process in which people re-

\footnotetext{
${ }^{19}$ For a more comprehensive discussion of durable solutions see (1) Chimni, B. S., 2004 (2) Crisp, Jeff, 2004. (3) Gottwald, Martin, 2012 (4) Weiner, Myron,1998
} 
embed social relations that have been "distanciated" and "disembedded" by disruptions, dislocations and deterritorializations'. In this way, refugees who have spent decades in foreign camps, villages or urban centers have become rooted in their host countries by the creation of new families, communities and conceptualizations of home. This rootedness makes legal integration desirable in its ability to ensure security and economic opportunity while also helping to shed the last vestiges of being a "temporary" outsider. However, legal integration is a complex process that is often riddled with political complications and economic barriers. As Wernke (2007) has argued, emplacement is also a process of negotiation between citizens and the state. For refugees, obtaining citizenship in a neighboring country is often not an option and many countries of first asylum lack the political will or economic resources to support a mass integration. An estimated $84 \%$ of refugees are currently hosted in developing countries (see figure 5.1), which can also make integration problematic by way of refugees competing for resources with their host communities. As such, UNHCR estimates that over the past decade, only 1.1 million refugees around the world became citizens in their country of asylum. This is a staggeringly small number in comparison to the 68.5 million people who were living as refugees or internally displaced persons in 2017. 


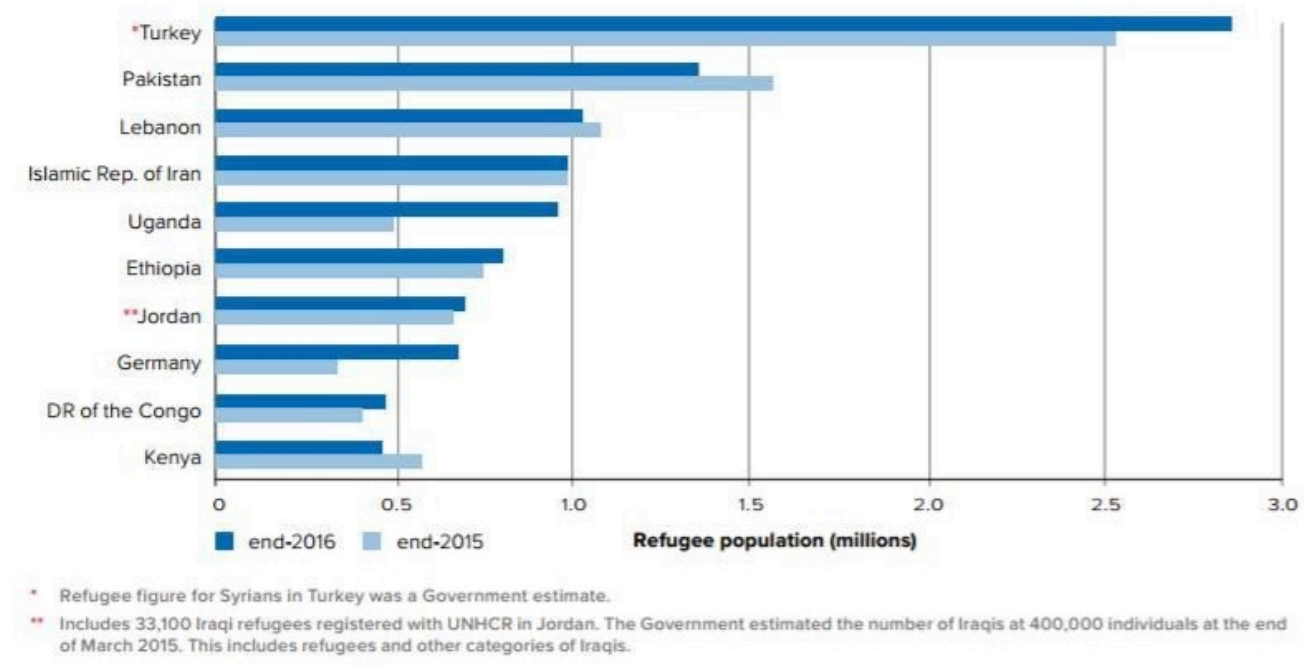

Figure 3: Major refugee-Hosting Countries 2015-2016. (Source: UNHCR, June 2017)

However, the 1951 Convention does provide a legal framework for the integration of refugees and its relevance as a solution is increasing as the popularity of special economic zones and their corresponding labor markets grow. Additionally, some host countries have adopted an incremental approach to local integration by granting residency or work permits that gradually lead to a wider range of rights and entitlements. For example, in 2008 Panama enacted the Regularization Law and Public Awareness Programme to offer a solution for refugees who fled conflicts in Nicaragua and El Salvador during the 1980s. The law allowed refugees who had held refugee status in Panama for 10 or more years to apply for permanent residency status. In Panama, permanent residents have the right to apply for naturalization after five years (or after three years if they have Panamanian children). Prior to the enactment of the law, refugees and their families only had temporary status, which greatly impeded their local integration. Tanzania, Iran, Belarus, Moldovia and the Ukraine have all also enacted similar programs. Most recently, 
Thailand also moved to regularize status for the estimated 3.8 million irregular migrant workers in the country by way of a Royal Ordinance in 2017. While the registration of migrant workers is a positive step forward in that it ensures protection under Thai labor laws, it is not without flaws. Most notably, due to agreements between the Thai Royal Government and the Governments of Myanmar, Cambodia and Laos, a migrant cannot register without the proper identification issued from their country of origin. This requirement effectively excludes the tens of thousands of refugees in Thailand from registration, as many do not possess national identification and cannot enter their home country to obtain it out of a fear for their safety, issues of time, lack of permission to leave or the prohibitive cost of travel to obtain such documents ${ }^{20}$. While local integration may indeed be the preferred option of many refugees along the Thai-Myanmar border, there is not yet a legal framework in place to accommodate their inclusion in legal migration.

Further complicating the potential of local integration in Thailand are both social and political barriers. In 2004, Human Rights Watch noted a "growing populist-nationalist sentiment that illegal migrant workers were taking Thai jobs and causing economic, security, and public health problems" (HRW, 2004:17) Brees (2010) has also argued that the Thai government and the local population perceive refugees from Myanmar as a threat to security and social order. She notes that the media has often furthered xenophobic rhetoric that implies Thailand is being overwhelmed by foreigners and habitually portrays refugees as troublemakers. Additionally, Thailand's growing economic and political ties to the Myanmar government has resulted in a hardline stance against refugees observed to be

\footnotetext{
${ }^{20}$ As noted by A. Kaun from UNHCR in a personal correspondence from 2019, it is also worth mentioning here that even if refugees had these documents in their possession, in theory they would not be able to leave the camp unless they obtained prior permission from MOI given the encampment policy for displaced persons from Myanmar, which is in contrast to urban asylum seekers.
} 
activists or outspoken critics of the Myanmar government (HRW, 2004:24). While research has shown that refugees from Myanmar positively contribute to the Thai economy (Brees, 2010), many social and political factors must be addressed for local integration to be successful.

(2) Third-country resettlement:

For refugees who cannot return home due to persecution or on-going conflicts, third country resettlement is sometimes an option for a long-term solution. As UNHCR notes, resettlement can also be an 'effective mechanism for burden sharing and international cooperation, providing options to assist first countries of asylum consistent with the principle of international solidarity'. Since 1975, the U.S. has resettled over 3 million refugees, the most of any nation, with annual admission figures ranging from a high of 207,000 in 1980 to a recent low of 22,491 in 2018. However, resettlement to a third country is not only rare (less than $1 \%$ of refugees are resettled) but can also be problematic in both procedure and outcome. For example, in Tanzania, Thomson (2012) argues that the resettlement approval process for Congolese refugees is confusing and opaque, which can further exacerbate the stress of displacement. This theme of disempowerment by overly complex and restrictive policies has also emerged from research with refugees on the ThaiMyanmar border attempting to resettle to the U.S. (see Mathews, 2012). Thomson notes that a successful resettlement bid is premised almost entirely upon proving one's own trustworthiness, which often involves producing official documents to back up claims of identity or proof of persecution. What Thomson describes in Tanzania is particularly applicable for many Karen in Thailand, as attempts to acquire formal documentation are often stymied by the bureaucratic processes that surround obtaining birth certificates or 
national identity cards. In both scenarios, dismantling the bureaucratic process in a way that demystifies where decisions are made would make the system more accessible for refugees.

For many Karen along the border, Canada, and to a lesser extent, Australia, have effectively become the last bastions of real hope for third-country resettlement. The U.S. officially ended its Myanmar resettlement program in 2014, although thousands of applicants remained in the system and have slowly been granted admission over the past four years (see figure 4). Currently, the U.S. will still accept applications from family members who wish to be reunited with relatives who have previously been resettled and cases with extenuating circumstances that are specifically referred by UNHCR ${ }^{21}$. Canada, Australia, New Zealand, Finland and Norway continue to admit a small number of refugees from Myanmar, although only Canada (and very recently Australia) operates what are known as special humanitarian programs, which allow for private individuals or organizations to sponsor a specific person or family. This is how many Karen have made their way into Canada as groups such as The United Church of Canada and the Canadian Baptists of Ontario and Quebec have sponsored hundreds of families through affiliated networks in the camps. Still, the numbers are low in comparison to the amount of people who still remain on the border and third-country resettlement remains an unlikely option.

\footnotetext{
${ }^{21}$ As noted by P. Trotter in a personal correspondence from 2019, there still remains some possibility of resettlement not dependent on refugee status by way of the "visa 93" programme which is still active although subject to nationality bans that are currently being challenged in court. For more information on the Visa 93 program visit: https://tr.usembassy.gov/visas/immigrant-visas/immigrant-visa-additional_info/
} 


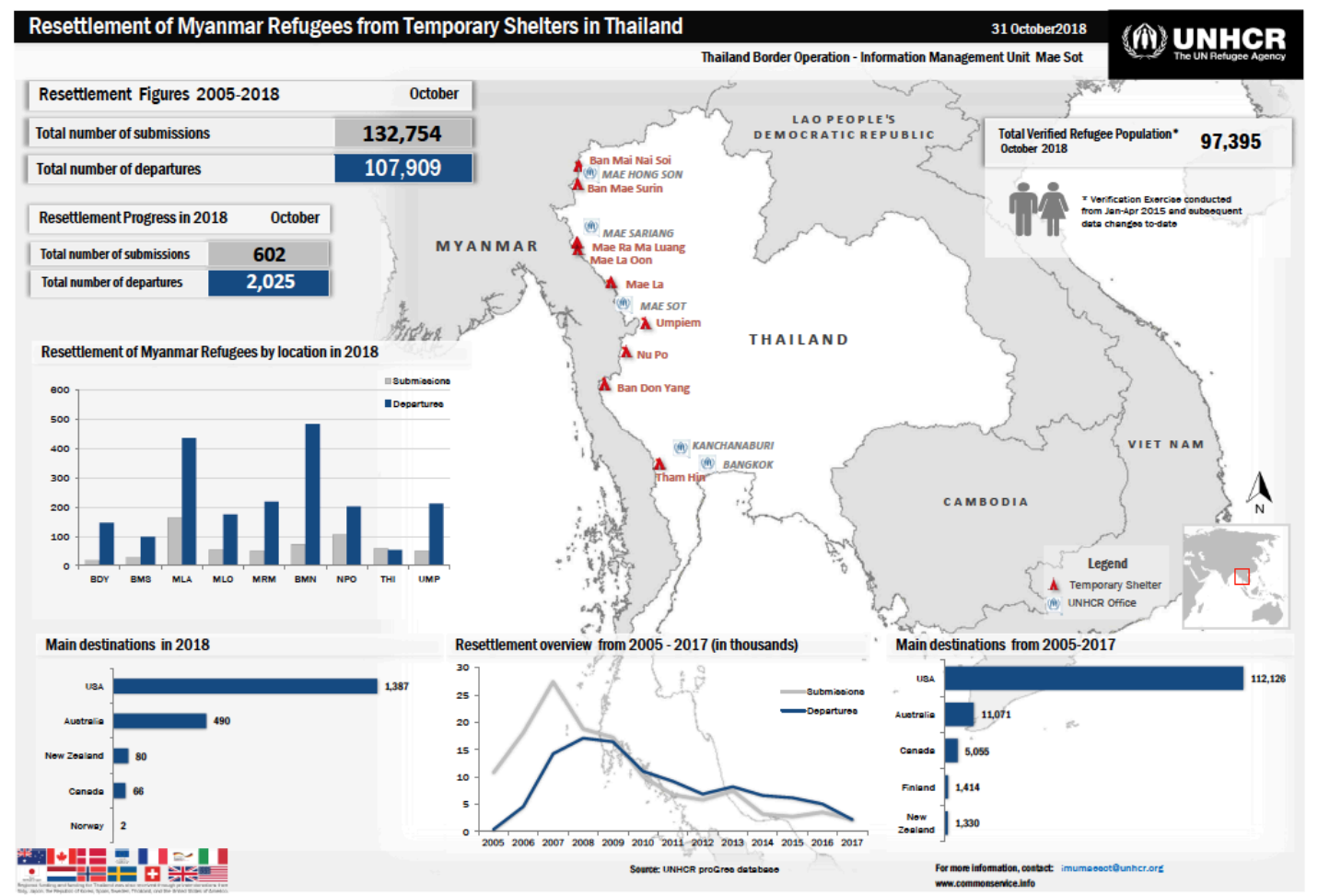

Figure 4: Resettlement of Myanmar Refugees from Temporary Shelters in Thailand 2005-2018; (Source: UNHCR 2018)

(3) Voluntary repatriation:

Out of the three options, UNHCR promotes voluntary repatriation to the country of origin as the most ideal solution. Voluntary repatriation is often regarded as the hallmark signal of a conflict's conclusion as well as a significant phase of the post-conflict peacebuilding process (Black \& Gent 2006; Crisp 2000). It is also generally seen as the most costeffective, logistically efficient and logical conclusion to a mass displacement of people. Voluntary repatriation programs are supported by the fact that the right to return to one's country of origin has become accepted as a fundamental human right. This has been explicitly stated in article 13 (2) of the Universal Declaration of Human Rights as noting that everyone has the right to "leave any country, including his own, and to return to his 
country." While the Declaration is not legally binding, it has been tremendously influential in the shaping of national and international laws, treaties, and constitutions for more than 70 years and continues to do so for the Thai-Myanmar border. Most notably this influence can be seen in UNHCR's direct involvement with local refugee policy and the recent implementation of a voluntary repatriation program inside the nine camps along the ThaiMyanmar border.

UNHCR's role in voluntary repatriation can be traced back to its inception, when in December of 1949, the United Nations General Assembly established a High Commissioner's Office for Refugees. Thus the Statute of the Office of the United Nations High Commissioner for Refugees ${ }^{22}$ was adopted by the General Assembly on December $14^{\text {th }}$, 1950, to be effective as of January 1 st, 1951 . Among the other duties assigned to UNHCR, the Statute outlined the conditions for return and called upon governments to cooperate by "assisting the High Commissioner in (her) efforts to promote the voluntary repatriation of refugees" (par. 1). The initial directives outlined in the Statute for UNHCR are significant in that they laid the groundwork for the guiding principles of future repatriation policy. These include the tenets that (1) repatriation should always be voluntary; (2) UNHCR, governments and private organizations (NGOs) all have a joint role to play; and (3) voluntary repatriation should be both facilitated and promoted to ensure the safety and security of refugees.

22 UN General Assembly, Statute of the Office of the United Nations High Commissioner for Refugees, 14 December 1950, A/RES/428(V), available at: https://www.refworld.org/docid/3b00f0715c.html Adopted at the 325th plenary meeting, 14 Dec. 1950. "Annex: Statute of the Office of the United Nations High Commissioner for Refugees". In: Resolutions adopted by the General Assembly during its 5th session, Volume I, 19 September-15 December 1950. - A/1775. - 1951. - p. 46-48. - (GAOR, 5th sess., Suppl. no. 20). 
Over the past several decades UNHCR's role in voluntary repatriation has expanded significantly. As seen in their current mandate (see table 3), a much more comprehensive effort has been put forth to ensure all stages of repatriation allow refugees to return in safety and dignity. UNHCR also plays a more pivotal role in the coordination of States and other partners to promote and facilitate voluntary repatriation programs. In this regard they have slowly adopted a more inclusive approach in hopes of bringing refugee voices to high-level policy discussions. For example, UNHCR has initiated several tripartite commissions that can be 'useful mechanisms for the official recognition of refugee priorities and barriers to return, as well as ensuring refugee participation in planning and peace processes 23 . These have led to several signed tripartite agreements between host country governments and UNHCR for the voluntary repatriation of refugees such as Nigerian refugees in Cameroon (2017), Sudanese refugees in Chad (2017) and Afghan refugees in Pakistan (2016). This is indeed the goal for the Thai-Myanmar border situation as described by UNHCR in their 2015 report titled Strategic Roadmap for Voluntary Repatriation of Refugees from Myanmar in Thailand. Within the report UNHCR lists several benchmarks, which must be met prior to either the facilitation or promotion of repatriation along the Thai-Myanmar border. In addition to benchmarks concerning signed ceasefire agreements and mine-risk awareness training, is the requirement for a tripartite agreement for promoted return, which confirms national protection of returning refugees. Progress has been slow on this front, although in late March of 2017, a bilateral meeting between Myanmar and Thailand resulted in an informal agreement to facilitate returns

\footnotetext{
${ }^{23}$ As stated in the 66th Meeting of the Standing Committee of the Executive Committee of the High Commissioner's Programme, Update on voluntary repatriation, Geneva, 21-24 June 2016.
} 
twice a year. As of the end of 2018, two facilitated returns have occurred with a third in process, although the total number of people repatriated was less than 200, falling well below projected figures (see discussion in next section).

While voluntary repatriation has indeed been the most common and preferred durable solution, it has not always been successful. Lubkemann (2013) argues that recent scholarship has debunked the notion that return is the most 'natural' or self-evident post conflict outcome for refugees. Instead proposing that prolonged wars dramatically alter the social, economic and political landscapes of the country they fled, essentially making the 'home' they knew a very different place. Additionally, the new social and economic connections made over many years in exile can tie refugees to their areas of war-time resettlement and lead to reluctance or outright refusal to return. In the Great Lakes Region of Africa, which includes Burundi, the DRC, Kenya, Rwanda, Tanzania, and Uganda, the repatriation of large refugee populations has 'often incited violent conflict, contributing to an ongoing cycle of war, exile, and repatriation' (Baregu 2006b).

The case to refute repatriation as the most natural solution to displacement is further strengthened by literature that offers a critical analysis of existing systems of return. Of particular relevance to the refugees on the Thai-Myanmar border is research concerning the intersectionality of protractedness in relation to conceptualizations of home. Hammond (1999) describes a "discourse of repatriation" prevalent in humanitarian policy that often uses terms such as 'reintegration' and 'rehabilitation'. This is problematic as the concept of 'return' and 'returnee' imply that by entering one's native country a person is returning to something familiar. The terms above are "riddled with value judgments that reflect a segmentary, sedentary idea of how people ought to live, what their 
relation to their homeland should be, and ultimately how they should go about constructing their lives once the period of exile ends"(pg. 230). In essence, it implies that refugees should go backwards in time and find life as it used to be before becoming a refugee. As many Karen were born in exile, this is an impossible task. Along this same vein, Malkki (1995) has argued that assumptions of refugees often imply that they lose their national identity when they flee, but this way of thinking fails to consider refugees' capacity to develop new social identities and life strategies. For Karen refugees, their protractedness has come to define a key component of their lived experience. Their social identities have become inextricably linked to their lives in Thailand and the communities they have formed in exile. Repatriation assumes that the connection to one's homeland (or a parent's homeland) will supersede the bonds formed in exile, which is quite clearly, not always the case. 


\begin{tabular}{|r|l|}
\hline \multicolumn{2}{|l|}{ Summary of the Current UNHCR Mandate for Voluntary Repatriation } \\
\hline i. & Verify the voluntary character of refugee repatriation \\
\hline ii. & $\begin{array}{l}\text { Promote the creation of conditions that are conducive to voluntary return in safety } \\
\text { and with dignity }\end{array}$ \\
\hline iii. & $\begin{array}{l}\text { Promote the voluntary repatriation of refugees once conditions are conducive to } \\
\text { return }\end{array}$ \\
\hline iv. & $\begin{array}{l}\text { Facilitate the voluntary return of refugees when it is taking place spontaneously, } \\
\text { even if conditions are not conducive to return }\end{array}$ \\
\hline v. & $\begin{array}{l}\text { Organize, in cooperation with NGOs and other agencies, the transportation and } \\
\text { reception of returnees, provided that such arrangements are necessary to protect } \\
\text { their interests and well-being }\end{array}$ \\
\hline vi. & $\begin{array}{l}\text { Monitor the status of returnees in their country of origin and intervene on their } \\
\text { behalf if necessary }\end{array}$ \\
\hline vii. & $\begin{array}{l}\text { Undertake activities in support of national legal and judicial capacity-building to } \\
\text { help states address causes of refugee movements }\end{array}$ \\
\hline viii. & $\begin{array}{l}\text { Raise funds from the donor community in order to assist governments by } \\
\text { providing active support to repatriation and reintegration programmes }\end{array}$ \\
\hline ix. & $\begin{array}{l}\text { Act as a catalyst for medium and long term rehabilitation assistance provided by } \\
\text { NGOs, specialized development agencies and bilateral donors }\end{array}$ \\
\hline Source: UNHCR Handbook for Voluntary Repatriation: International Protection (1996:1.6)
\end{tabular}

Table 3: Summary of Current UNHCR Mandate for Voluntary Repatriation (Source: UNHCR 1996)

\subsection{The Current State of Voluntary Repatriation on the Thai-Myanmar Border}

"Someday we will return to Kawthoolei and it will be ours. We will be free to

farm our land and live in peace. I believe this. The Karen people will not

disappear until we have been returned to our land. Thay gan ma-yuk, thet mapyauk (It is our fate)" - Poe Thaw Lay, 42, Mae La Camp

The notion of return has long been a point of contention for many Karen living along

the Thai-Myanmar border. References to 'Kawthoolei', the S'gaw Karen word for Karen

State, invoke deep emotional connections to ancestral lands and dreams of independence.

The story of Kawthoolei has become the narrative of a homeland that is "constructed,

imagined, and contested in the context of displacement and political exile in the margin of 
two other nations" (Horstmann, 2011:86). It has become, in its current idealized iteration, the only place to which many Karen want to return. However, the physical space that Kawthoolei occupies within Myanmar is riddled with land mines, patrolled by the Burmese military and has little chance of achieving status as an independent nation. Thus the collision of idealism and pragmatism has created a deep uncertainty about when, how and why one might return.

Further exacerbating the uncertainty surrounding repatriation are recent cuts in humanitarian funding and declining international support for maintaining the camps along the Thai-Myanmar border. "With the war in Syria and the refugee crisis in Europe, it has become increasingly difficult to secure humanitarian funding for long-lasting refugee situations" explained Iain Hall, a senior coordinator for UNHCR. As such, refugees have reported feeling pressured to return due to reductions in food rations and declining living standards in the camps. This has often been seen as an unofficial agency strategy and a way to push people out. As one refugee in Mae La explained:

“They want us to leave. They don't want to let us live here anymore. So they have taken away the rations to force us to go. They have figured out that this is the way they can do it and not have to say they don't care about us refugees. I don't know what we will do." Taw Po, 36 


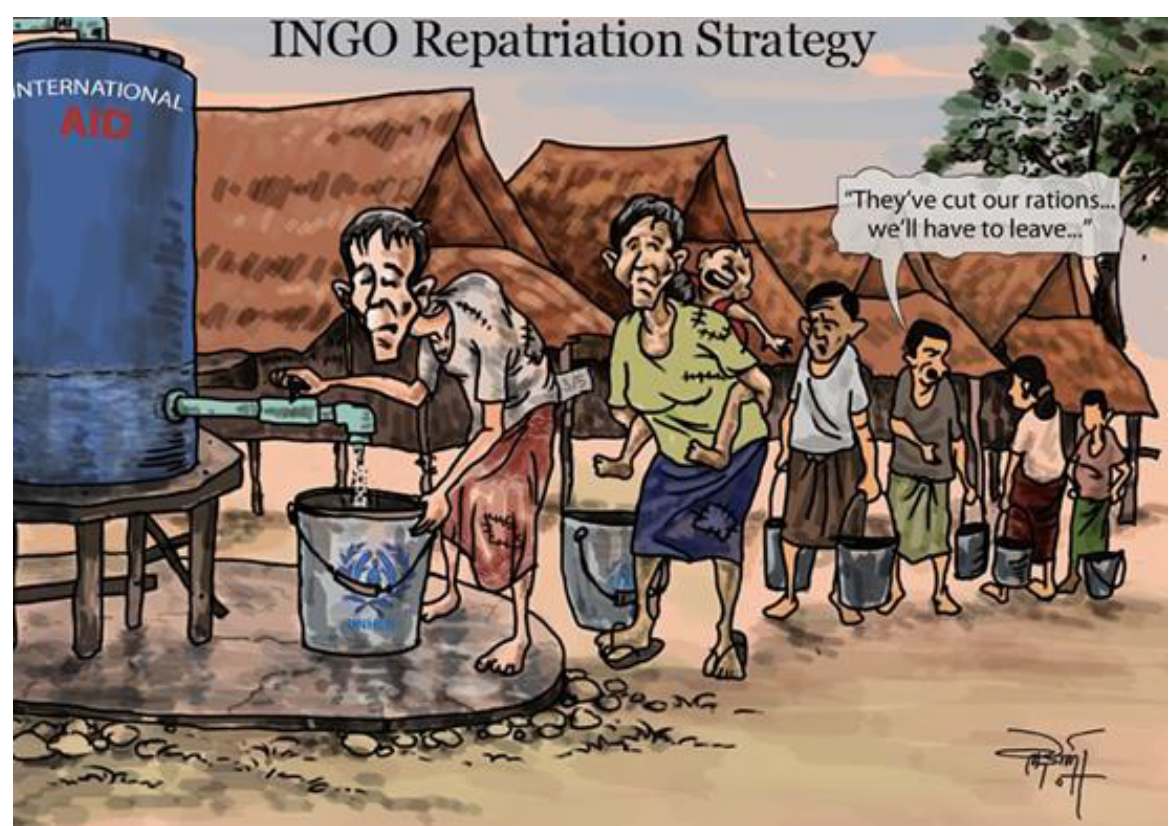

Figure 5: INGO Repatriation Strategy Political Cartoon (Source: Karen News)

There are currently three modes of return that are used to describe the status of voluntary repatriation on the Thai-Myanmar border. These are: (1) spontaneous returns, which are organized by individual refugees themselves without UNHCR's direct engagement or support before or during the movement (2) facilitated returns, which involve UNHCR's active engagement including protection counseling, informational sessions prior to departure, travel arrangements and financial assistance for initial reintegration (note that UNHCR's engagement in facilitating voluntary return is contingent upon an assessment of the conditions in a specific location and key benchmarks being met) and (3) promoted returns, which occur within a formalized framework between the country of origin, country of asylum and UNHCR when the overall conditions throughout Southeast Myanmar are conducive to return for the vast majority of refugees.

From 2012 until today, a rough estimation of approximately 18,000 refugees are believed to have spontaneously returned to their homes in southeastern Myanmar without government assistance, according to The Border Consortium (TBC, 2018). The exact figures 
are difficult to ascertain, as many people do not report their departures in fear that they will lose their status as a registered refugee in camp (thus also losing the access to food rations and housing). Further, many refugees have returned on what have been termed "go-and-see" visits to assess the situation for themselves. While these trips are encouraged and sometimes even funded by UNHCR, many are done informally between community networks. The occurrence of informal spontaneous return is noteworthy in that it speaks to the much broader issue of decision-making and autonomy on the part of the refugee. By returning through their own informal networks, they disrupt the existing hegemonic power structures that have governed their 'refugeehood'. In this way, refugees reclaim control over their lives while shedding an identity that was interrelated with dependency on foreign aid. Spontaneous return may therefore be the most natural form of return with the best rates of success. Unfortunately, these types of returns are difficult to track, can often be circular in nature and ultimately have not been significant enough to impact the overall population numbers in the Thai camps. However, during the course of my fieldwork I noted both a favorable view of spontaneous return as well as its current dismissal as an option. In nearly a quarter of my interviews with Karen refugees living in Mae La camp $(n=9)$, I recorded sentiments that can be summarized as: 'if things in Karen State improved significantly, refugees would go back on their own with no need for assistance'. For example, one Karen man in his mid-thirties stated firmly:

"If the Tatmadaw left Brigade 7 and stopped the fighting with KNLA, we would not have a problem with going back. You wouldn't even need to tell us, we will go back tomorrow on our own. We don't need help. But there are more and more soldiers everyday and we don't have any guarantee."

However, the probability of a complete military withdrawal from Karen state remains unlikely and strong stances such as these would have little chance of being tested anytime 
soon. In nearly every interview I conducted with refugees inside Mae La camp, spontaneous return was never mentioned as an actual planned solution $(n=36)$. Rather, if faced with an imminent camp closure, the most common answer was the desire to attempt to stay in Thailand ( $n=29)$. A small number of refugees mentioned the possibility of applying for third country resettlement if the camp were to close $(n=4)$ and most stated that they would only consider repatriation if there were no other options and certain conditions were met $(n=31)$.

There is a clear majority of opinion amongst the Karen concerning the lack of a desire to repatriate into Myanmar anytime soon. This position is often reinforced by statements from the Karen National Union (KNU) and other ethnic based organizations (EBOs) in the area. As one woman, a mother in her late twenties put it:

"We don't know the truth about what happens in Burma. Our leaders need to decide whether to make a deal with the government there or not. So we will wait and see when the KNU says it is ok to go back. But right now, they do not say it is safe."

In addition to the influence held by the KNU, groups such as the Karen Refugee Committee (KRC) and the Karen Student Network Group (KSNG) have released formal positions on voluntary repatriation. The KSNG, an independent student group made up of over 15,000 members, is active in most of the camps along the border. In December of 2016, KSNG reportedly organized a meeting inside Ma La Oon camp that included approximately 120 representatives from community-based organizations, camp leadership and local human rights groups. The result was a position paper with 19 stipulations for return. It was divided into two main positions: (1) pre-departure of refugees and (2) post-departure and reintegration of refugees. (see table 4) 


\section{Karen Student Network Group (KSNG) \\ Position Paper on Refugee Return to Burma \\ June 20, 2017}

\begin{tabular}{|c|c|}
\hline 1.KSNG's Posit \\
\hline 1.1 \\
\hline 1.2 \\
\hline 1.3 \\
\hline 1.4 \\
\\
\hline 1.5 & \\
\hline 1.6 & \\
\hline 1.7 & \\
\hline 1.8 & \\
\hline 1.9 & \\
\hline
\end{tabular}

\section{KSNG's Position on Post-departure and Reintegration of Refugees}

$2.1 \quad$ Adequate land should be provided by the government for internally displaced person (IDPs) and refugees who have lost their land in line with the UN's Pinheiro Principles and with full guarantee for livelihood activities.

2.2 $\quad$ Return should take place only after political dialogue is successful in forming a federal democracy.

2.3 $\quad$ The curricula of Karen Education Department (KED) should be recognized and supported by the government.

$2.4 \quad$ Karen national flag should be allowed to be raised in front of Karen national schools without any hindrance.

2.5 $\quad$ Karen students should have the right to learn Karen curriculum which includes Karen history, culture and tradition and Karen language produced by the KED.

2.6 $\quad$ Karen students and youth should be provided with national identification cards identifying them as citizens with equality and without any discrimination.

2.7 $\quad$ Humanitarian assistance provided by supporting organization should be provided for the returning refugees until they can be self-reliant.

2.8 $\quad$ Karen youth should be provided with job opportunities for their livelihood and be free from any form of slavery.

$2.9 \quad$ Karen students and youth organizations should have the right to freedom of formation of organizations, expressing opinion and freedom to act independently in community development.

2.10 Karen students and youth organizations should have the right to build network with other ethnic groups in Burma and all over the world.

Table 4: KSNG Position Paper on Refugee Return to Burma (Source: Karen Student Network Group, June 2017) 
The formal position paper released by KSNG was largely in response to the commencement of UNHCR's voluntary repatriation program, which began in August of 2016. During this time UNHCR began to build and operate voluntary repatriation centers in all 9 camps along the Thai-Myanmar border. The Voluntary Repatriation Centers (VRCs) were billed as facilities where repatriation-related activities would be conducted for refugees who were interested in returning home. This included protection counseling on the voluntariness of return as well as mine risk education sessions to learn how to recognize landmines and prevent related accidents. The centers also acted as information hubs for any issues related to conditions in the areas of return, such as livelihood opportunities, education and health services or obtaining civil documentation. In addition to these services, refugees could sign up at the centers to voluntarily repatriate and learn about the specific assistance packages available to them. The voluntary repatriation support as outlined by UNHCR can be described as:

1. Ensuring that refugees have access to protection counseling, where the voluntariness of return is verified, any questions or concerns related to the area of return and expectations regarding assistance can be clarified, and any special needs of the individual(s) can be identified and support options discussed.

2. All refugees undergo a mine-risk awareness session organized by Handicap International

3. All refugees receive mosquito nets and WASH kits

4. Organized transport from the temporary shelters to the transit location across the border will be arranged

5. Cash assistance in 4 components will be given on the day of departure to include:

5.1. Transport grant to support travel from the Thai border to the return location in Myanmar (THB 1,800 per person)

5.2. Reintegration grant (THB 1,800 per person)

5.3. Household support grant (THB 3,600 per adult and THB 1,800 per child)

5.4. Food support for 3 months (THB 1,10024 per person supported by World Food Program)

24 This amount has increased to THB 2,100 (from 3 months to 6 months of support) as of the second return in May 2018 
Once a refugee has volunteered to repatriate, the actual process of return is a somewhat complex coordination between UNHCR, the Royal Thai Government (RTG), the Thai Ministry of Interior (MOI) and the Government of Myanmar (see full booklet for Process of Facilitated Voluntary Repatriation- 2016 in appendix). If return is requested after the initial counseling and information sessions, each returning household must first sign a Voluntary Repatriation Form (VRF) to confirm their voluntariness to return. Once this document is signed, UNHCR sends a list of basic bio-data to both governments (such as name, sex, DOB, and location returning to) to the Government of Myanmar for a "green light". The family or individual's information will be shared with the RTG, UNHCR Myanmar and the Government of Myanmar to check local conditions. UNHCR will be informed when the "green light" (clearance) is received and the Government of Myanmar may issue a travel document to help facilitate the return process at this time. Once the green light is received, UNHCR will reconfirm with the family or individual of the voluntary decision to return and set a departure date. Following this confirmation, UNHCR and the RTG will inform all applicable partners such as Camp Committees or NGOs for preparations for return. Prior to the day of departure every returning individual must visit the Voluntary Repatriation Center to update their internal camp documents such as their VE registration card and Household Registration Document (HHRD). They must also undergo a "fit to travel" medical check by IOM, an overview on RTG immigration procedures, and collect non-food items such as mosquito nets and sanitary kits for women. On the day of departure, UNHCR issues 5 copies of the Voluntary Repatriation Form (VRF): 1 for the refugee to travel with; 2 for UNHCR; 1 for IOM, and 1 for the RTG. IOM then takes a copy of the VRF and provides the family or individual with the cash assistance package. The RTG 
also takes a copy of the VRF and confirms departure from the camp. After departure, each individual is de-registered from the UNHCR-MOI database and effectively forfeits their refugee status. For a visual summary of the facilitated voluntary repatriation process, refer to the FVR flowchart found in the appendix.

In a review of all existing literature provided by UNHCR concerning the VRCs on the Thai-Myanmar border, I noted that UNHCR continually stressed that return to Myanmar was an individual decision and they would only support repatriation that was voluntary, safe and dignified. Vivian Tan, the UNHCR spokesperson for the region at the time stated, "There is no specific time frame for voluntary return, though we stand ready to facilitate it as and when the refugees tell us they would like to go." In October of 2016, the first voluntary repatriation of 71 refugees was initiated from $\mathrm{Nu}$ Po and Tham Hin camps back into Myanmar. Subsequently in May of 2018, 93 more refugees from the Mae La, Umpiem, $\mathrm{Nu}$ Po, Ban Mae Nai Soi and Ban Don Yang refugee camps also voluntarily repatriated. Most recently, 565 refugees who signed up for voluntary repatriation officially returned in February of 2019. In total, these returns account for less than $1 \%$ of the current population of refugees living along the Thai-Myanmar border. Although Myanmar has made drastic changes over the last several years including a democratic election and a landmark national ceasefire agreement, much more remains to be done in order to overcome the barriers that have prevented return for the past three decades.

\subsection{Barriers to Return}

Several reasons emerged for opposing voluntary repatriation throughout the course of this fieldwork, all of which were deeply intertwined with the various motivations individuals had for fleeing in the first place. Many of the barriers identified by refugees I 
interviewed in Mae La were similar to those that had been widely circulated within the greater Karen community beginning around 2012. Outlets such as Karen News, Burma link, and the Karen Human Rights Group published interviews and articles that focused on the instability in Myanmar, the lack of available land and resources in Karen State and a general sense of unease with the Myanmar government.

In this way, a narrative of resistance developed within the community that synthesized the most common and pressing concerns of many displaced Karen. The construction of this overarching narrative was significant in that it allowed for 'the innovation of multiple small stories, or voices, while still preserving the possibility of a stable community, making it possible to construe resistance as a positive, continuous, recursive force of social reproduction' (Myrsiades, 1993). At times I noted the inclination of informants to default to resistance narratives when questioned about repatriation, regardless of their personal experience. For example, some respondents who had been born in the camp or relocated at a very young age would note a fear of the military as a reason they would not return to Myanmar, even though they had never personally encountered a soldier. This was by no means an attempt at being deceitful, but rather the reproduction of a very real fear that had been passed along both culturally and generationally.

In light of this, I found it helpful to make a distinction in my analysis between what I came to call the 'reported' and 'observed' barriers to voluntary repatriation: 'Reported' meaning those barriers which were verbalized often and reproduced in the cultural discourse, and 'observed' as the non-verbalized barriers identified through a more 
thorough observational analysis. Among the most reported reasons for opposing repatriation among refugees in Mae La camp were:

1. Fear of the security situation in one's home village and/or the presence of Tatmadaw (Burmese military) ( $n=27$ )

2. Dispute over land rights or lack of available space for building a home and/or farming $(n=17)$

3. Lack of economic livelihood opportunities in Burma $(n=16)$

4. Distrust of Burmese government $(n=14)$

5. Lack of KNU involvement in repatriation planning $(n=10)$

6. Lack of educational or health resources in Burma ( $n=9)$

All of the reported barriers spoke to conditions that would need to be met to ensure sustainable reintegration, which UNHCR defines as, "a process which enables formerly displaced people and other members of their community to enjoy a progressively greater degree of physical, social, legal and material security" (UNHCR 2012). Through the communication of these reported barriers, refugees in Mae La clearly refuted the pillars of sustainable reintegration by focusing on specific areas of insecurity. For example, the presence of the Burmese military creates physical insecurity whereas distrust in the government or a lack of control from local leaders such as the KNU creates a social and psychological insecurity. Further, lack of identity paperwork or the right to own land breeds legal insecurity, while lack of economic resources or education causes material insecurity. While the importance of these barriers and their potential solutions cannot be overstated, their identification has been fairly widespread among academics and practitioners (Lang, 2002; Brees, 2010; South, 2011; Moretti, 2015). My discussion of them here is by no means groundbreaking and in fact mirrors much of the reporting that has 
summarized these insecurities for the last several years ${ }^{25}$. Rather, what I found to be more useful was a careful analysis of the more obscure barriers that were preventing return along the Thai-Myanmar border.

One of the first things that struck me as an impediment to return was the fact that the population in Mae La camp was a mixture of long-time residents, people fleeing from war or environmental disasters, as well as those who were clearly economic migrants or others who would not meet the standards for international refugee protection. Thus simply ending a civil war in Myanmar would not be enough motivation for many of the residents in Mae La to return to their country. This mixed population is related to the fact that the push factors from Myanmar have shifted somewhat over time and many refugees who experienced violence first-hand no longer reside in the camps, having already resettled to a third country. Conversely, some refugees who came to the camps more recently seeking economic or educational opportunities are now unable to return due to increased militarization or fighting in their home region. For example, the recent deployment of Tatmadaw troops in Karen State's Papun district over the rebuilding of a road, resulted in fighting between the military and the Karen National Liberation Army (KNLA), which displaced some 2,000 locals.

From a historical perspective, at the height of the refugee influx to Thailand in 2005, the refugee population living within the camps on the Thai-Myanmar border peaked at approximately 150,000 people (TBC, 2018). That year also marked the beginning of several third country resettlement programs to countries such as the United States, Australia and

\footnotetext{
${ }^{25}$ For a recent example, see Chandran's January 2019 article in Reuters: Too scared to return home, Myanmar refugees in Thai camps face an uncertain future http://news.trust.org//item/20190114005252-xqkkj/
} 
Canada. A significant number of refugees were resettled by UNHCR, which reported 107,909 departures between 2005 and2018. However, as of October 2018, the total verified refugee population remained at 97,395 . The refugee camps seemed to be filling up almost as fast as they were being emptied by resettlement. These new arrivals have to some degree altered the makeup of the camp in regards to motivations for leaving Myanmar. As explained to me by Saw Eh Paw, a camp leader and refugee who had lived in Mae La for nearly 20 years:

"The way I see it there are really three categories of people coming here as refugees. First are those people really affected by civil war, like me, and some other Karen people living in Karen territory. I say that because they (the Karen) are brutally persecuted and tortured by the Burmese military, its like genocide. Everywhere there is land relocation, forced labor and portering. So it is very dangerous to live in Karen state. That's the first group, the ones very affected by the civil war that takes place in their territory so they cannot live on their land anymore. Their land was taken away by the government, who took everything away and destroyed it. The second group, are like farmers or people with no job and no economic security. The economy in Burma is not good and there is no education, so most of the parents are coming to refugee camp looking for a better life, especially for the parents looking for education for their children. The third one is people just purely looking for a chance or an opportunity. Or they think 'oh if I come to a refugee camp I can get opportunity to go to the $3^{\text {rd }}$ country', that's how they think. There are so many groups of people who come like that. That's why the first group of the refugees, they went to resettle in third country, but the newcomers, keep on coming, based on the 3 reasons. "

The distinctions described by Saw Eh Paw as to who is a refugee, economic migrant or purely an opportunist were characterizations I often heard echoed by both NGO staff and other refugees in the region. These informal assessments as to who was or was not an actual "refugee", as defined by the UN's definition ${ }^{26}$, seemed to indicate the supposed level

\footnotetext{
26 The primary and universal definition of a refugee that applies to states is contained in Article 1(A)(2) of the 1951 Convention, as amended by its 1967 Protocol, defining a refugee as someone who: "owing to wellfounded fear of being persecuted for reasons of race, religion, nationality, membership of a particular social group or political opinion, is outside the country of his nationality and is unable or, owing to such fear, is
} 
of deservingness for an individual to receive international protection. It also precluded their ability to resettle to a third country.

The confusion surrounding official status can be traced back to the refusal of the Thai government to allow UNHCR to conduct standard refugee status determination (RSD) after January of 2004. Prior to 2004, the camp population was registered and considered similar to a typical prima facie status. Instead, the Thais introduced a camp-based government-led procedure to assess the status of "persons fleeing fighting" and "persons fleeing political persecution" through the provision of Provincial Admission Boards (PABs). The PABs ultimately failed at creating a comprehensive screening mechanism and in 2005, UNHCR were allowed to resume registration, but only to register people who had already entered the camps prior to 2005. In the subsequent years, the government has failed to screen or register the majority of new arrivals, which the TBC (2018) estimates have left over a third of camp residents in a precarious legal state. While UNHCR and the RTG have been able to record individuals and families as residents of the camp, they have generally not granted the type of refugee status that would permit a third country resettlement or guarantee international protection.

At this point, it would be both difficult and time consuming to determine with complete certainty, which camp residents fit the legal definition of a refugee. Rather, lines have become blurred, circumstances have changed and individual motivations for leaving Myanmar have varied considerably from one person to the next. Thus the camp population in Mae La is a mixture of people fleeing persecution, looking for work, pursuing educational opportunities or simply seeking a better life, none of which are mutually exclusive. 
An outcome of the camp's blended population is that creating a consensus among camp residents regarding the terms under which people would return to Myanmar becomes increasingly complex. It also creates a situation in which the conditions of return stipulated by camp representatives may exceed the standard of protections historically offered for refugees who voluntarily repatriate. For example, the position paper released by KSNG in June of 2017 contained 19 points to address before an agreement to repatriate could be made. However, the 19 points covered a broad range of topics, not all of which are internationally accepted as compulsory actions to be undertaken by the state in order to ensure refugee protection in return. For instance, the requirement that 'refugee students have the right to continue their further studies in Thai universities as well as in Asia and all over the world' (table 4, section 2.1) is presented in a way that is untenable. Certainly the denial of a student visa does not justify refugee protection, thus its inclusion, however well meaning, may actually impede negotiations. In this way, some of the most difficult barriers to overcome for a mixed population have to do with untangling what constitutes a human rights violation versus what may just be an unfavorable or unfair reality of life in Myanmar.

In the absence of violence, racism, discrimination and other structural inequalities do not typically justify international interventions or support claims of asylum. Nor does a lack of economic or educational opportunities in one's home country warrant refugee status protection. Thus if refugees won't voluntarily repatriate unless stipulations are met concerning items not directly related to a well-founded fear of persecution, and Myanmar refuses to implement those demands, a stalemate may continue to define life on the border. As one woman explained to me during an interview, "I can't go back to Burma because my husband died and now there is nothing for us there. We don't have any land or a home, so 
we must stay here so we can live." Unfortunately, what may eventually break the impasse is known as the "fundamental change of circumstances" clause of the UN Convention. The Refugee Convention states that refugee status may end in situations where "the circumstances in connection with which [a person] has been recognized as a refugee have ceased to exist", in which case the refugee could be repatriated to their country without their consent. What complicates this matter significantly is the lack of formal refugee status determination for residents in Mae La as well as Thailand's policy of deporting illegal migrants. However, if the situation in Myanmar in regards to the treatment of the Rohingya continues to deteriorate, it is unlikely the UN would deem Myanmar as having met the standards of a "fundamental change of circumstances" to justify repatriation on the Southeastern border. Nevertheless, the presence of a mixed population of refugees and migrants in Mae La creates a barrier in terms of overreach regarding conditions of return.

The second obstacle to repatriation I observed was the lack of a mechanism for sustained and accurate information reporting for the residents of Mae La. The most common answer I received when asking where one acquired information, was that they heard news or rumors from a friend or relative. As one mother recalled, "Sometimes my son will tell me what he heard on facebook or at school. But I know what is going on here because my neighbor speaks to the camp leader." However, there was a distinct lack of engagement with the local or international news which created a silo effect on the population, notwithstanding their unfettered access to the internet. To many residents in Mae La, Facebook was the internet, and its ability to spread inaccurate information quickly worked against more formal information campaigns from the government or international organizations. Without a clear picture of all available facts concerning the evolving peace 
process in Myanmar, Thailand's stance on legalizing migrant workers or the status of humanitarian funding for the camps, people relied heavily on their social networks to form opinions concerning repatriation. More often than not, the social networks amongst the Karen perpetuated the reported barriers to repatriation and rarely offered any nuanced debate surrounding negotiations, the reasons why funding was decreasing or how the community might leverage existing laws or policies to achieve common goals. Rather, rallying the population around the common themes of persecution and deservingness of humanitarian aid overshadowed any attempts at discourses aimed at practical solutions. In one of the most surprising conversations I had in Mae La, a refugee in her late twenties told me, “I remember being so surprised that we weren't the only refugees in the world. A Cambodian woman came to speak to us once at the school about her experience as a refugee, and I had never heard of these things before." Or in another conversation with a refugee in his mid-twenties, I was taken aback at his complete lack of awareness concerning the recent crisis in Syria, the influx of refugees in the Middle East and Europe and its effect on international humanitarian funding. Although he had access to the internet via smartphone, this news had never breached his silo of the camp. Subsequently, he had no basis to understand why international funding had been decreasing in Southeast Asia: "I don't know why they have forgotten about us. I think they just don't care about us Karen people anymore and don't want to give us anymore money."

Closely related to this reliance on social networks to inform decision-making was the third barrier I observed which was as an adoption of resistance narratives as a component of cultural and social identity. With a lack of the information required to form an independent opinion, people often align with the interests and perspectives of social 
groups they identify with. In early social identity theory, it is argued that any perceived lack of conformity to group norms is seen as a threat to the legitimacy of the group (Hogg and Turner, 1987). In this manner, not only is participation in a resistance narrative key to maintaining ones social identity as a Karen refugee in exile, but openly accepting repatriation may be seen as delegitimizing the greater effort of the Karen community to advocate for a safe and dignified return. Additionally, in chapter four I discussed how the introduction of Christianity to the Karen impacted cultural narratives of exile and persecution (see pages 93-94 in relation to descriptions of the Karen as Israelites), sometimes going as far as linking the Karen fate to refugeehood. In this way, voluntarily repatriating would also disrupt a key component of one's cultural identity as being oppressed. In the confines of Mae La camp, these cultural identities of oppression and persecution were constructed and made visible in such a permanent way that their dismantling would require the creation of an entirely new identity.

The final barrier to repatriation I observed was simply that the experience of living in a protracted refugee situation informed people's perception on the reality of the camp actually closing. As one man in his late fifties explained, "Every couple years we hear this word 'repatriation' and they say that Thailand will close the camps. But it never happens. So I don't pay much attention to these things." Indeed, in the year since my fieldwork concluded, the situation in Myanmar has declined and the optimism has faded from the announcements concerning UNHCR's voluntary repatriation program. While funding continues to decrease, it is becoming clearer that a combined approach to implementing durable solutions must be undertaken. 


\subsection{Conclusion - An Impossible Choice}

Colson (2003) wrote that in the last several decades anthropologists have created an ethnographic base large enough that we ought to be able to generalize about likely consequences of forced uprooting and resettlement, while recognizing that human beings are creative and can come up with surprising, never before imagined, solutions. And indeed there is much literature that deals with many of the challenges faced by the Karen and the subsequent consequences for their persecution and protracted situation in exile. Furthermore, over the past three decades myriad solutions and their various components have been discussed ad nauseam by international actors, western academics and wellmeaning policy analysts who possess no actual framework for implementation. Rather the stasis felt by the refugees trapped in Mae La is mirrored by the political inertia that precludes its solution. But this motionlessness is confined within the barbed wire fences of the camp while the rapidly changing world outside has begun to exert pressure on its existence. Many Karen are facing a future where there is not enough international funding to support their survival in camp but there is also not enough international pressure to enact the changes needed in Myanmar for a safe return. Further, the challenges involved in advocating for legal status in Thailand are riddled with the bureaucratic and geo-political landmines that could derail future positive economic outcomes in the borderlands. The solutions will ultimately have to come from those who have been disenfranchised and their willingness to negotiate, leverage and compromise on a way forward. A passive voice will need to be replaced with an active one and the long process of redefining the story of the Karen must begin. 


\title{
Chapter 6 \\ BEYOND DURABLE SOLUTIONS: Rethinking Repatriation
}

\begin{abstract}
"We feel at home on our land, and we want to go back. But based on the current situation, it is not possible. It is not easy, we can't just go back to our enemy and surrender ourselves, surrender our everything. If we go back, there will be fighting. And if we win, we can reoccupy our land. But there are only 2 options, win or lose" Naw Hser Bo, 27
\end{abstract}

\subsection{Introduction}

The goal of refugee protection is quite simply to ensure the human rights of individuals are met when their state has failed them in this most basic of responsibilities. Thus, the notion of returning to one's country of origin after the bond between citizen and state has been so thoroughly broken is fraught with years of social, emotional and political turmoil. Hannah Arendt (1973) notably questioned in her reflections on totalitarianism how the universal rights of man could ever truly be upheld within the sovereignty of individual nation states. Those who work to resolve protracted refugee situations still struggle with this question as ensuring adequate protection in return is often impossible without legal mechanisms of enforcement. Thus the impetus to find new or alternative solutions for refugees who have spent decades in exile is growing as long-term encampment becomes more untenable.

In the previous chapter, UNHCR's three primary durable solutions were discussed in relation to the protracted refugee situation along the Thai-Myanmar border (see pg. 105- 
116). This chapter will offer a discussion of how durable solutions have evolved in response to protracted refugee situations as well as an examination of what has recently been termed the 'fourth durable solution'. Additionally, this chapter will offer a brief commentary on the rise of strategies that seek to promote self-reliance prior to return and how they may aid sustainable forms of repatriation. Finally, special consideration is paid to the notable emergence of a 'model village' to house returning refugees and IDPs in Myanmar in relation to its efficacy as a durable solution.

\subsection{Moving Beyond Three Durable Solutions}

In the aftermath of the Vietnam War, the exodus of hundreds of thousands of Indochinese refugees and Vietnamese "boat people" inundated the Southeast Asian countries of British Hong Kong, Malaysia, the Philippines, Indonesia, Singapore and Thailand. As a result, in July of 1979, the United Nations convened an international conference in Geneva confirming that "a grave crisis exists in Southeast Asia for hundreds of thousands of refugees"27. The outcome of the conference was an agreement that receiving countries would continue to provide temporary asylum, while Western countries would accelerate resettlement initiatives and Vietnam would move to a system of orderly departures rather than the ad hoc departures of "boat people". However, by the late 1980's, North America, Australia and Europe grew reluctant to maintain resettlement agreements and there was substantial pressure from the countries of first asylum to stop the flow of refugees. As such, in 1989 UNHCR enacted what is known as the Comprehensive Plan of

\footnotetext{
27 Quote attributed to High Commissioner Poul Hartling via UNHCR, 'Note by the High Commissioner for the Meeting on Refugees and Displaced Persons in Southeast Asia', 9 July 1979
} 
Action for Indochinese Refugees (CPA), which effectively marked one of the first attempts at offering a multi-dimensional approach to solving a protracted refugee crisis.

The CPA endeavored to reaffirm a commitment to the principle of first asylum, ensure the protection of refugees, and stop the outflow of persons leaving for reasons unrelated to the UN refugee definition. Notably, it also recognized that an important component for a comprehensive approach would be to include the active involvement of the country of origin (the Socialist Republic of Vietnam in this case) in order to address the root causes of refugee movements (Bronee, 1993). The CPA effectively halted prima facie refugee status for new arrivals, and instead offered a more thorough refugee status determination procedure that was enacted in conjunction with the repatriation of those deemed unqualified for international protection. The CPA was mostly seen as a success at the time. During the closing ceremony for Malaysia's last refugee camp in 1996, the head of the UNHCR steering committee remarked:

"There are few happy moments in the career of a refugee official, and this is one of them. The CPA has been a model for multilateral cooperation, built on the principles of international solidarity, burden-sharing and proper acceptance of responsibilities. Its purposes were to end the ongoing tragedy on the high seas and to preserve asylum while reducing incentives for further mass outflow. It has been successful." (Sergio de Mello, 1996)

The CPA was not without criticism however, and some suspected the screening procedures did not offer the benefit of the doubt to asylum seekers, as was the standard in customary international law. Aside from this, the consensus has generally been that the CPA is an example of how "interlocking commitments to asylum, resettlement and repatriation can promote regional cooperation in response to protracted refugee crises" (Robinson, 2004:319). In subsequent years, many of the policy documents released by UNHCR concerning protracted refugee situations have recommended an approach that blends the 
three classic durable solutions (voluntary repatriation, local integration in the country of asylum, and resettlement in a third country). More recently, they have also adopted a more comprehensive approach titled "Complimentary Pathways", which looks for solutions through different pathways such as those 'used to facilitate international mobility for education, work and family reunion' (UNHCR, 2016).

In spite of the general recognition of the efficacy of a blended approach, most solutions offered in regards to the protracted refugee situation along the Thai-Myanmar border still revolve around efforts towards voluntary repatriation. This is due in part to the termination of large-scale resettlement programs coupled with a low level of confidence in ever achieving significant rates of local integration in Thailand. Additionally, international humanitarian funding has slowly been shifting from the border into development projects inside Myanmar, further strengthening the message that return is the preferred outcome for international stakeholders.

\subsection{Labor Migration as the Fourth Durable Solution}

"If the Thai government said, those who have stayed here more than 15 years, they are qualified to remain and stay in Thailand. If they opened up this opportunity, maybe 75\% will remain. That's the truth."

$\sim$ Moo Beh, 39

The possibility of incorporating labor migration as an official component to voluntary repatriation programs started to gain traction during the repatriation of Afghan refugees from Pakistan and Iran in 2002 through 2009. The Afghan repatriation was significant in this regard as it represented refugees who were returning to a fragile country that was still emerging from a long-term conflict. Specifically, the remittances provided by 
Afghan refugees who were also working as labor migrants in Pakistan and Iran created 'an important source of economic capital for reconstruction, reducing dependency on international aid and contributing to the state's reconstruction' (UNHCR, 2003a; Monsutti, 2006; Tennant, 2008; Long 2009:14). In another example, Long (2009) has pointed out that practices of labor migration in fragile states such as Somalia have played a 'crucial role in sustaining economic survival in major segments of the country', with one-third of families receiving remittances estimated to bring in up to a billion dollars a year (as cited in Fagen 2006:15).

However, the concept of labor migration has not always been a natural fit for resolving protracted refugee situations. This is largely due to the vehement assertion by both practitioners and academics of forced migration, that refugees and migrants are two distinct categories of people. A salient example of this can be seen in the comments made by Erika Feller, the Director of the Department of International Protection at UNHCR in 2005, when she cautioned that it could be "dangerous and detrimental to refugee protection, to confuse the two groups, terminologically or otherwise"(Feller, 2005:27). The inclination to differentiate the two groups lies in the legal protections afforded only to the official categorization of 'refugee', namely in the principle of non-refoulement ${ }^{28}$. In this way, it has been argued that while regular migrant workers are usually expected to return to their country of origin, refugees may still be at risk and should not be expected to return

\footnotetext{
28 The principle of non-refoulement constitutes the cornerstone of international refugee protection. It is enshrined in Article 33 of the 1951 Convention, which is also binding on States Party to the 1967 Protocol. Article 33(1) of the 1951 Convention provides:

"No Contracting State shall expel or return ("refouler") a refugee in any manner whatsoever to the frontiers of territories where his [or her] life or freedom would be threatened on account of his [or her] race, religion, nationality, membership of a particular social group or political opinion."
} 
should their work come to an end (Moretti, 2015). Long (2013) provides an excellent analysis and historical contextualization of the separation between 'refugee' and 'migrant' that lends itself to the current discussion of refugee labor migration. She notes that refugees were essentially separated from migrants in the 1950's when they were provided with an exceptional right to cross borders and claim asylum. However, she argues that in creating a special route for admission deliberately set apart from migration, "the humanitarian discourse that protects refugees from harm actually prevents refugees from finding durable solutions, which depend upon securing an economic livelihood and not just receiving humanitarian assistance" (pg.4-5). Thus the housing of refugees as a separate population and their exclusion from the labor market exacerbates the protractedness of refugee situations.

By 2007, UNHCR was actively discussing the benefits of regularization of status in one's country of asylum, noting that people could develop skill sets, save money and provide support to families and communities back home by means of remittance transfers. They had also amended their formal position on labor migration as an effective compliment to voluntary repatriation, noting in their 10-Point Action Plan on Mixed Migration and Refugee Protection that "beyond the classic durable solutions, legal migration opportunities may open up a complementary avenue for some refugees" (Para. 7). Additionally, UNHCR recognized that when refugees engaged in the labor market abroad, they effectively reduced the competition for jobs and other scarce resources in their country of origin, indirectly contributing to the peace-building process. These changes in policy have come to represent a more progressive approach towards solving protracted refugee situations and have been mostly positive for the outlook on the Thai-Myanmar border. However, in order 
for refugee policy involving labor migration to succeed, the receiving country must be amenable to altering their foreign labor laws to allow for forced migrants. This has been difficult to achieve across the board, especially in relation to requiring identification and citizenship documents from a labor migrant's home country, something most refugees are unable or unwilling to obtain.

In Thailand alone, there have been seven regularization campaigns organized for labor migrants from Laos, Cambodia, or Myanmar between 2004 and 2018 (Moretti, 2015; CSEAS, 2018). This has resulted in the registration of 2.4 million migrant workers and incentivized employers to continue the effort. However, the trend towards the increased criminalization of irregular migrants in Thailand coupled with a policy that offers little to no path for stateless refugees to register is highly problematic. Additionally, the ability of the government to require that foreign workers live in fixed areas of the country creates a situation ripe for exploitation not dissimilar to the current context of illegal workers residing in camps or settlements.

In order for a "fourth solution" to offer a plausible resolution to the protracted refugee situation along the Thai-Myanmar border, three primary areas would need to be addressed. First, Thailand must amend its migration law, specifically the Alien Employment Act B.E. 25512 (AEA 2008), in relation to Nationality Verification (NV) requirements for the registration of labor migrants. Currently, the country of origin is obliged to process nationality verification and issue formal identification such as passports or other documents to irregular migrants. To accommodate those individuals unable to obtain nationality verification, such as stateless refugees, Thailand would need to accept UNHCR identity documents (or something similar) for registration in lieu of official documents 
from Myanmar. Secondly, Thailand has frequently raised concerns that a less burdensome registration policy for irregular migrants, such as one that allows exceptions for national identity verification, would create an overwhelming pull factor for new labor migrants into specific regions. In order to allay these fears, stricter refugee status determination procedure should be implemented by either the Thai Provincial Admissions Boards (PABs) or UNHCR that guarantees the validity of identification documents for refugees. Thirdly, Thailand must address the barriers migrant workers face in accessing social protection benefits to reduce further exploitation. Labor migration cannot be an effective strategy for resolving the protracted refugee crisis along the border if there are still substantial gaps in protections for workers. Human trafficking, low wages, and forced labor continue to be problems for many industries in Thailand including both the fishing and agricultural sectors. This area does appear to be progressing however; in November of 2017, both Prime Ministers from Thailand and Myanmar signed the ASEAN Consensus on the Protection and Promotion of the Rights of Migrant Workers and agreed to abide by its regulations. This is indeed a hopeful development and potential sign of a more orderly and effective transnational migration agreement for Thailand and Myanmar.

\subsection{Self-Reliance Pending Return}

The concept of self-reliance or 'standing on ones own two feet' was a topic that came up time and again in my conversations with Karen living inside Mae La camp. It was an issue that was deeply linked to notions of pride, self-worth and ancestral history. I frequently heard stories celebrating the resourcefulness of the Karen, often highlighting the parents or grandparents who had crossed mountains or survived in jungles for months or years on end. There were also first hand accounts of living through vicious fires and 
devastating cyclones, civil wars and the myriad internal struggles that come with them all. Embedded within each of those stories was a resoluteness of character and the possibility to overcome the deep unfairness that had colored many pages of the past. When conversations drifted to current circumstances, there was a noted desire to transcend what was perceived as the paternalistic structure currently governing their lives. "We are all treated like children here, having to ask permission for everything" one young woman remarked to me while holding her own child in the same moment. In another conversation, the inclination towards self-reliance was clear. "I think Thailand might let us stay here, even if there was no more funding. We already have a lot of shops and some people have been able to save up a lot of money. We could stay here on our own". In this way, incorporating strategies of self-reliance into the management of a protracted refugee situation are not only natural, but pragmatic as well.

In 2003, Jeff Crisp coined the term of 'self-reliance pending return' in a UNHCR policy paper aimed at solving the protracted refugee situations unfolding in Africa at the time. Under a section themed 'Exploring alternative solutions', Crisp argued that:

"The notion of 'self-reliance pending return' has advantages for all of the stakeholders in a protracted refugee situation. It would improve the quality of life for refugees, giving them a new degree of dignity and security. It would enable refugees to make a contribution to the economy of the host country and thereby make their presence a boon, rather than a burden, to the local population. And it would enable UNHCR, its donors and implementing partners to withdraw from costly and complicated 'care-and-maintenance' programmes, which only enable refugees to survive at the level of basic subsistence." (p.26)

While mostly unclear on the specifics of what such a policy to promote self-reliance would actually look like, the argument generally centered on the restoration of the rights and 
security to which refugees are entitled under international law ${ }^{29}$. Additionally, promoting self-reliance would mean providing access to education, work or income-generating activities, start-up funding and other forms of financial capital as well as a long-term commitment from host countries. The problem however, is that many refugee-hosting countries currently do not support such initiatives, due in part to the fear that refugees might become too comfortable, and thus never leave. In Crisp's initial plea for policies aimed at self-reliance, he pointed to the case of Ukwimi camp for Mozambican refugees in Zambia. In this instance, research was able to show (Lin, 2001) that when refugees were able to attain a high degree of self-reliance in the camp, they returned to their own country almost immediately, once it became safe to do so. Thus the argument can be made that "refugees who have led a productive life in exile, received an education, developed practical skills, and accumulated some resources may actually be better prepared and equipped to go home and contribute to the reconstruction of their country than those who have languished in camps for years, surviving on minimal levels of humanitarian assistance" (Crisp:2003:26).

Unfortunately it has taken more than a decade for the argument of self-reliance to take root in refugee policy and we are just now beginning to see examples in practice. One such example is that of Kenya's Kalobeyei settlement. Kenya, a country that has hosted refugees from Somalia and South Sudan since the early 1990's, is now leading the way in reconceptualizing how to resolve protracted refugee situations. The Kalobeyei settlement was essentially created from scratch in 2015 through a joint endeavor of UNHCR and

\footnotetext{
${ }^{29}$ For a comprehensive overview of these rights, see the UN High Commissioner for Refugees (UNHCR), Agenda for Protection, October 2003, Third edition, available at: https://www.refworld.org/docid/4714a1bf2.html
} 
Kenya's Turkana County Government with the goal of supporting refugee self-reliance and greater refugee-host interaction. The settlement was designed like a city rather than a refugee camp, which meant including things like a market and shared public services for refugees and the indigenous Turkana hosts. Additionally, levels of food security were raised as the incorporation of a form of cash assistance, called Bamba Chakula ("get your food" in Swahili) and allocated plots of land for subsistence agriculture were implemented (Betts and Collier, 2018). In December of 2018, in collaboration with the World Bank, UNHCR has also developed the Kalobeyei Integrated Social and Economic Development Programme (KISEDP), which they describe as a multi-agency collaboration to develop the local economy and service delivery at Kalobeyei. The significance of this approach cannot be overstated and its potential to affect refugee policy in other regions is substantial. As described by UNHCR:

"This represents a major paradigm shift. The overall objective of this initiative is to re-orient the refugee assistance program to contribute to improvement of the socio-economic conditions of the refugees and host communities, better prepare the host community to take advantage of emerging economic opportunities in upcoming extraction and potential irrigation-fed agriculture and reduce over-dependence on humanitarian aid and support the refugees to achieve durable solutions." (in Kalobeyei Strategic Overview, 2018)

Research is ongoing into the efficacy of the Kalobeyei model and it may be several years before its success or failure as a durable solution can be measured. However, Kalobeyei's mere existence speaks to the emerging will of both host governments and international humanitarian agencies to try new approaches for old problems. This in itself is a hopeful development for those who have been wedged within the same set of problems for many years on the Thai-Myanmar border. 


\subsection{The Case of Lay Kay Kaw}

In early 2011, Thein Sein, Myanmar's first non-interim civilian president in 49 years began to launch the peace process that would eventually lead to the historic (although now somewhat beleaguered) Nationwide Ceasefire Agreement of 2015. As part of this initiative, President Thein Sein released a new "Roadmap for Peace" which heavily pushed the concept of peace through development. The reception was mixed as many of the armed ethnic groups, including the armed wing of the KNU, were extremely skeptical of development projects. Over the past several decades, projects sold as "development" were seen as actually just ways in which the Burmese military executed land grabs and maintained control over ethnic regions. KNU vice-chair Naw Zipporah Sein summed up this position when she was quoted in July of 2011 as saying to Karen News, "the new Burma military government uses development as a weapon to destroy and wipe out the resistance groups and to persuade ethnic groups to forget about their struggle." In spite of this, whispers of a curious new development project began to surface and within 4 years, the first tidy rows of concrete homes began to appear in Southeastern Myanmar.

Lay Kay Kaw, as the new settlement came to be called, was initially billed as a 'model village' to accommodate internally displaced Karen and refugees returning to Karen State. The project began with the support of the Nippon Foundation, a privately held Japanese non-profit, with an interesting history of its own. The Foundation's mission is to direct Japanese motorboat racing revenue into philanthropic work, which it has successfully done for almost six decades. Among an impressive portfolio of humanitarian endeavors ranging from eradicating leprosy to traffic safety education, the Nippon 
Foundation worked in the early 1990's to build model retirement homes for the elderly in Japan. Thirty years later they found themselves building model villages in Myanmar in addition to hundreds of schools across Myanmar and Cambodia.

The existence of the project at all is something of a marvel, as an agreement had to first be reached between the former warring factions of the Tatmadaw and the KNU as well as the central government of Myanmar. This detail was not lost on many Karen, and the KNU chairman himself remarked at the project launch "We have fought, we have killed each other. We have seen them burn our houses and take our land ... So it is very difficult for us to trust the Burmese." Still, a 'water under the bridge' attitude seemed to prevail and the project, which promised to build 1,250 houses in 24 project sites, along with wells, health clinics and schools, officially got the green light.

In June of 2013, the economic committee of the KNU formed the Thoolei Company Ltd, and was subsequently awarded a contract to implement the Lay Kay Kaw New Town project in June of 2014. The total project, located nine miles south of the border town of Myawaddy, was spread out over a five-year development period with 10 million dollars in funding. Oversight was given to the newly formed Lay Kay Kaw rehabilitation committee and as of today, approximately 600 homes have been built with 3,200 IDPs, former refugees and family members of the KNU residing in the settlement. 


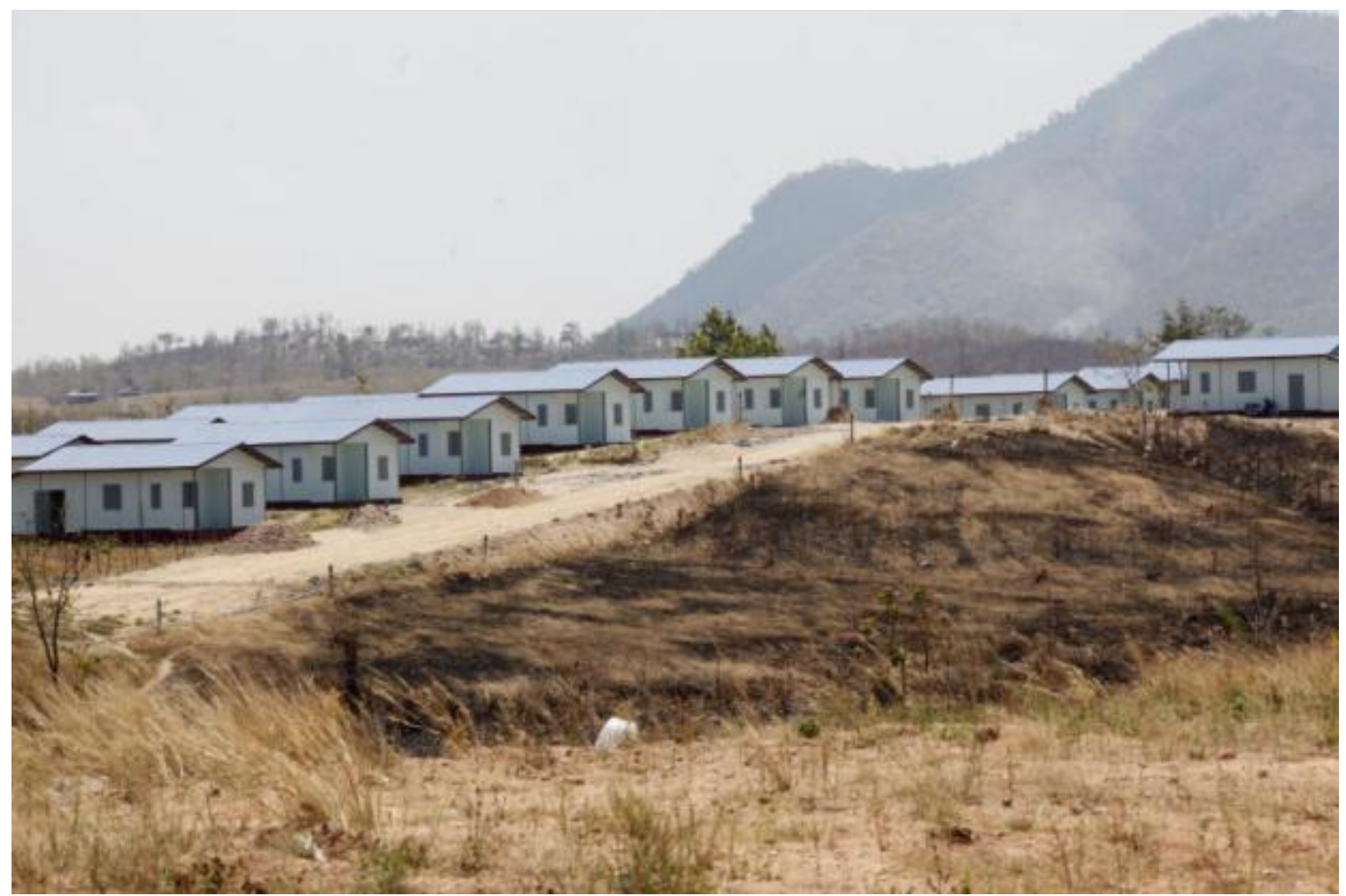

Photo 2 -Lay Kay Kaw Village, Kawkareik Township, Southeastern Myanmar; Source: Pattarapong Chatpattarasill, Bangkok Post, April 2017

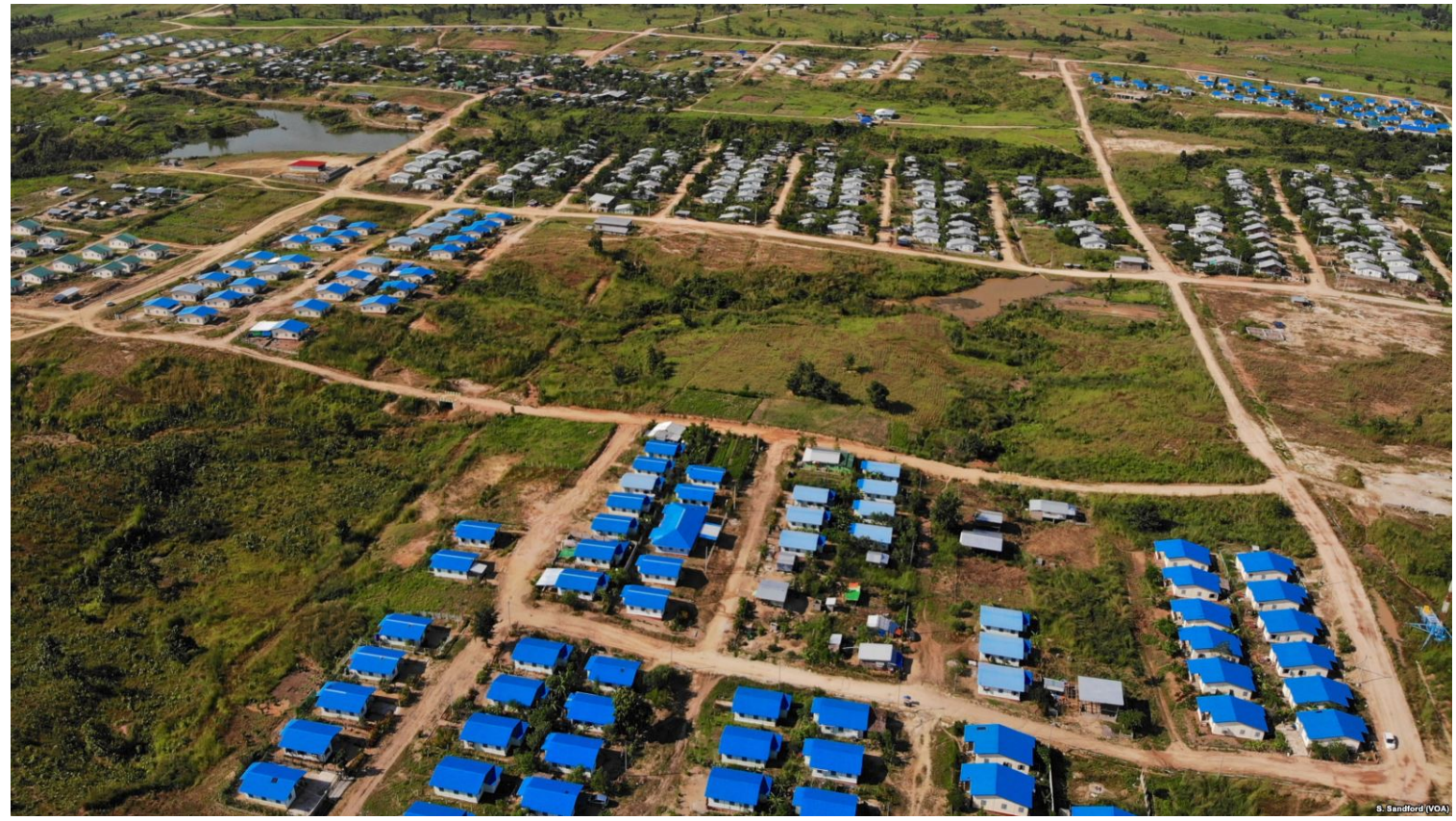

Photo 3 -An overview of Lay Kay Kaw as seen from footage shot by drone.

Source: Steve Sanford, VOA, November, 2018 
Results so far have been mixed as water shortages, a lack of electricity and little to no job prospects have created tension among the residents. Additionally, the mostly barren landscape that Lay Kay Kaw was built on holds little promise for the type of long-term sustainable agriculture that would be needed to support the entire population. However, discussions involving improvements in 2019 such as the installation of solar energy and the construction of a new water pond are currently underway. The Nippon Foundation has also begun to implement several "make-work" projects at Lay Kay Kaw, including an attempted agricultural center and other job training programs.

Perhaps the real strength of Lay Kay Kaw though is in its potential to stabilize the region. A sustained partnership between former enemies would go a long way toward rebuilding trust amongst the Karen. Bradley (2013) and Long (2013) have both argued that for repatriation to be successful, the bond between refugee and the state must be restored. Hargrave (2014) has reasoned that trust is the primary driver for restoring this bond, and that repatriation policy and related preparedness and integration efforts should be viewed through a "trust-based lens". This entails opportunities for refugees to participate in their own repatriation planning and being granted control of governance over their communities once returned. In this way, a KNU managed Lay Kay Kaw can potentially facilitate the sort of trust building between the KNU and the Tatmadaw that will be necessary to maintain the peace process. While it is clear that a great deal of work remains to be done, how the Lay Kay Kaw experiment unfolds will offer a unique insight into how matters of place-making, self-governance and reconciliation intersect with voluntary repatriation. 


\subsection{Conclusion}

Far removed from the breathless coverage of an emergent refugee crisis, sit those who have waited in protracted refugee situations for years and sometimes decades of their lives. Fading in and out of the public discourse with sporadic headlines urging readers to remember the victims of a forgotten civil war, they bide their time and contemplate the future. It's within these lengthy periods of time that return is both conceptualized and reimagined by those who were forced to flee, and ultimately must come to terms with what living a life in exile means. Often the problems that led to their flight are complex in ways that preclude a tidy resolution by way of a packaged "durable solution". Rather, resolution is messy and the realities of being stateless in a foreign country force many to rethink what repatriation actually means.

Repatriation in itself is an abstract concept, one of political ideology that promises to reunite the citizen with the state that betrayed them. In practice, simply returning to one's country of birth does nothing to "repatriate" the individual to a homeland that is often vastly different than the one they left. As Hammond described, "Many returnees...do not see the object of repatriation as the 'rebuilding' or 'reconstruction' of their lives. Likewise, they often do not aspire to reclothe themselves in the culture of the past or to rejoin the community that they left" (1999:235). Rather for many refugees who have forged new ties in their country of asylum or resettled to third countries, ideas of what constitutes a homeland have become linked to the places that offer a sense of belonging. Nothing so clearly illustrated this multidimensional sense of home as the description given to me by a young woman who had recently returned to visit Mae La camp after spending twelve years in Canada: 
"I do feel like Mae La camp is my home. But I was born in Burma, although I didn't live there for a long time, only 7 or 8 years, I felt like that is my home too. But I haven't been back. So yes, Mae La camp is home but we have no legal papers. So becoming a Canadian was my first citizenship ever. Because I am now a Canadian, I feel like Canada is also my home."

Thus, repatriation is as much about recreating a bond between a citizen and the state as it is about creating a sense of belonging and social inclusion. As Edward Said argued, "As any displaced and dispossessed person can testify, there is no such thing as a genuine, uncomplicated return to one's home" (Said 1999, as cited in Oxfeld and Long 2004:15). In this way, for repatriation to truly work as a resolution for a protracted refugee situation, multiple avenues of return have to exist. Avenues not only created in linear trajectories towards the homeland, but also those paths that may weave around or join up with other routes. We have started to see some of these alternative approaches emerge, and indeed models such as Kenya's Kalobeyei settlement offer glimpses of what a smarter more dignified methodology might entail. Additionally, rethinking the role of labor migration in the plight of the stateless may have substantial implications for not only eradicating the confinement of refugee camps, but also for demonstrating how neighboring countries can help rebuild and lift up marginalized communities. For the Karen in Mae La camp, the road to repatriation must offer not only reconciliation, but also recognition of what they have lost. The restoration of rights must include a way to regain control of ancestral lands as well as opportunities to become self-sufficient, which also means the right to choose where to live and work. For many, true freedom is born in self-reliance and sustained return will be impossible without efforts that encourage it. 


\section{Chapter 7}

\section{CONCLUSIONS: Protracted Sanctuary}

\subsection{Introduction}

It was during my third month living inside Mae La when Khu Htoo and I arranged to visit the small care villa set up in camp that assisted the survivors of landmine accidents. On a sweltering August afternoon we made our way over to the open-air building that operated as a dormitory for those who were disabled and had no means of family support. The care villa was situated atop a small hill, with open doors revealing a simple concrete floor and a row of beds on each side. A faded blue sign greeted us, which hung in front of two lines of laundry that neatly flanked the path between the beds. We were there to interview Saw Ehmoo, a 27-year-old former KNLA soldier who had lost his sight and both hands in a landmine accident 8 years prior. The main room was quiet apart from the normal sounds drifting in from camp and the soft whirring of a small plastic fan in the corner.

We greeted Saw Ehmoo and moved into the open space at the front of the building where we proceeded to talk for the next hour and a half. As Saw Ehmoo told his story I noted the quiet distinctions he made between 'before' and 'after' the accident that had so profoundly changed his life. He spoke about his time as a soldier with the KNLA and how it was the KNU that had arranged his transport to Mae La after the accident, noting it was the 
only place he could receive care. He explained that with little to do over the past several years he had become an avid radio listener of the BBC world service, picking up both Thai and Burmese broadcasts along the border. The inflection in his voice changed when he began to speak about cross-border politics or the government in Myanmar, becoming louder and more confident in tone. He offered a nuanced view on the efficacy of the ongoing National Ceasefire Agreement, lamenting the fact that the military still retained 25 percent of seats in parliament, effectively making it impossible to amend the constitution without their support. Speaking on the topic of reconciliation he argued, "For the peace process to work, the military, not just the government, needs to meet with the ethnic groups. It was the military that came to our villages and burned our homes and killed our families. They need to show us that they want peace. It means nothing if only the government does this". His comments spoke to a recognition of the importance of holding people accountable in some way for their actions in order for a nation to heal. They reminded me of the Indonesian anti-communist purge of 1965-1966, when those who committed genocide remained in power, while living side by side with the families of those they murdered. In situations such as those, peace becomes superficial until there is an acknowledgment of what others have lost. Or as in the case of post-apartheid South Africa, when the first Truth and Reconciliation Commission allowed a country to bear witness to the human rights abuses perpetuated over four decades. 


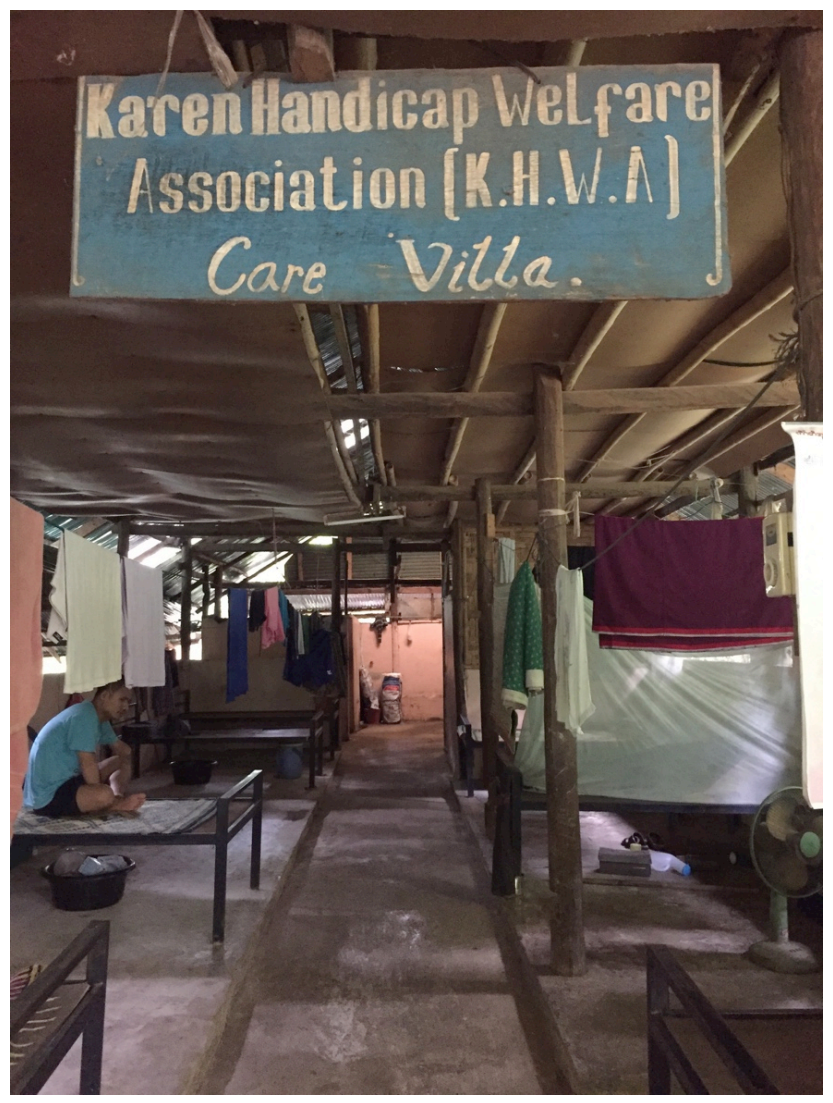

Photo 4 - Care Villa for Landmine Survivors, Mae La Refugee Camp, Thailand (Source: Carrie Perkins, 2017)

It struck me during this time how valuable Saw Ehmoo's contribution to the peace process negotiations in Myanmar would be. Although still a young man, he had now spent years thinking deeply about the conflict--about what he had lost personally, but also what the Karen had lost and how they might regain it. To me it was quite clear what Myanmar had lost as I listened to Saw Ehmoo speak. They had lost an entire generation whose potential had languished inside refugee camps instead of thriving in universities and cities and communities. When I inquired about the availability of prosthetic limbs to perhaps help regain any functionality, Saw Ehmoo noted that because of his blindness it had not been attempted. He reasoned that even if there were available prosthetics, he would not be able to fit them himself or have an opportunity to see a therapist. Instead he said, "There are so 
many things I want for my life, but because of my physical body, the disability, I can never reach them". I sat in that moment surrounded by the deep unfairness that so matter-offactly had been laid before me. Landmines still litter 9 of Myanmar's 14 states and regions and the government and military have yet to sign a Mine Ban Treaty. While I have seen news of hospitals in Jordan and Lebanon testing the use of 3D-printed prosthetic limbs to treat Syrian refugees, it all seems very far away from a sparse Care Villa sitting in a 33 year old refugee camp. Rather for Saw Ehmoo, his options are severely limited by his disability and the dependence on foreign aid that ensures his care. Without a mechanism to receive official refugee status or a path to regularization in Thailand, he joins one of the most vulnerable populations in Mae La. It is this type of tragedy --the loss of potential and selfdetermination-- that truly characterizes a protracted refugee situation. While solutions exist, it is the process of creating the political will to enact them that remains a challenge. In the following concluding remarks I will address the contribution of my research to the anthropology of forced migration. Additionally, I will also offer some ideas, within the framework of applied anthropology, about how we might rethink repatriation in the context of the protracted refugee situation along the Thai-Myanmar border.

\subsection{Scholarly Contributions}

In a broad view, this dissertation contributes theoretically to work in the anthropology of forced migration that is concerned with refugee repatriation and experiences of exile. However, in a more narrow sense it expands research dedicated to understanding the link between waiting and resistance specifically in the context of a protracted refugee situation. Located within domains of migration, anthropology and the study of temporalities, I demonstrate in Chapter Four how work in the area of waiting has 
primarily focused on those within broader marginalized contexts such as prisoners, economic migrants and their families, the unemployed or underemployed or the homeless (Harms, 2010; Brettell, 1986; Kwon, 2015; Main, 2007; Jeffrey 2008, 2010; O’Neill, 2014). There is a limited amount of research that has peripherally mentioned the experience of waiting in refugee camps as an experience of being stuck in limbo or liminal spaces (Bousquet 1987; Hitchcox 1990, 1993; Huseby-Darvas, 1994; Reynell 1989). There has been even less work that has focused on waiting in the context of protracted refugee situations, such as with Palestinians (Peteet, 1991, 1995, 2005, 2015; Gren, 2002.).

In this way, this dissertation expands its analysis to focus on refugees specifically waiting within the confines of a camp in one of the most protracted refugee situations of record. Additionally, this work considers the unique context of the shifting relationship between Myanmar and Thailand, the presence of an impending voluntary repatriation program as well as Thailand's willingness to regularize labor migrants. In light of these factors, I have demonstrated in Chapters Four and Five that the introduction of facilitated return has transformed the act of waiting into an active form of resistance. For example, in Mae La repatriation was resisted by choosing to wait for a job, a third country resettlement (pg. 89), or for the situation to improve in Burma (pgs. 72, 84, 91, 102, 120). Additionally, those who had spent decades in the camp exerted their agency by simply staying put (pg. 90) or ignoring the information about repatriation (pg. 133). Expanding the conceptualization of 'waiting as resistance' in the context of protracted refugee situations is vital both to furthering the discourse in refugee studies as well as to ensuring the principles of voluntary repatriation are respected in policy development.

Another primary contribution of this study is to highlight the voices of refugees that 
challenge us to rethink repatriation in terms of the circularity of forced migration. While much of research in forced migration has looked at repatriation as a process of homecoming, where linear trajectories flow in a single direction toward one's country of birth, I have shown in Chapters Five and Six that this does not accurately reflect the feelings of many Karen in Mae La. Rather, the story of 'Kawthoolei' has become the narrative of a homeland that is "constructed, imagined, and contested in the context of displacement and political exile in the margin of two other nations" (Horstmann, 2011:86). Thus a return to the 'homeland' is more about regaining independence and freedom than occupying a specific physical territory. In this way, many Karen voiced their preference to stay in Thailand (pg. 120, 138, 143) in order to obtain economic self-sufficiency and the freedom of movement. In the following section I will discuss how these empirical findings translate into applied contributions of this work.

\subsection{Applied Contributions: Towards Protracted Sanctuary}

Many anthropologists who work on forced migration place importance on how their research can inform policy while also giving voice to those who may have been excluded from the bureaucratic conversations that structure their time in exile. As Dawn Chatty

(2014) has argued, anthropological engagement with forced migration has created:

"...a body of work that has helped maintain a balance between state-centric work in politics, international relations, and law with a continuing interest in the refugees and forced migrants themselves [...] the primacy of the vision of anthropology has been the perspective and voice of the forced migrant, the phenomenological encounter that permits the uprooted, the displaced, and the refugee to break out from the category of 'object of study' and to bring to life the individual experience of dispossession." (p. 83)

Colson (2003) provides another, perhaps more pragmatic answer in her assertion that,

"Since anyone, including social scientists, may be uprooted, we want to know what to 
expect and how one learns to live with the uncertainties, the loss of trust, and the indignities that [forced migrants] are experiencing and surviving" (p.4).

However, the task of translating anthropological research into a tangible outcome can become complicated as ethical considerations arise concerning issues of objectivity and the role of advocacy. Applied anthropology provides a basis in which to weigh these considerations, by offering a framework to balance the core principle of "Do No Harm ${ }^{30 "}$ with the responsibility that many feel to give back to the communities in which they conduct research. In their aptly named paper Beyond 'Do No Harm', Mackenzie et al. (2007) argue that, "In our view, it is unethical for researchers merely to document the difficulties of refugees and their causes without, whenever possible, offering in return some kind of reciprocal benefit that may assist them in dealing with these difficulties and, where possible, in working towards solutions (p. 310)". I tend to agree with this position and indeed, my past work in applied anthropology has often colored the lens in which I view what my own research may offer.

In this way, I recognize that how Thailand will ultimately resolve the protracted refugee situation along it's Western border with Myanmar will have long lasting implications for global refugee policy. Throughout the course of this study and with the benefit of many conversations with refugees and other stakeholders, I have often thought about how the situation could move toward resolution. Thailand has a unique opportunity

\footnotetext{
30 The American Anthropological Association Code of Ethics (2012) describes the fundamental principle of "Do No Harm" as "It is imperative that, before any anthropological work be undertaken each researcher think through the possible ways that the research might cause harm. Among the most serious harms that anthropologists should seek to avoid are harm to dignity, and to bodily and material well-being, especially when research is conducted among vulnerable populations. Anthropologists should not only avoid causing direct and immediate harm but also should weigh carefully the potential consequences and inadvertent impacts of their work."
} 
to demonstrate the power of transforming a perceived burden into an economic benefit while also maintaining a commitment to humanitarian principles.

In light of Thailand's growing support for regularizing labor migrants, I argue that it would be an ideal time to introduce a new solution for refugees who have lived in Thailand for extended periods of time. Within this vein and building upon the ideas discussed in Chapter 6 surrounding self-reliance pending return, I would suggest a hypothetical new category of status termed "Protracted Sanctuary Status" (PSS) for those living as refugees along the border. The framework for such a status would be similar to that of a "Temporary Protected Status" (TPS) in the United States, which provides freedom of movement and work rights for foreign nationals already in the United States from countries experiencing armed conflict, natural disaster, or other extraordinary circumstances that prevent their safe return. As Jill Wilson noted in her recent analysis of TPS for the members of congress, "TPS is a blanket form of humanitarian relief. It is the statutory embodiment of safe haven for foreign nationals within the United States who may not meet the legal definition of refugee or asylee but are nonetheless fleeing—or reluctant to return to—potentially dangerous situations" (2018:2).

There are a few key differences that I imagine would exist between the TPS model and the proposed PSS model (see table 5 below). I offer an example here of a potential solution as a tangible recommendation and outcome of my engagement with the subject. While implementing regularized labor migration as a component of a durable solution is crucial, so too is ensuring adequate protection while acknowledging resistance to return. A policy that combines these elements within a recognizable framework may effectively offer a way in which protracted refugee situations can move from camps to communities. 


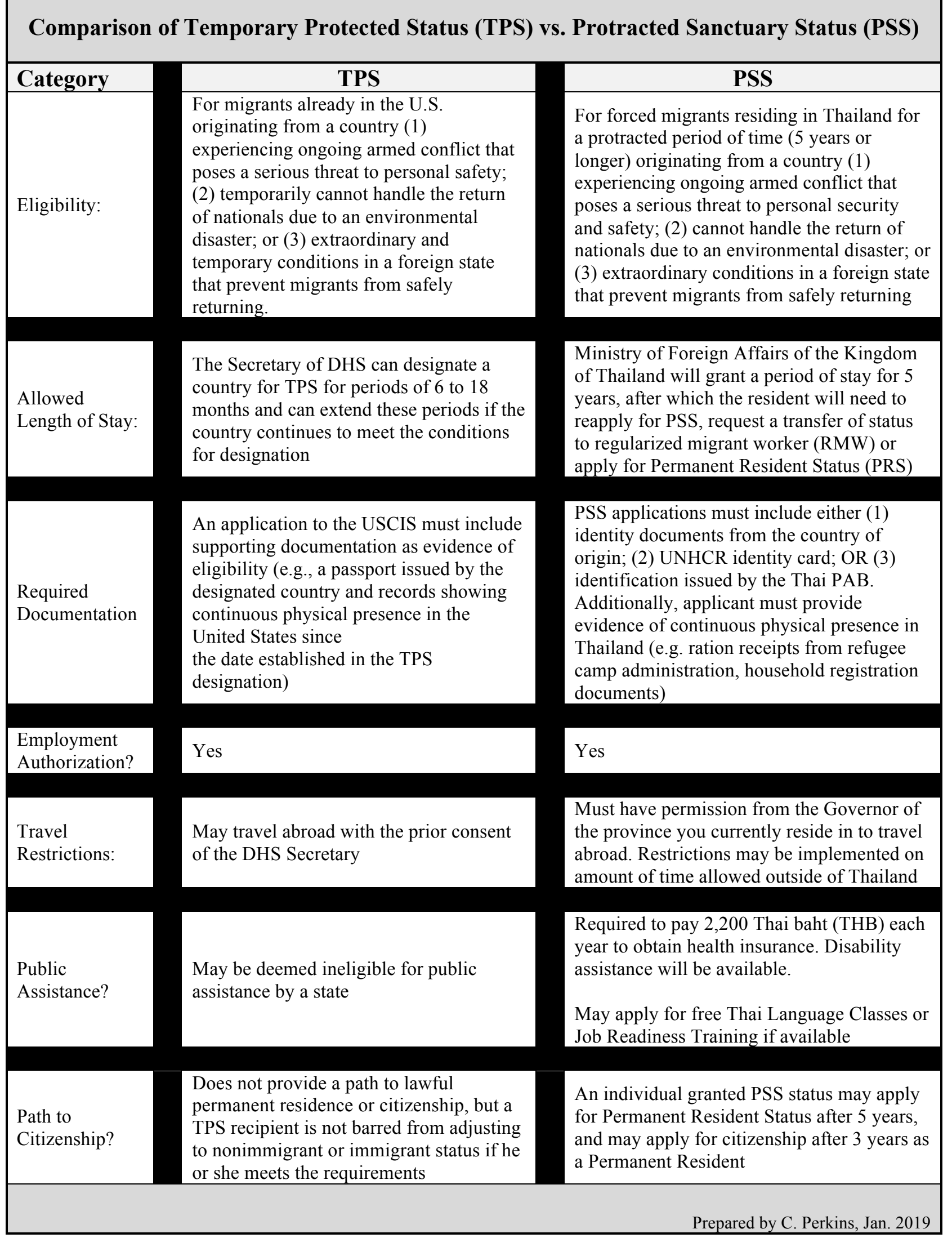

Table 5: Protected Status (TPS) vs. Protracted Sanctuary Status (PSS). (Source: Carrie Perkins, 2019) 


\subsection{Final Remarks and Recommendations for Future Research}

In the year following the completion of fieldwork, there have been some notable developments along the border. Unfortunately, most prominent among these developments is the resurgence of fighting in the ethnic regions of Myanmar. Starting in January of 2018 there were several reported clashes between the Tatmadaw and ethnic armed groups occurring in Shan, Karen and Kachin states. A report from the Institute of Peace and Conflict Studies stated that:

"Overall, there were 17 broad instances and at least 60 micro incidents of violence between January-May 2018, and only eight visible instances of dialogue (albeit without settlement) between core negotiating parties. The pattern-some emergent and others a continuation of the past-reflect the complex escalation dynamics in Myanmar's protracted civil war." (Choudhury 2018:1)

Further, in March of 2018, violence erupted in Karen State's Hpapun district, ultimately leading to the killing of local humanitarian aid worker Saw 0 Moo by the Tatmadaw. Saw 0 Moo's death was widely criticized by both local and international aid organizations and was seen as a gross violation of the NCA Code of Conduct and International Human Rights law. In October of 2018, the KNU announced its temporary suspension from peace process negotiations amid dissatisfaction over recent high-level talks between the government, Tatmadaw and signatories of the Nationwide Ceasefire Agreement (NCA). They made their position official on January $3^{\text {rd }}$ of 2019 stating that they believed the talks no longer focused on the principles of equality, self-determination, democracy and federalism or implementing the issues agreed to in the NCA. While they have agreed to continue to try and find a solution through informal meetings with the Myanmar government and military officials, the formal withdrawal from the process is highly problematic. As Choudhury 
noted back in June of 2018, "The KNU is the most powerful and influential of all NCA signatories, and therefore a crucial dialogue partner for Naypyitaw. A fallout with the group would reverse all positive gains painstakingly accrued over the past five years in this sensitive ethnic state and more importantly, damage the NCA's credibility as an instrument of reconciliation" (2018:2).

It is against this background that I place my suggestions for future research. As the protracted nature of the conflict in Myanmar continues to preclude a substantial or sustained voluntary repatriation effort, anthropology will have a role to play in understanding how to best implement a solution that is both human-centered and effective. As anthropology has become more politically engaged ${ }^{31}$, there is a wider body of literature to pull from in which to understand best practices of policy implementation. Additionally, the growth of virtual and digital anthropology have transformed cyberspace into a field site where one can observe how national and transnational communities connect, organize and shape social narratives. Within this context, the research contained in this dissertation would be best built upon by asking questions such as: "How is political will generated in Thailand in the context of offering protection for refugees?" or "How are public perceptions shaped in Thailand by the discourse surrounding refugees and migrants from Myanmar?" and "How do policies towards refugees in Thailand impact local integration as a durable solution to protracted refugee situations?"

Only through continuous and proactive engagement will the resolution of a protracted refugee situation ever be achieved in a way that ensures the security and dignity

\footnotetext{
31 See Setha Low and Sally Engle Merry's 2010 edited volume of Current Anthropology on 'Engaged Anthropology: Diversity and Dilemmas' for an excellent overview of the growing interest in engaged political anthropology
} 
of those who are displaced. By nature, protracted refugee situations fall to the wayside, to the back burners of international consciousness while our attention is given to what is directly in front of us. Donor fatigue and the slow decline of public support over decades can effectively create impossible choices for those who are not afforded a way to earn an income in their country of asylum. Thus simply rejecting repatriation is only the first step in asserting the agency that is required to advocate for better solutions. Solutions that reject narratives that paint refugees as mere passive recipients of aid, and instead offer routes to self-sufficiency and freedom. 


\section{APPENDIX}

\subsection{UNHCR Documents}

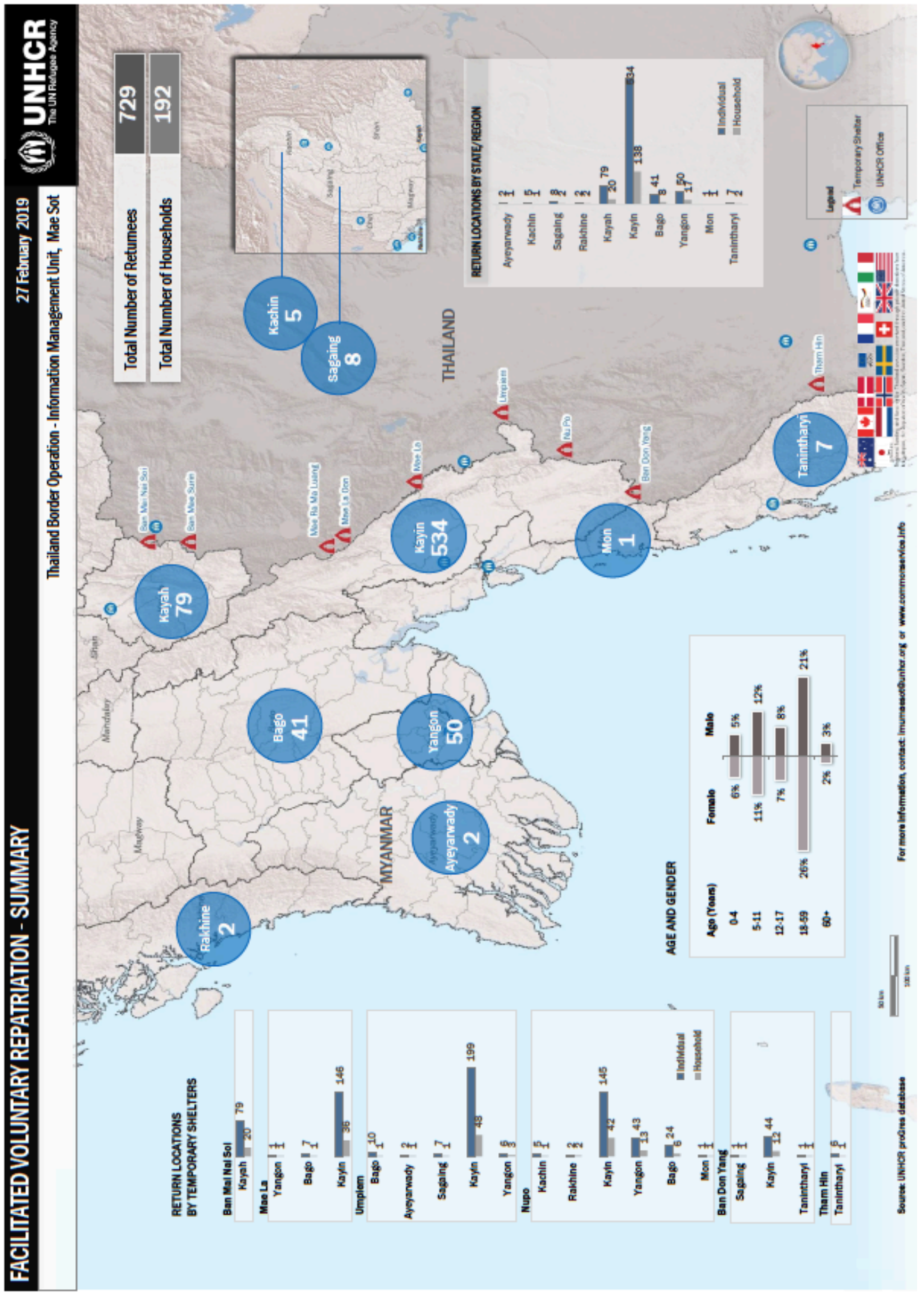




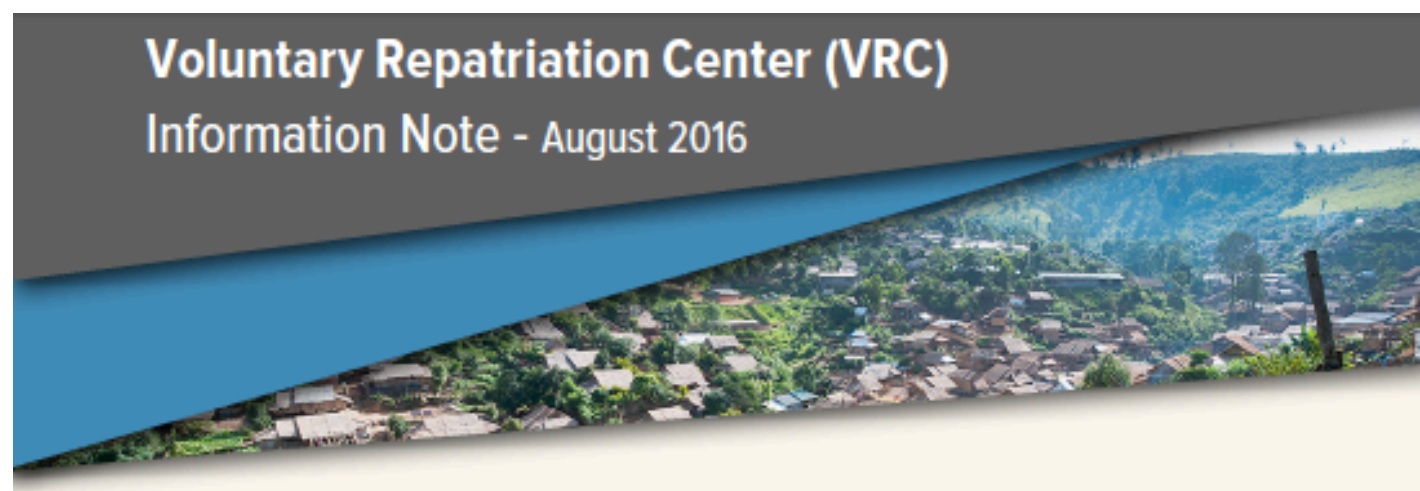

The Voluntary Repatrlation Center (VRC) is a faclity where repatrlation-related activities will be conducted for refugees who are interested in returning home. The VRC will be established in each of the nine camps.

\section{WHICH ACTIVITIES WILL TAKE PLACE AT THE VRCs?}

ition Voluntary Repatriation Protection Counseling UNHCR will conduct counseling for any refugees that approach UNHCR and who want to return to Myanmar. The counseling will Include discussion on the voluntariness of return and conditions in the areas of return.

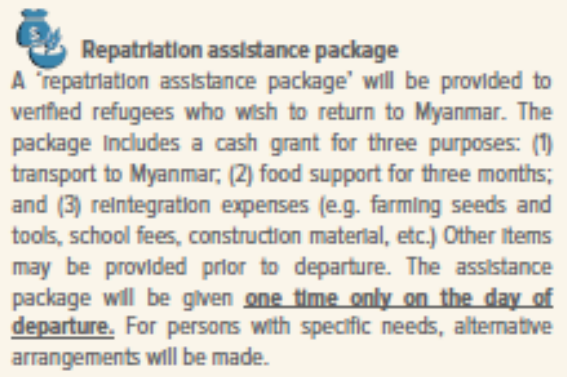

\section{Mine awareness pre-departure session}

Mine Risk Education sessions on how to recognize landmines and explosive remnants of war and how to prevent related accldents will be conducted by Handicap International.

\section{(1) Information-sharing}

Information will be avallable on issues related to conditions In the areas of retum, such as Ilvelihood opportunities, education and health services, clMl documentation, etc. The VRCs will be a place where NGOs and CBOs can also provide information that will help refugees prepare for return.

\section{WHO WILL BE PRESENT AT VRCs?}

UNHCR, IOM, Hl and the Royal Thal Government. NGOs or CBOs that wish to share Information about voluntary retum can also use the VRC.

\section{WHEN IS THE VRCS OPEN?}

The VRCs can be used by the refugees at any time during the week. The hours of operation and schedule of actlivitles will be posted on the notice board in front of the VRC and at the UNHCR work station in all nine camps.

NOTE: Return to Myanmar is an Individual decision and UNHCR will only support repatriation that is voluntary, safe and digniffed. All services at the VPCs are free of charge.

If rou have any questlons, please contact: UNHCR in the camps or IOM Operation Unit Office at +66 55039809 Ext. 9522

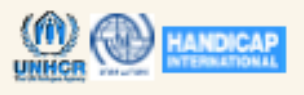




\section{(i) Assistance for Verified Refugees Returning uNHCR to Myanmar through Facilitated Voluntary Repatriation}

A pockage of assistance will be provided to MOI-UNHCR verifled refugees (Indlviduols and familles) who are voluntarily returning to Myanmar through the foclitated Voluntory Repatriation Operation that is supported by the Royal Thal Government and the Government of Myanmar.

The assistance will Include the following components:

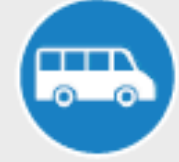

2

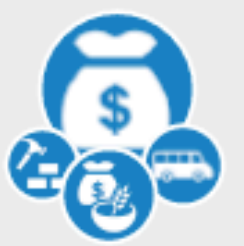

3
Transportation:

- From the camp up untll the border: transportation will be provided by UNHCR Thalland (through IOM).

Cash assistance (through IOM on the day of departure):

- Transport grant from the border-crossing point to the finol destination in Myanmar): THB 1,800 per person

- Reintegration grant: THB 5,400 per adult and THB 3,600 per child

- Food support grant (cash equivalent to 6 months' food, funded by World Food Program): THB 2,100 per person

\section{- IOIAL: THB 9,300 per adult and THB 7,500 per child}

In-kind assistance from UNHCR (through IOM prior to departure):

- Mosquilto net (1 net per 2 persons)

- Sonitary ket (1 per woman)

- Travel bag (1 per household)

- Document folder (1 per adult) 


\section{PROCESS OF FACILITATED VOLUNTARY REPATRIATION}

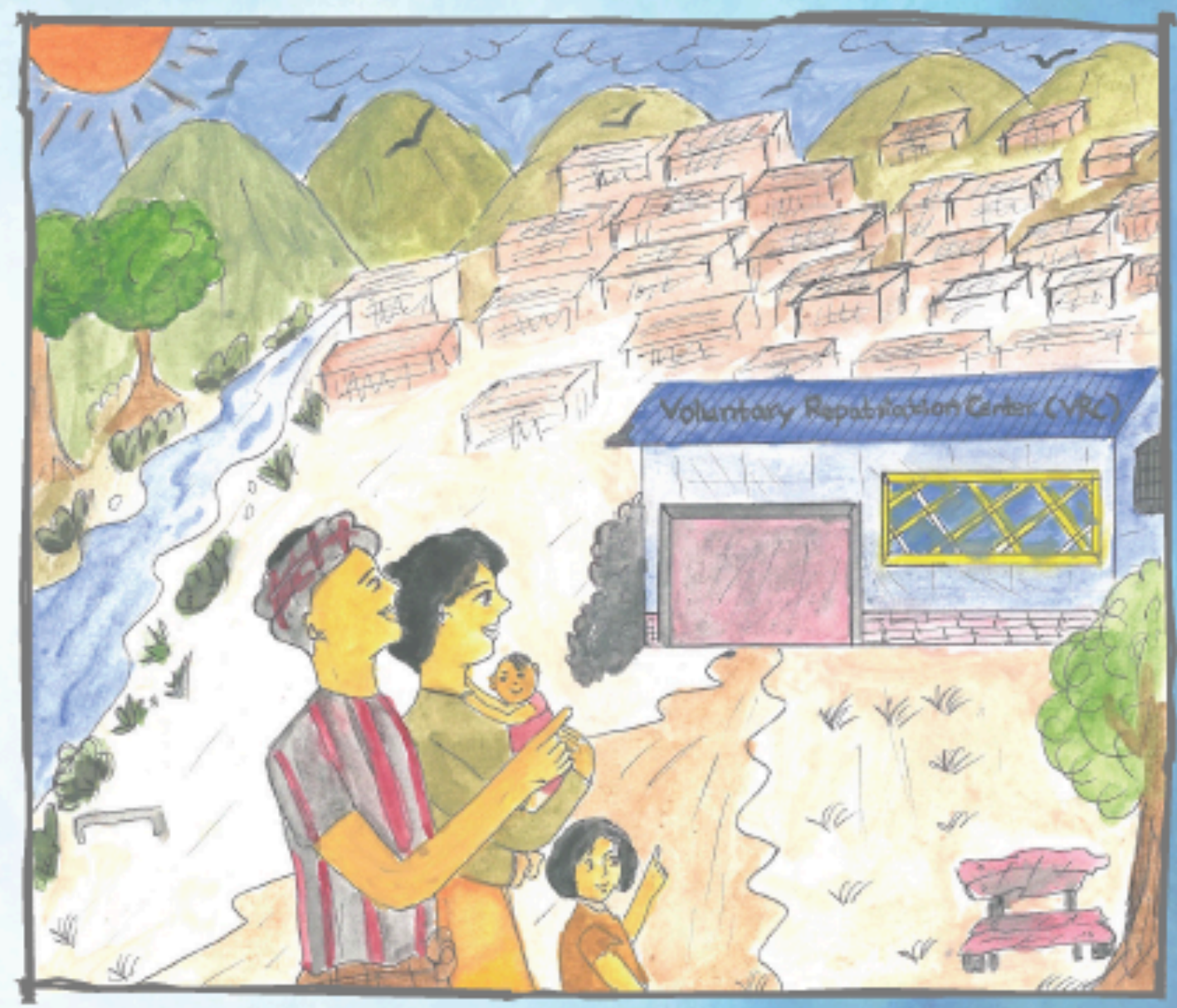

(i⿱宀)

UNHICR 


\section{Protection Counseling}

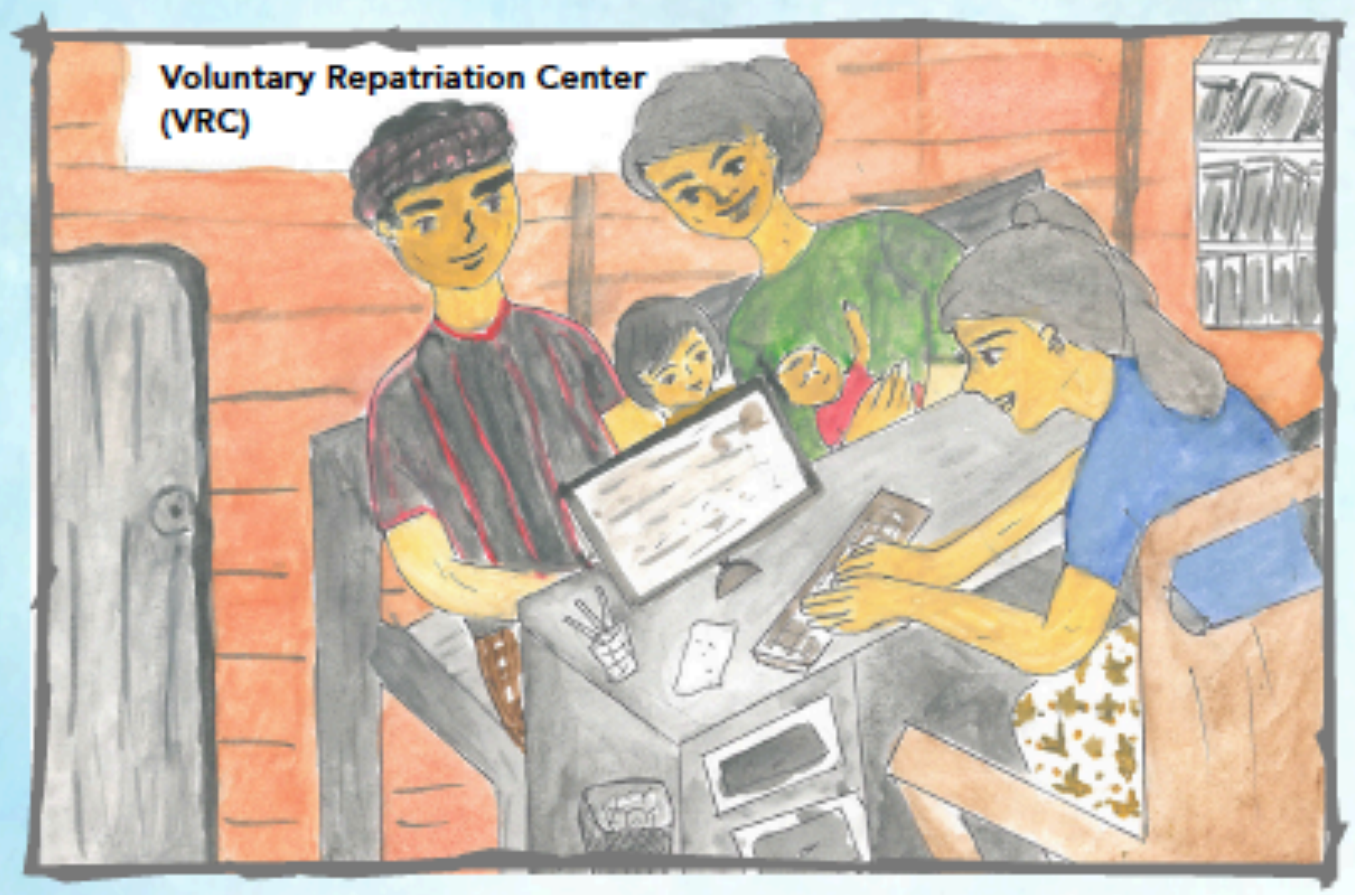

Please make sure that all family members are present and please show your VE card and Household Registration Document (HHRD) to UNHCR. UNHCR protection staff will ask questions about your family and information on the place of return. If any member of your family has specific needs, e.g. disability, serious illnesses, or other conditions that would cause difficulties in traveling back, please inform UNHCR. Those with chronic medical conditions will be asked to consult the relevant health agency in the camp. Each returning household will sign a Voluntary Repatriation Form (VRF) to confirm their voluntariness to return. 


\section{Myanmar "Green Light"}

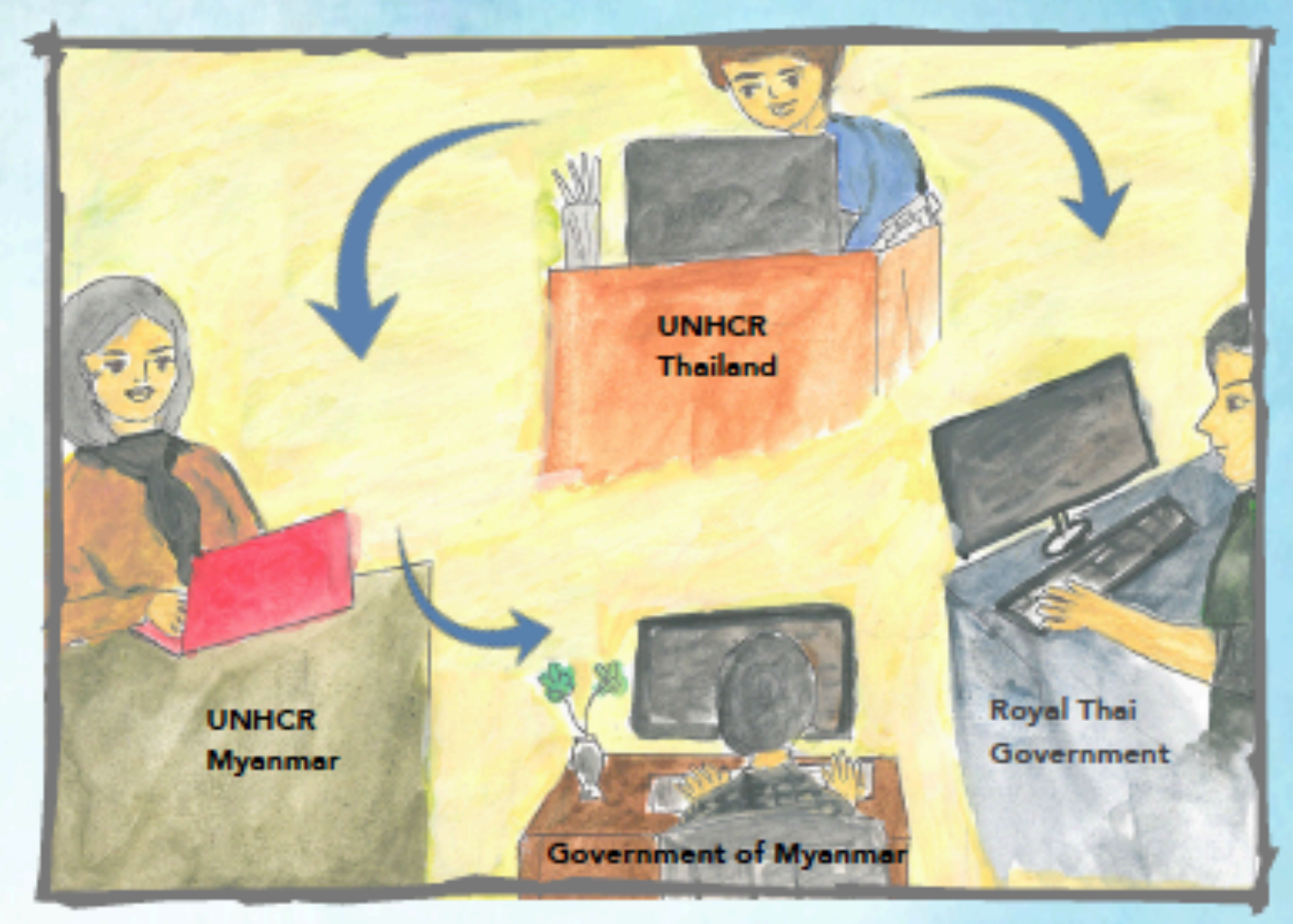

Your information will be shared with the Royal Thai Government, UNHCR Myanmar and the Government of Myanmar to check local conditions. UNHCR will be informed when the "green light" (clearance) is received. The Government of Myanmar may issue a travel document to help facilitate the return process. 


\section{Reconfirm Your Decision}

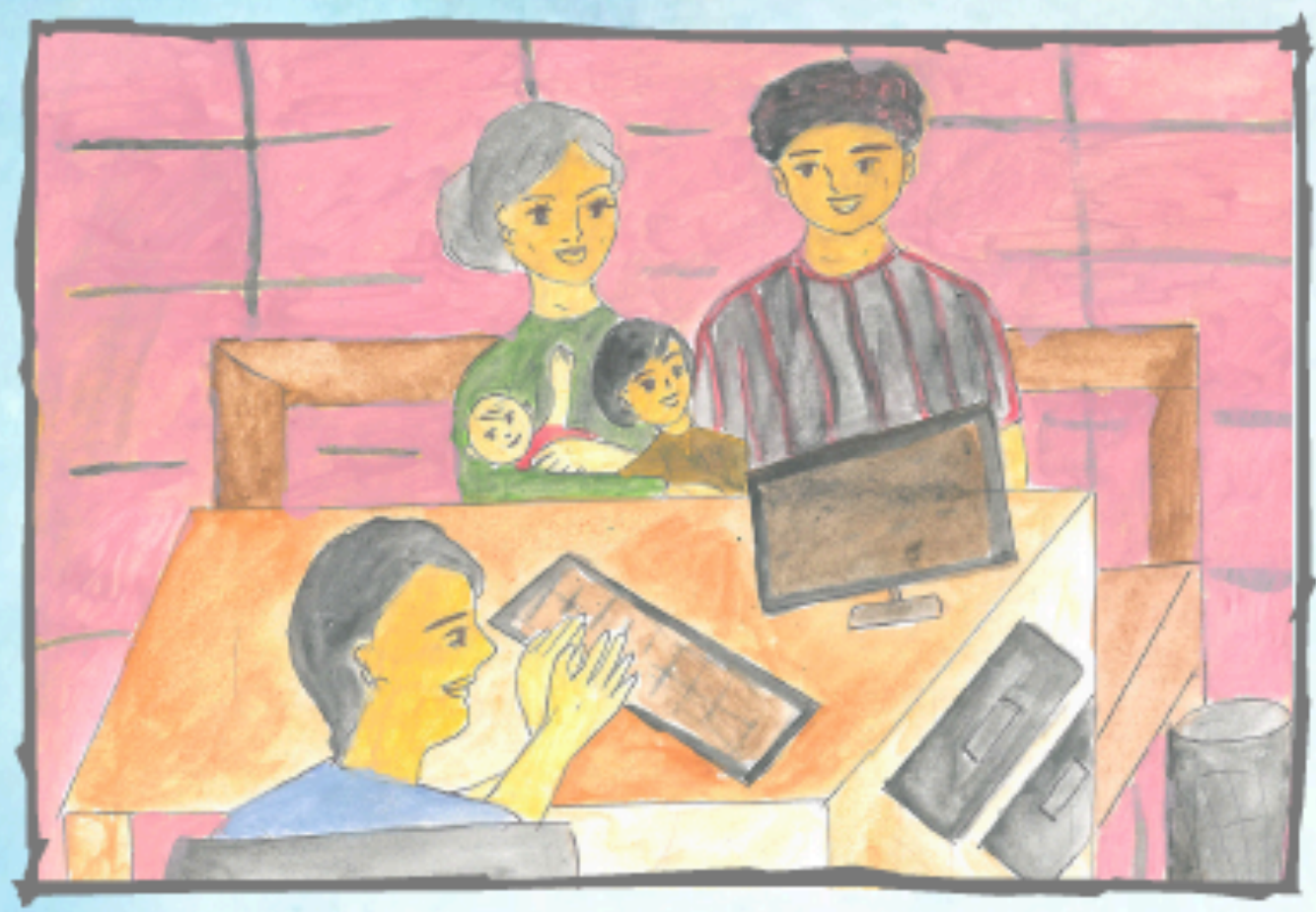

You will be contacted by UNHCR to inform you of the clearance from the Government of Myanmar and to reconfirm your voluntary decision to return. Your departure date will be agreed upon together with RTG (Palad), IOM and UNHCR. UNHCR will share any further details available regarding conditions in your area of return. You will be encouraged to collect any education/training certificates and health records that you might need before returning. 


\section{UNHCR Informs Partners}

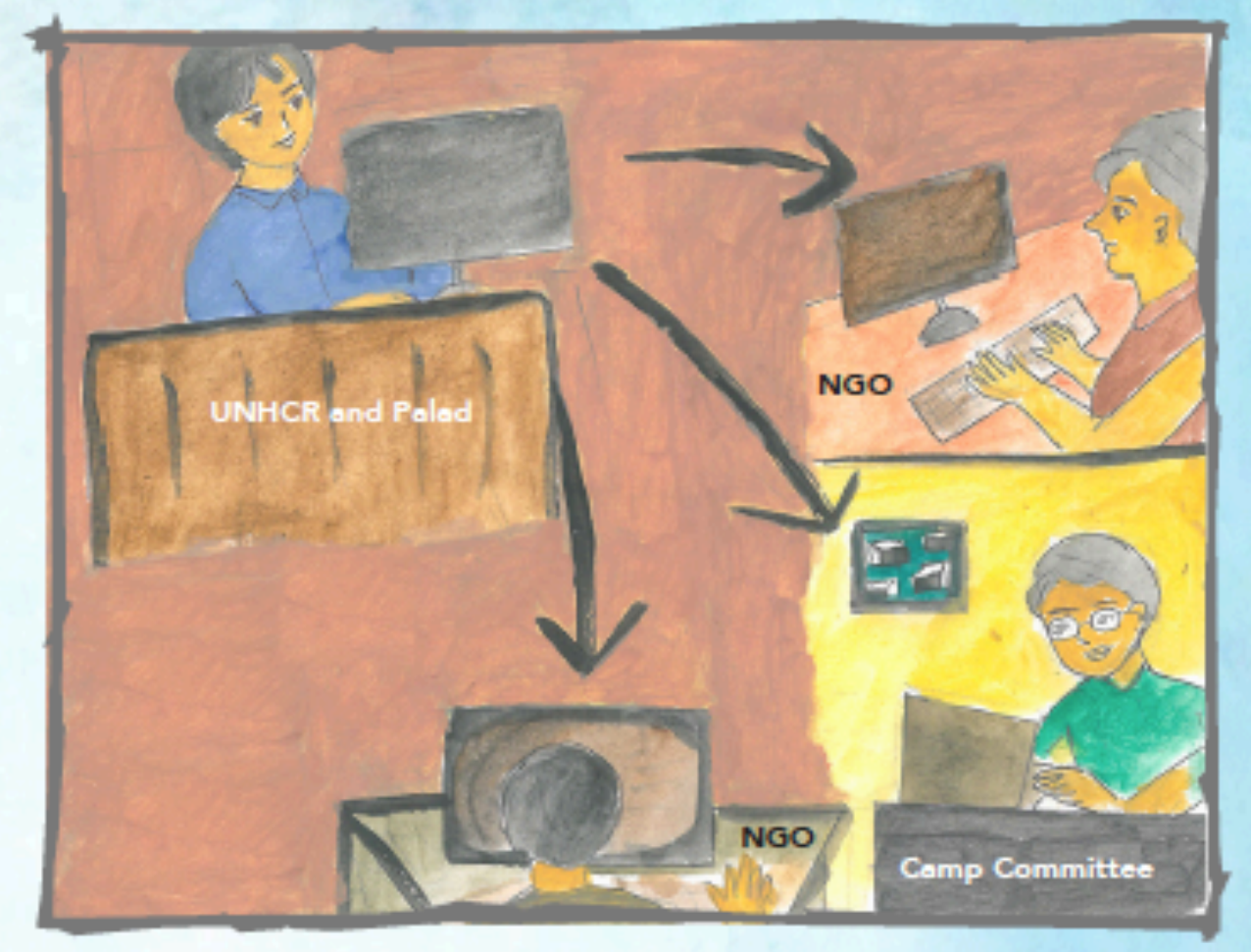

UNHCR and the RTG (Palad) inform the Camp Committee and concerned NGOs for preparations for your return. 


\section{Mine-Risk Awareness and Other Information Sessions}

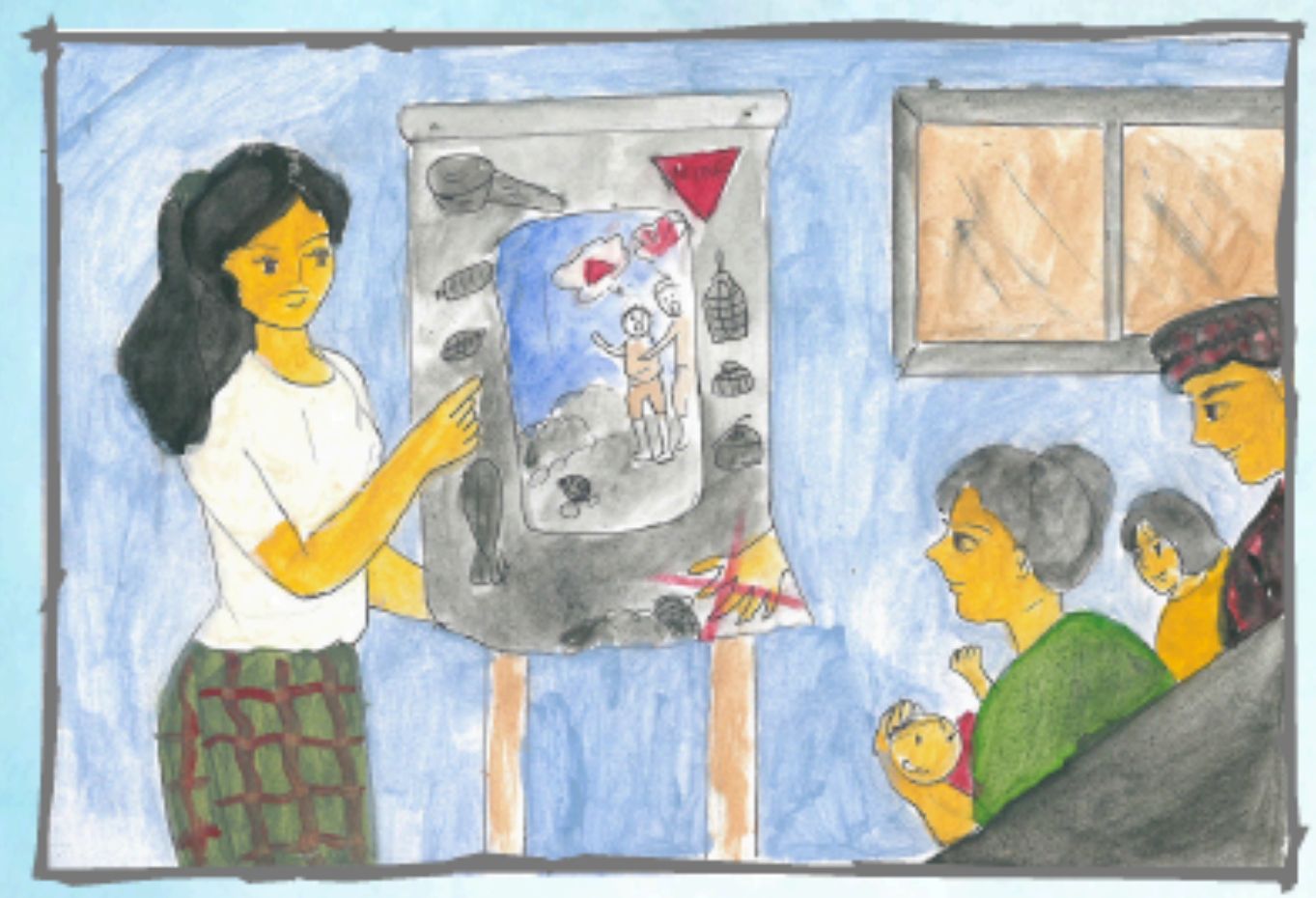

A mine-risk awareness session will be organized by Humanity \& Inclusion at the VRC, and other information sessions may be offered to help you prepare for return. 


\section{Before Departure}

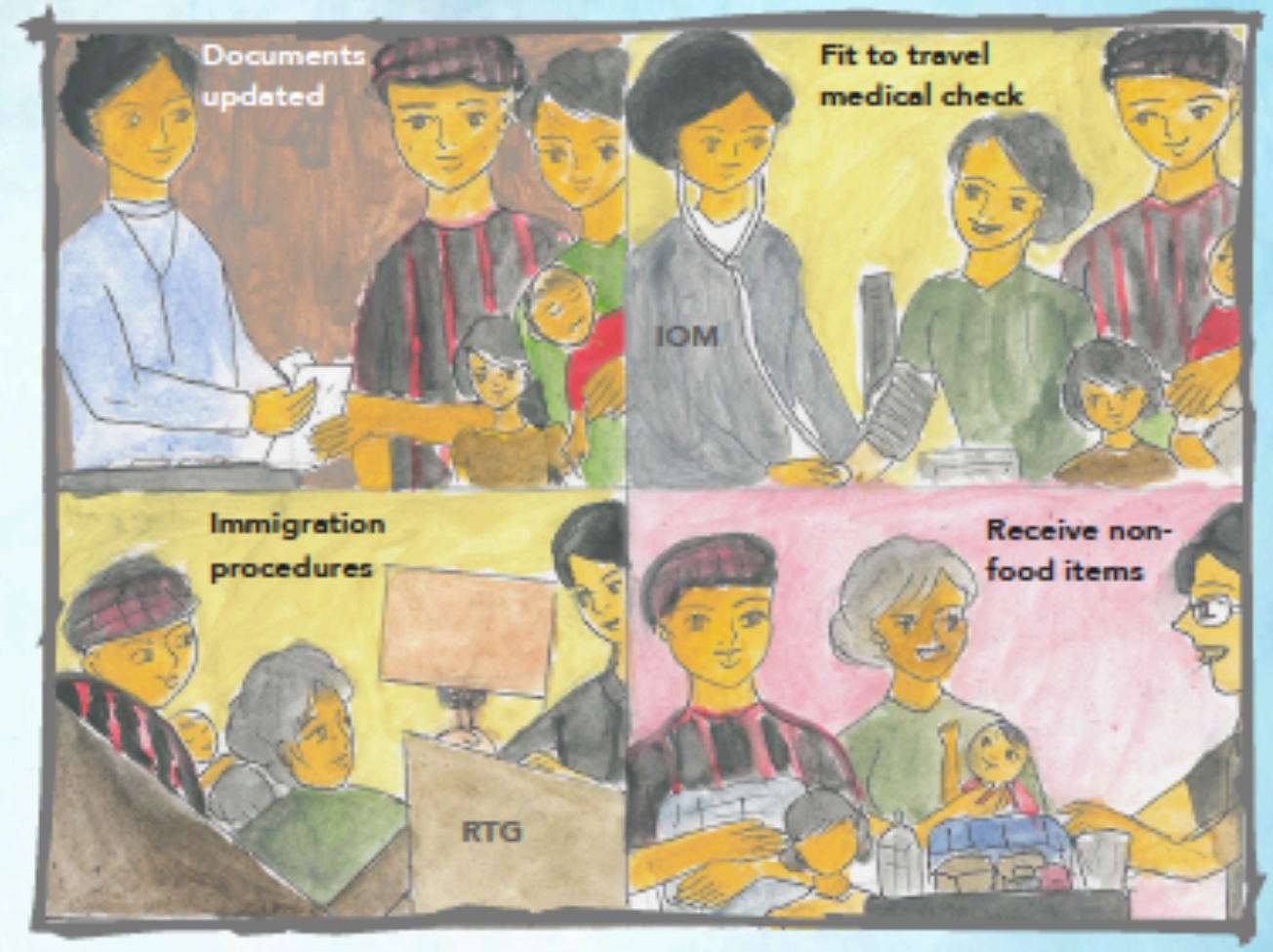

The day before return to Myanmar, you will be asked to come to the Voluntary Repatriation Center (VRC) to have your documents (VE card, HHRD) updated by UNHCR; undergo a "fit to travel" medical check by IOM; undergo RTG immigration procedures, and collect non-food items such as mosquito nets and sanitary kits for women. 


\section{Day of Departure}

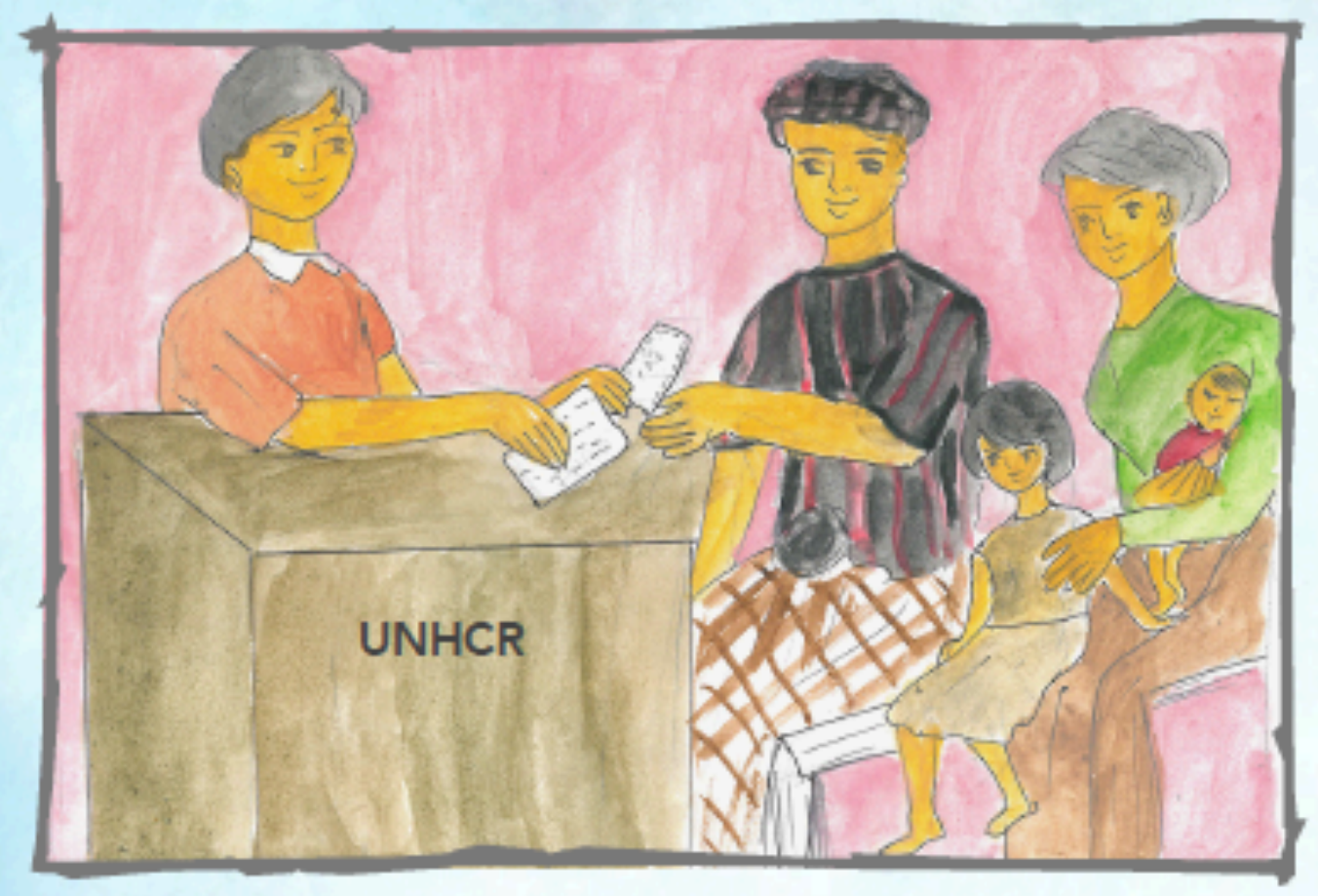

On the day of departure, UNHCR will issue 5 copies of the Voluntary Repatriation Form (VRF): 1 for you to travel with; 2 for UNHCR; 1 for IOM, and 1 for RTG (Palad). IOM will then take a copy of the VRF and provide you with the cash assistance package. RTG (Palad) will also take a copy of the VRF and confirm your departure from the camp. 


\section{Departure}

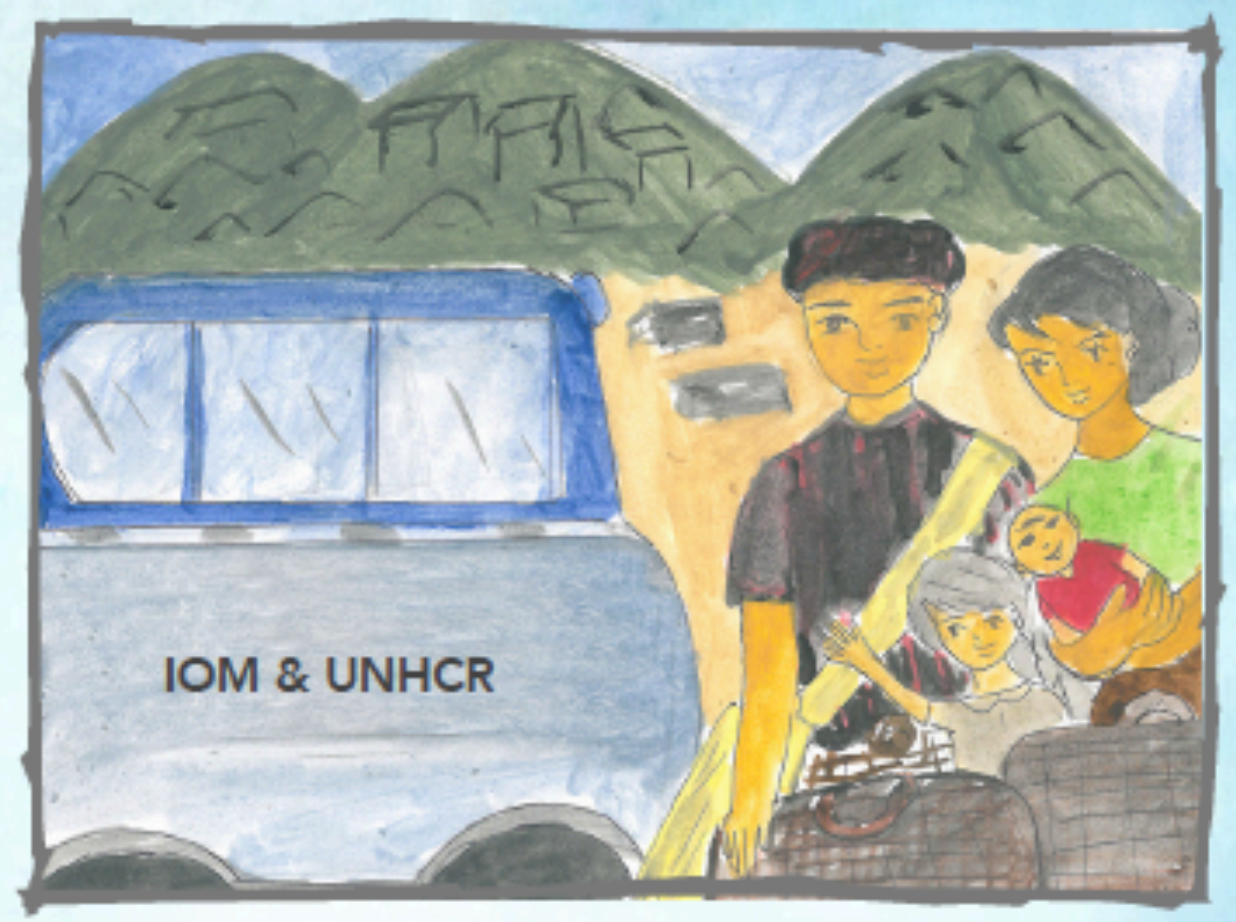

After you have gone through these steps, you are ready to leave the camp with transport organized by IOM. Please keep all of your documents secure (VE card, HHRD, VRF, education/ health certificates, etc.) as you may need them during your journey and/or when you are back home in Myanmar. 


\section{De-registration}

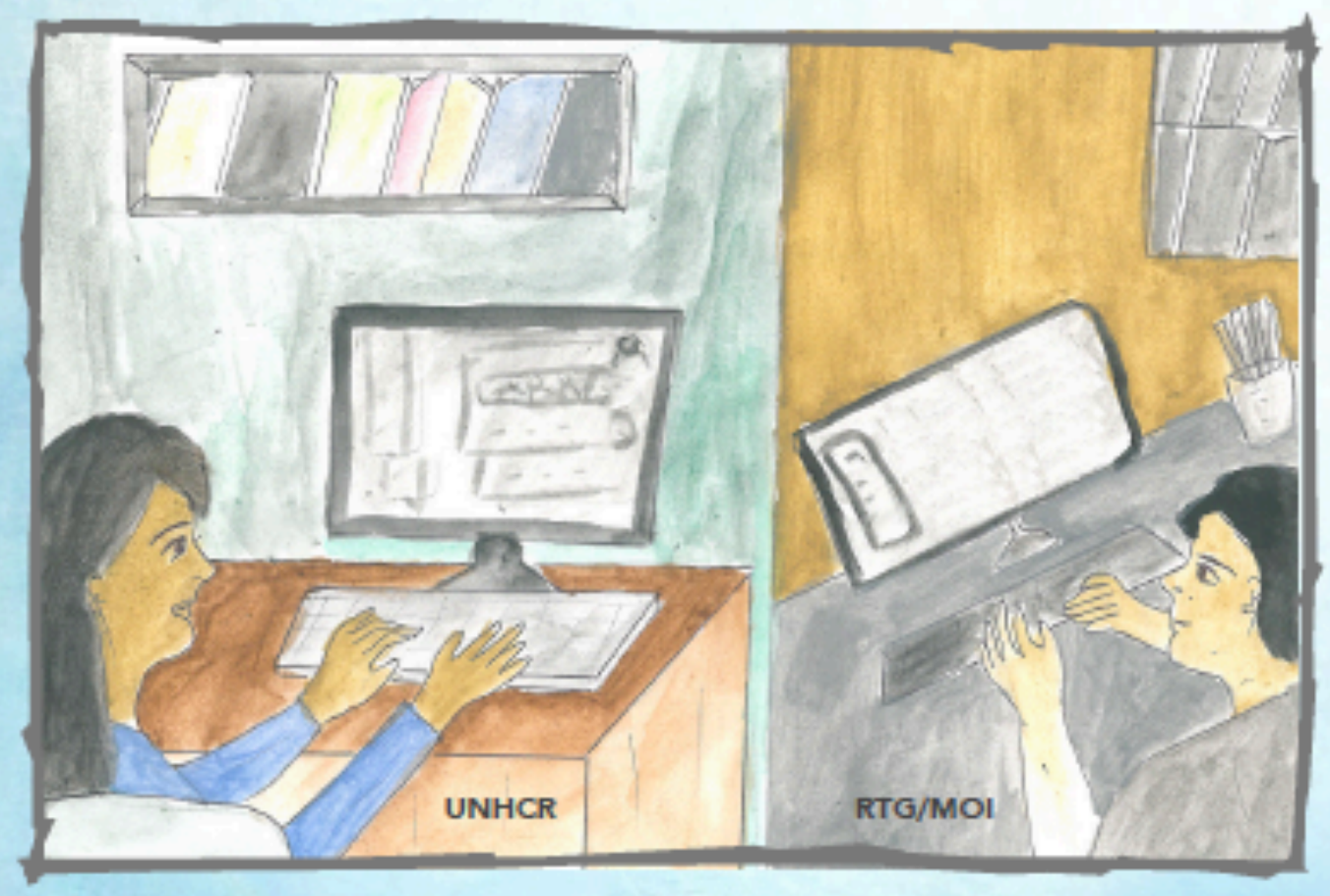

After your departure, you will be de-registered from the UNHCRMOI database. 


\subsection{Interview Guide}

\section{Perkins}

Study ID: H17-037-PERC

Dissertation Title: A Life in Limbo: Waiting for Repatriation on the Thai-Burma Border

Skeleton Interview Guide- Sample Questions

Interview Questions concerning daily life and boredom:

Why did you leave Burma?

Can you tell me about your journey to Mae La?

How long have you lived in Mae La camp?

Can you tell me about your life here?

Do you consider Mae La to be your home? Why or why not?

Do you have a job here?

If so, what do you do?

How much time each day do you spend working?

How much time each day do you spend with your family?

How much free time do you have each day?

What do you do in your free time?

Do you ever feel bored? Why or why not?

Do you feel that there is too much free time, not enough free time, or just enough free time?

Do you feel like time passes slowly or quickly here? Why?

Questions concerning repatriation and migration:

Have you heard any information about possible repatriation back to Burma? If so, what have you heard? And from whom?

How do you feel about this information?

Do you feel like the information you receive is true? Why or why not?

Who are your trusted sources of information in your community?

How do you presently get information on services/assistance?

Do you have family members or friends that intend to return to Burma? Why or Why not?

Do you know anyone who has returned to Burma?

If so, what do you know about their return? Where did they go? Has the return been successful?

What would you say your willingness to return to Burma is on a scale of 1-3? (0-

undecided)

0 - undecided 1- not willing at all 2- somewhat willing 3-very willing

Do you have any fears or concerns about going back to Burma?

Do you have family members or friends that have moved to Malaysia or another country?

If so, what do you know about their move? Where did they go? Has the move been successful?

Would you consider moving to another country?

0 - undecided 1- not willing at all 2- somewhat willing 3-very willing 


\section{REFERENCES}

Abrar, Chowdhury R, 2001. Legal protection of refugees in South Asia . Forced Migration Review, April 2001, FMR 10

Adas, Michael, 1981, 'From Avoidance to Confrontation: Peasant Protest in Precolonial and Colonial Southeast Asia', Comparative Studies in Society and History, Vol. 23, No. 2, April, pp.217-47.

Anderson, B. 2007. Battles in Time: The Relation between Global and Labour Mobilities. COMPAS Working Paper 55. Oxford: Centre on Migration, Policy and Society.

Anderson, R. 2014. Time and the Migrant Other: European Border Controls and the Temporal Economics of Illegality. American Anthropologist, Vol. 116, No. 4, pp. 795-809

Arendt, H., 1976. The Origins of Totalitarianism, London, (2nd edn), pp.279-296

Asian-African Legal Consultative Organization (AALCO), Bangkok Principles on the Status and Treatment of Refugees ("Bangkok Principles"), 31 December 1966, available at: https://www.refworld.org/docid/3de5f2d52.html [accessed 5 December 2018]

Banjong, 0. Dietary assessment of refugees living in camps: a case study of Mae La Camp, Thailand. Food Nutrition Bulletin. 2003 Dec;24(4):360-7.

Barbelet, J., Hagen-Zanker, J., Mansour-Ille, D. The Jordan Compact Lessons learnt and implications for future refugee compacts Feb 2018 https://data2.unhcr.org/fr/documents/download/61932

Barron, L., 2017. Japan's gamble to help Myanmar's peace process. Nikkei Asian Review < https://asia.nikkei.com/Politics/Japan-s-gamble-to-help-Myanmar-s-peace-process>

Bousquet, G. 1987. 'Living in a State of Limbo: A Case Study of Vietnamese Refugees in Hongkong Camps' in Morgan, S. and Colson, E. (eds.) People in Upheaval. Staten Island: Center for Migration Studies.

Bradley, M. 2013. Refugee Repatriation: Justice, Responsibility and Redress, Cambridge, Cambridge University Press.

Brant, Charles S. and Mi Mi Khaing, "Missionaries among the Hill Tribes of Burma", in: Asian Survey, Vol. 1, No. 1 (Mar. 1961), p. 44, 46 - 50. 
Brees, Inge 2010. Burden or Boon: The Impact of Burmese Refugees on Thailand. The Whitehead Journal of Diplomacy and International Relations p 35-47

Brettell, C. 1986. Men Who Migrate, Women Who Wait. Princeton: Princeton University Press.

Brettell, C. (Ed.), Hollifield, J. (Ed.). (2015). Migration Theory. New York: Routledge, https://doiorg.proxy.libraries.smu.edu/10.4324/9781315814933

Bronee, S., 1993. The History of the Comprehensive Plan of Action, 5 Int'l J. Refugee L. 534

Brown, A. 1998. “'Doing Time': The Extended Present of the Long-Term Prisoner.” Time \& Society 7 (1): 93-103.

Camurri, R. “The Exile Experience Reconsidered: a Comparative Perspective in European Cultural Migration during the Interwar Period". Transatlantica [Online], 1 | 2014, Online since 02 October 2014, connection on 30 September 2016. URL : http://transatlantica.revues.org/6920

Castree N. 2009. The spatio-temporality of capitalism. Time \& Society 18: 26-61.

Chan, S. 2004, Survivors - Cambodian Refugees in the United States, University of Chicago Press, Urbana and Chicago. pp.43-4

Charoensuthipan, P. “1.6m Illegal Alien Workers Register”, The Bangkok Post, 31 Oct. 2014, available at: http://www.bangkokpost.com/news/general/440671/16m-illegal-alienworkers-register.

Chatty, D. (2014-06-01). Anthropology and Forced Migration. In (Ed.), The Oxford Handbook of Refugee and Forced Migration Studies. : Oxford University Press,. Retrieved 15 Feb. 2019, from http://www.oxfordhandbooks.com/view/10.1093/oxfordhb/9780199652433.001.0001/ oxfordhb-9780199652433-e-035.

Chimni, B. S. "From resettlement to involuntary repatriation: towards a critical history of durable solutions to refugee problems". Refugee Survey Quarterly 23.3 (2004): 55-73

Choudhury, A (2018). Myanmar's Ethnic Armed Conflict: Emerging Trends in Violence. Institute of Peace and Conflict Studies, 12 Jun, 2018 , article 5480, pp 1-5.

Chowdhury R. Abrar, 'Legal protection of refugees in South Asia', Forced Migration Review, No. 10, April 2001, pp. 21-23

Christie, Clive J. \& Institute of Southeast Asian Studies. (1996). A modern history of Southeast Asia : decolonization, nationalism and separatism. London; New York : Singapore : Tauris Academic Studies ; Institute of Southeast Asian Studies 
Clinton, Hillary Rodham (4 April 2012). "Secretary Hillary Clinton On Recognizing And Supporting Burma's Democratic Reforms". U.S. Department of State. Retrieved 5 April 2012.

Colson, Elizabeth. (2003). Forced Migration and the Anthropological Response. Journal of Refugee Studies Vol. 16, No. 1

Conlon, D. 2011. "Waiting: Feminist Perspectives on the Spacings/Timings of Migrant (Im) Mobility." Gender, Place and Culture 18 (3): 353-360

Corcoran, PE, 'Godot is Waiting Too: Endings in Thought and History', Theory and Society , vol. 18, 1989, pp. 495-529.

Crapanzano , V, Waiting: The Whites of South Africa, Random House, New York, 1985.

Crisp, J. "The local integration and local settlement of refugees: a conceptual and historical analysis." Geneva: UNHCR Evaluation and Policy Analysis Unit, 2004.

Crisp, J. "No solutions in sight: the problem of protracted refugee situations in Africa," UNHCR, New Issues in Refugee Research 75, (2003): 9.

Drennan , J. (2014) Myanmar's ASEAN Chairmanship: Lessons from Cambodia. January 13, The Diplomat

Emmott, R., Blenkinsop, "EU Considers Trade Sanctions on Myanmar Over Rohingya Crisis" Reuters. Oct 3 2018. https://www.reuters.com/article/us-myanmar-rohingya-euexclusive/exclusive-eu-considers-trade-sanctions-on-myanmar-over-rohingya-crisisidUSKCN1MD28E Accessed Dec 62018

Fabian, J. 1983. Time and the Other: How Anthropology Makes its Object. New York: Columbia University Press.

Feller, E.. Refugees are not Migrants, Refugee Survey Quarterly, Volume 24, Issue 4, 1 January 2005, Pages 27-35, https://doi.org/10.1093/rsq/hdi077

Fiddian-Qasmiyeh, E., Loescher, G., Long, K., \& Sigona, N. (Eds.), (2014-06-01). , The Oxford Handbook of Refugee and Forced Migration Studies. : Oxford University Press,. Retrieved 16 Feb. 2019, from http://www.oxfordhandbooks.com/view/10.1093/oxfordhb/9780199652433.001.0001/ oxfordhb-9780199652433.

Gill, N. 2009a. “Governmental Mobility: The Power Effects of the Movement of Detained Asylum Seekers around Britain's Detention Estate.” Political Geography 28 (3): 186-196.

Goffman, E. 1959. The Presentation of Self in Everyday Life. Doubleday, Anchor. 
Gottwald, Martin. "Back to the Future: The Concept of "Comprehensive Solutions." Refugee Survey Quarterly 31.3 (2012): 101-136.

Gravers, Mikael (2007). Exploring ethnic diversity in Burma. NIAS Press, Copenhagen, Denmark

Griffiths, M. 2013a. “'Here, Man Is Nothing!' Gendered Tensions and Male Failed Asylum Seekers.” Refugee Studies Centre Public Lecture, University of Oxford, March 6.

Griffiths, Melanie B.E. (2014) Out of Time: The Temporal Uncertainties of

Refused Asylum Seekers and Immigration Detainees, Journal of Ethnic and Migration Studies, 40:12, 1991-2009.

Government of Myanmar, "Framework for Social and Economic Reforms: Policy Priorities for 2012-15 towards the Long-Term Goals of the National Comprehensive Development Plan," presented to the First Myanmar Development Cooperation Forum, January 14, 2013.

Guyot, James F. "Myanmar." The World Book Encyclopedia; Vol. 13. Chicago: World Book, 2004. 970-70e. Print.

Hägerstrand, T. 1975. "Space, Time and Human Conditions." In Dynamic Allocation of Urban Space, edited by A. Karlqvist, L. Lundqvist, and F. Snickars, 3-12. Farnborough: Saxon House.

Hagerstrand, T. (1982), Diorama, Path and Project. Tijdschrift voor economische en sociale geografie, 73: 323-339. doi:10.1111/j.1467-9663.1982.tb01647.x

Hall, A. 2012. Border Watch: Cultures of Immigration, Detention, and Control. London: Pluto Press.

Hammond, Laura. (1999). Examining the Discourse of Repatriation: Toward More Proactive Theory of Return Migration. In The End of the Refugee Cycle? Refugee Repatriation and Reconstruction, ed. Richard Black and Khalid Koser. New York: Berghahn.

Hargrave, K. (2014) Repatriation through a trust-based lens. Refugee Studies Centre, Working Paper Series No. 104. University of Oxford.

Harms, E. 2013. Eviction Time in the New Saigon: Temporalities of Displacement in the Rubble of Development. Cultural Anthropology, Vol. 28, Issue 2, pp. 344-368

Heijmans, P. (2014). Big Year for Myanmar Economic Reforms January 28, The Diplomat

Hitchcox, L. (1990) Vietnamese Refugees in Southeast Asian Camps. London: Macmillan. (1993) 'Vietnamese Refugees in Hong Kong: Behaviour and Control', in Buijs, G. (ed.) Migrant Women: Crossing Boundaries and Changing Identities. Oxford: Berg

Horstmann, Alexander. (2011). Sacred Spaces of Karen Refugees and Humanitarian Aid Across the Thailand-Burma Border. Austrian Journal of South-East Asian Studies. 4. 254-272. 
Human Rights Watch (2004) Out of Sight, Out of Mind Thai Policy Towards Burmese Refugees and Migrants https://www.hrw.org/report/2004/02/24/out-sight-out-mind/thai-policytowards-burmese-refugees-and-migrants\#

Huseby-Darvas, E. V. (1994) “"But Where Can We Go?” Refugee Women in Hungary from the Former Yugoslavia', in Zaharlick, A. and MacDonald, J. (eds.) Selected Papers on Refugee Issues: III. Arlington American Anthropological Association.

Jeffrey, C. 2008. “Waiting.” Environment and Planning D: Society and Space 26 (6): 954-958.

Jeffrey, C. 2010. "Timepass: Youth, Class, and Time among Unemployed Young Men in India." American Ethnologist 37 (3): 465-481.

Jeshurun, Chandran (1970). The Anglo-French Declaration of January 1896 and the Independence of Siam. Journal of the Siam Society. Vol. 58.21970

Jolliffe, K. Ceasefires, "Governance, and Development: The Karen National Union in Times of Change". The Asia Foundation. Dec. 2016.

Jones, L. (2014) The Political Economy of Myanmar's Transition, Journal of Contemporary Asia, 44:1, 144-170, DOI: 10.1080/00472336.2013.764143

Kettler, D., The Liquidation of Exile. Studies in the Intellectual Emigration of the 1930s, London, Anthem Press, 2011.

Keyes, Charles F. (2003) Living at The Edge of Thai Society: The Karen in The Highlands of Northern Thailand. Routledge. pp. 210-212.

Kloos, P.(2001) A turning point? From civil struggle to civil war in Sri Lanka (176-196) In Anthropology of Violence and Conflict. Routledge: New York.

Kwon, June Hee. 2015. The Work of Waiting: Love and Money in Korean Chinese Transnational Migration. Cultural Anthropology, Vol. 30, Issue 3, pp. 477-500

Lang, H. (2001) The repatriation predicament of Burmese refugees in Thailand: a preliminary analysis. New Issues in Refugee Research, Working Paper No. 46, UNHCR

Lewis, H., Dwyer P., Hodkinson, S. (2014) Hyper-precarious lives Migrants, work and forced labour in the Global North. First Published September 17, 2014 Research Article https://doi.org/10.1177/0309132514548303 https://journals.sagepub.com/doi/full/10.1177/0309132514548303

Long, K. (2009). Early Repatriation Policy: Russian Refugee Return 1922-1924. Journal of Refugee Studies, 22(2), 133-154. 
Long, K. (2013). Repatriation, Refugees, and Returning Home. Refugees, Rights, and Repatriation The Point of No Return, 4-26.

Long, K. (2013). Voluntary Repatriation after 1992: Continuing Crises. Refugees, Rights, and Repatriation The Point of No Return, 105-137.

Low, Setha M., and Sally Engle Merry. 2010 Engaged Anthropology: Diversity and Dilemmas, An Introduction to Supplement 2. Current Anthropology 51(supp.2):S203-S226.

Lowman, S. (1992). The Cambodian repatriation: Fall 1992. Washington: United States Catholic Conference, Migration and Refugee Services.

Lubkemann, S. (2008) In Culture in Chaos: An Anthropology of the Social Condition in War. University of Chicago press: Chicago.

Mackenzie, C., C. McDowell, and E. Pittaway. "Beyond 'Do No Harm': The Challenge of Constructing Ethical Relationships in Refugee Research." Journal of Refugee Studies 20.2 (2007): 299319. Print.

Mains, D. 2007. "Neoliberal Times: Progress, Boredom and Shame among Young Men in Urban Ethiopia." American Ethnologist 34 (4): 659-673.

Malkki, L. (1995) Refugees and Exile: From "Refugee Studies" to the National Order of Things. Annual Review of Anthropology, Vol. 24. (1995), pp. 495-523.

Malseed, K. 2009. "Networks of noncompliance: grassroots resistance and sovereignty in militarised Burma." The Journal of Peasant Studies, 36:2, 365-391, DOI:

$10.1080 / 03066150902928348$

Mansouri, F., and S. Cauchi. 2007. "A Psychological Perspective on Australia's Asylum Policies." International Migration 45 (1): 123-150.

Marfleet, P. (2006). Refugees in a global era. New York: Palgrave Macmillan.

Massey, D. 1992. "Politics and Space/Time." New Left Review 196: 65-84.

Mathews, Emily. (2012). Barriers of Karen Resettlement in Minnesota: A Qualitative Study. Retrieved from Sophia, the St. Catherine University repository website: https://sophia.stkate.edu/msw_papers/56

Mauss M (2004[1905]) Seasonal Variations of the Eskimo: A Study in Social Morphology. London: Routledge.

Mellinger , H., van Berlo, P. The Jordan Compact: Turning the Syrian Refugee Crisis into a Development Opportunity Posted on August 20, 2016 in Criminal Law and Criminology https://leidenlawblog.nl/articles/the-jordan-compact-turning-the-syrian-refugee-crisis 
Mullin, Gerald, 1972, Flight and Rebellion, New York: Oxford University Press.

Munn, N. D. 1992. “The Cultural Anthropology of Time: A Critical Essay.” Annual Review of Anthropology 21 (1): 93-123.

Myanmar: Growth rate of the real gross domestic product (GDP) from 2012 to 2022 (compared to the previous year) https://www.statista.com/statistics/525748/gross-domestic-productgdp-growth-rate-in-myanmar/ Source: IMF

Narayan, Sharma. Refugee Situation in South Asia: Need of A Regional Mechanism, Kathmandu Law Review, Vol. 1, No. 1 (103-122)

Nehru, V. (2015) The Political Economy of Reform in Myanmar: The Case of Rice and the Need for Patience. Sasakawa Peace Foundation ,USA.

Norum, Roger, et al. "The Chronopolitics of Exile: Hope, Heterotemporality and NGO Economics along the Thai-Burma Border." Critique of Anthropology, vol. 36, no. 1, 2015, pp. 61-83., doi:10.1177/0308275x15617305.

Olivius, Elisabeth (2017) Sites of repression and resistance: political space in refugee camps in Thailand, Critical Asian Studies, 49:3, 289-307, DOI:10.1080/14672715.2017.1333268

Peteet, J. M. (1995) 'Transforming Trust: Dispossession and Empowerment among Palestinian Refugees' in Daniel, E. V. and Knudsen, J. (eds.) Mistrusting Refugees. Berkeley: University of California Press.

Phoophongphiphat, A. Thailand scraps new economic zones and plans regional linkups, Nikkei staff writer August 15, 2018 13:50 JST https://asia.nikkei.com/Economy/Thailand-scrapsnew-economic-zones-and-plans-regional-linkups

Preeda Parkpian, Shing Tet Leong, Preecha Laortanakul, Regional Monitoring of Lead and Cadmium Contamination in a Tropical Grazing Land Site, Thailand Environmental Monitoring and Assessment, 2003, Volume 85, Number 2, Page 157

Reynell, J. (1989) Political Pawns: Refugees on the Thai-Kampuchean Border. Oxford: Oxfam.

Robinson, C W.; The Comprehensive Plan of Action for Indochinese Refugees, 1989-1997: Sharing the Burden and Passing the Buck, Journal of Refugee Studies, Volume 17, Issue 3, 1 September 2004, Pages 319-333,

Said, E., "Intellectual Exile. Expatriates and Marginals", in Representations of the Intellectual, New York, Vintage, 1994, 47-64. ---, Reflections on Exile and Other Essays, Cambridge, Harvard University Press, 2003, 173-77.

Said, Edward. (1999) Out of Place: A Memoir. New York: Knopf. 
Sandford, S. (2018) Returning Refugees Face Uncertainty in Eastern Myanmar Settlement. VOA < https://www.voanews.com/a/returning-refugees-face-uncertain-future-in-easternmyanmar-settlement/4672077.html>

Sangwongwanich, P. (2017) Small Steps to Peace. Bangkok Post bangkokpost.com/business/news/1226040/small-steps-to-peace>

Sawitta Lefevre, A. and Hariraksapitak, P. "Thailand, under fire, says rejected China request to deport all Uighur Muslims", Reuters, 10 July 2015, www.reuters.com/article/us-thailanduighurs-turkey-idUSKCNOPKOE420150710.

Scott, James C, 1976, The Moral Economy of the Peasant, New Haven: Yale University Press.

Scott, James C , 1979, 'Revolution in the Revolution: Peasants and Commisars', Theory and Society, Vol.7, No. 1.

Scott, James C., 1984, Everyday Forms of Peasant Resistance, New Haven: Yale University Press.

Smith, Martin (1991). Burma : insurgency and the politics of ethnicity (2. impr. ed.). London: Zed Books.

Snaing, Y. (2016) 'Economic Growth Is Not the Best Way to Solve Economic Problems': Policy Advocate. February 29, THE IRRAWADDY

Standing, G. 2011. The Precariat: The Dangerous New Class. Bloomsbury.

Stein, B. N., \& Cuny, F. C. (1994). Refugee repatriation during conflict: Protection and post-return assistance. Development in Practice, 4(3), 173-187.

Suerbaum, M. "Defining the Other to Masculinize Oneself: Syrian Men's Negotiations of Masculinity during Displacement in Egypt," Signs: Journal of Women in Culture and Society 43, no. 3 (Spring 2018): 665-686.

Thai PBS (Aug. 2017) Thailand and Myanmar mark 20th anniversary of first Friendship bridge < http://englishnews.thaipbs.or.th/thailand-myanmar-mark-20th-anniversary-firstfriendship-bridge/>

Than, M. "Agriculture in Myanmar: What Has Happened to Asia's Rice Bowl?" Southeast Asian Affairs (1990), 240-254.

Thomson, Marnie. (2012). Black Boxes of Bureaucracy: Transparency and Opacity in the Resettlement Process of Congolese Refugees. Political and Legal Anthropology Review, Vol 35 , Issue 2 (186-205). 
Urry, J. 2001. Sociology beyond Societies: Mobilities for the Twenty-First Century. London: Routledge.

UN High Commissioner for Refugees (UNHCR), Comprehensive Plans of Action: Insights from CIREFCA and the Indochinese CPA, 1 January 2006, ISSN 1020-7473, available at: https://www.refworld.org/docid/4ff163c82.html [accessed 30 January 2019]

UN High Commissioner for Refugees (UNHCR), Refugee Protection and Mixed Migration: A 10Point Plan of Action, January 2007, (UPDATE 2016) Rev.1, available at: https://www.refworld.org/docid/45b0c09b2.html [accessed 31 January 2019]

UNHCR (1996) Press Release: 'UNHCR and Malaysia Close Camp for Vietnamese Boat-people', 25 June.

UNHCR Executive Committee, Conclusion on Comprehensive and Regional Approaches within a Protection Framework, EXCOM Conclusion No. 80 (XLVII), 11 Oct. 1996; UNHCR, The State of the World's Refugees 2006: Human Displacement in the New Millennium, Oxford, Oxford University Press, 2006, 120-127.

UNHCR, 'Note by the High Commissioner for the Meeting on Refugees and Displaced Persons in Southeast Asia', 9 July 1979

Walton, M. "Ethnicity, Conflict, and History in Burma: The Myths of Panglong," Asian Survey 48.6 (2008).

Warner, D. (1994). Voluntary Repatriation and the Meaning of Return to Home: A Critique of Liberal Mathematics. Journal of Refugee Studies J Refugee Stud, 7(2-3), 160-174.

Weiner, Myron. "The Clash of Norms: Dilemmas in Refugee Policies." Journal of Refugee Studies 11.4 (1998): 433-453.

Wilson, J. (2018) Temporary Protected Status: Overview and Current Issues. Congressional Research Service. 7-5700: RS20844 <www.crs.gov>

Wolf, Eric R., 1969, Peasant Wars of the Twentieth Century, New York: Harper and Row.

Zetter, R. (1988). Refugees, Repatriation, and Root Causes. Journal of Refugee Studies J Refugee Stud, 1(2), 99-106.

Zieck, M. (2004). Voluntary Repatriation: Paradigm, Pitfalls, Progress. Refugee Survey Quarterly, 23(3), 33-54. 